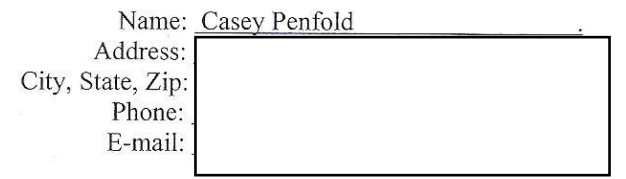

\title{
Project Proposal
}

(to be completed in conjunction with AGED 539)

Quality Criteria Number Addressed: 1-Curriculum and Instruction and/or

5-Facilities, Equipment and Materials

\section{Goal or Purpose of the Project:}

The goal of this project is to enhance the welding courses at Apple Valley High School into an agricultural / industrial engineering pathway.

The courses are currently ROP welding classes, which only allow juniors and seniors to take the courses because of the 16 years of age requirement. One of the problems with this is it does not allow a student to take the courses for a full four years. In most cases a student can only take one, or at the most, two years of the program.

Another problem is that the classes are too one dimensional, in that it only teaches basic welding skills. The program should be providing more of a designing and engineering element to enhance the fabrication of projects, as well as the basic welding skills of the students.

In order to address these two issues, I will be changing the course titles and curriculum content as well as the prerequisites to allow grades 9-12 into the program. This will allow students to have a full pathway to take agricultural / industrial engineering courses from start to finish from freshman year to senior year.

The major component being added into the curriculum to make it more of an engineering course will be the use of a computer solids modeling software, SolidWorks. This software will allow students to use industry standard technology to fully CAD design and engineer welding projects and create their own plans for building them. By adding this component to the program it increases the student's skill level, project quality, and makes the students more hire able in the real world. 
Specific Objectives to Accomplish (Be as detailed as possible):

-Create and submit new Course of Study to the school district to change course titles and add content from ROP Welding into Introduction, Intermediate, and Advanced Agricultural /

Industrial Engineering.

-Get quotes for laptop computers and SolidWorks software to be used for engineering courses and submit to theffrincipal for purchase.

-Organize a mobile storage system for computers to be stored in for protection and security that is functional for student use.

-Create a wireless network for the laptops so assignments and data can be sent and organized. -

-Create and compile curriculum to teach the software effectively. -

Estimated number of hours on this project: $40-50$ hours

Estimated expenditures $(\$)$ on this project yourseosts): $\$ 33,000$.

-30 Laptop computers $=\$ 30,000$

-SolidWorks Software $=\$ 3000$

Proposed timeline for completion of the project:

August 2010- Course changes from the district.

September 2010- Submit quotes for purchase of computers and software

November 2010- Set up computers, software, and storage system.

December 2010-April 2011- Create curriculum and start teaching the software -

Progress Report: How will you inform the Cal Poly faculty of your progress on a regular basis?

orce a mouth

E-mails and or phone calls to Dr. Kellogg when_necessary to stay updated on the progress.

For Office Use Only:

Project Approved By:

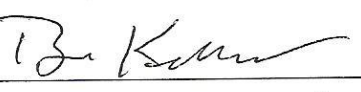

Date of Approval: $11-22-10$

Quarter student will enroll in AGED 539: _ Spring of 2011 


\section{First Year Internship Project}

Improving a two year ROP Welding Program into a four year Agricultural / Industrial Engineering Pathway

Quality Criteria

1-Curriculum and Instruction

$\boldsymbol{\&}$

5-Facilities, Equipment and Materials

Casey Penfold

AGED 539

Spring 2011 


\title{
Table of Contents
}

\author{
1)Introduction
}

2)Creation of New Courses

3)Computers and Software

4) Assignment Organization and Delivery

5)Curriculum 


\section{Introduction}

The goal of this project was to enhance the ROP welding courses at Apple Valley High School into an agricultural /industrial engineering pathway.

Before the completion of this project, the classes were a two year ROP welding course, which only allow juniors and seniors to take the courses because of the 16 years of age requirement. One of the problems with this was it does not allow a student to take the courses for a full four years. In most cases a student can only take one, or at the most, two years of the program.

Another problem was that the classes were too one dimensional, in that it only teaches basic welding skills. The program needed to be providing more of a designing and engineering element to enhance the fabrication of projects, as well as the basic welding skills of the students.

In order to address these two issues, I changed the course titles and curriculum content as well as the prerequisites to allow grades 9-12 into the program. This allowed students to have a full pathway to take agricultural / industrial engineering courses from start to finish from freshman year to senior year.

The major component being added into the curriculum to make it more of an engineering course was the use of a computer solids modeling software, SolidWorks. This software allows students to use industry standard technology to fully CAD design and engineer welding projects and create their own plans for building them. By adding this component to the program it increased the student's skill level, project quality, and makes the students more hire able in the real world. 


\section{Creation of New Courses}

The first step in creating new courses started with the Agriculture Advisory Committee and the Principal approving the changes in the program into a pathway. Once I had their support then it was up to me to create new course of study documents to submit to the district so that they could make it official.

I started looking around for other agriculture engineering courses for course descriptions and content to use as a reference. After looking at several similar courses, I pulled different pieces of them together along with the mechanical drawing and computer drafting content. I then created the goals and objectives of the course along with the academic and CTE standards that are tied with them. Once I had the introductory course completed I had a base to go off of to create the intermediate and advanced courses by adding or deleting content for the different levels.

The introductory course is mostly a $9^{\text {th }}$ and $10^{\text {th }}$ grade class. It is very heavy in the mechanical drawing and computer modeling with a small amount of welding and fabrication. The course concludes with a small project that uses all the skills learned in the class.

The intermediate course is more of a true beginning welding course where the students are in the welding booths most of the course learning the different welding processes. The students will also use the computer software and learn some design techniques. This course is open to any $11^{\text {th }}$ or $12^{\text {th }}$ graders that are new to the program along with the $10^{\text {th }}$ graders that have taken the introductory course. This will allow for both the students that want a four year pathway and the students that want only one or two years as an elective. 
The advanced course prerequisite is the completion of the intermediate course. This course is an extension of the intermediate course. The students will learn more advanced welding techniques along with the fabrication skills needed for building projects. The students will have all the skills needed to design a project on the computer, fabricate the design and weld it together.

The next few pages are the completed course of study documents that were submitted to the district office and approved: 


\section{Apple Valley Unified School District \\ Course of Study Description}

Course Title: Introduction to Agricultural/Industrial Engineering

Grade Level: 9-12

Check one: $\underline{X}$ Year Course/10 units credit

_ Semester Course/5 units credit:

Course Prerequisites: None

\section{Course Description:}

Introduction to the theory and practical applications of basic metalworking and design will be presented. This course will emphasize agricultural/industrial: shop safety, material selection, job planning, bench-work, quality control and inspection. Hand tools, drill presses, pedestal grinders, band saws, basic welding processes and precision-measuring equipment will be used to complete required projects. Also included are techniques in preventative and general maintenance of metalworking machinery. The student will study, interpret, and draw basic industrial blueprints through the use of mechanical and computer drawing equipment.

\section{Goals:}

The student will:

1. Practice the rules for personal and group safety while working in a fabrication shop environment.

2. Demonstrate safe work habits on the job.

3. Demonstrate the ability to work well with others.

4. Learn and follow an orderly process to create a project from idea to finished product.

5. Learn and demonstrate mechanical skills.

6. Follow directions

7. Critically evaluate good workmanship

8. Apply problem-solving skills in the production of projects.

9. Understand how to design project plans by using mechanical and computer drawing techniques

10. Employ math skills in working with measurements.

11. Know how to identify common metals, sizes, and shapes.

12. Know basic tool-fitting skills.

13. Know layout skills.

14. Know basic cold metal processes (e.g., shearing, cutting, drilling, threading, bending.).

15. Complete a metal project, including interpreting a plan, developing a bill of materials, selecting materials, shaping, fastening, and finishing.

16. Know how to properly set up, adjust, shut down, and maintain an oxy-fuel system.

17. Operate and maintain various arc welding and cutting systems safely and appropriately.

18. Operate and maintain fabrication tools and equipment safely and appropriately.

III. Standards Taught in the Course:

Geometry standards 8.0, 9.0, 10.0, 11.0, 14.0, 15.0, 16.0, 20.0

Algebra standards 10.0, 15.0

Agriculture Mechanics Pathway standards B1.1, 1.2, 5.1, 5.2, 5.3, 5.4, 5.5, 7.2, 8.1, 9.2, 9.3, 9.4

\section{Course Outline}

A. Basic Shop Safety
1. Housekeeping safety
2. Hand tool safety
3. Power tool safety
4. Personal protection gear
5. Arc and gas welding safety
6. Shop cleaning procedures 
B. Measurement and Layout

1. Common measuring tools

2. Units of measure

3. Layout tools and procedures

4. Area and volume calculations

C. Mechanical Drawings and Blue Prints

1. Mechanical sketching by hand

2. 3 Dimensional Computer Aided Drafting (Solids Modeling)

3. Reading and interpreting welding symbols and blue prints

D. Hand and Power Tools

1. Identification

2. Proper tool usage

E. Metal Materials

1. Identification of metal materials

2. Material properties and selection

F. Oxy-fuel Systems

1. Proper setup, usage, shutdown and maintenance

G. Arc Welding and Cutting Systems

1. Operate and maintain equipment safely and appropriately

H. Project Construction

1. Design, layout and construction of basic metal project

\section{Scope and Sequence of the Course:}

\section{Units in the Semester}

Basic Shop Safety

Measurement and Layout

Mechanical Drawing

Computer Solids Modeling

Hand and Power Tools

Metal Materials

Oxy-fuel Systems

Arc Welding and Cutting Systems

Project Construction

\section{Assessment and Standards for Student Performance}

A. Written tests and quizzes that are short answer in format- $30 \%$

B. Performance based assessments such as demonstrations of skills, and projects completed-30\%

C. Written assignments to include worksheets, book assignments and drawings-20\%

D. Teacher observation of participation on a daily basis- $20 \%$

\section{List Standards Based Textbooks}

\section{Modern Metalworking}

John R. Walker, The Goodheart-Willcox Company, Inc, 1985. 


\section{Apple Valley Unified School District \\ Course of Study Description}

Course Title: Intermediate Agricultural/Industrial Engineering

Grade Level: 10 th-12th grades

Check one: $\underline{X}$ Year Course/10 units credit

_ Semester Course/5 units credit:

Course Prerequisites: 10th graders will need to have taken Introduction to Agricultural/Industrial Engineering

\section{Course Description:}

This course introduces students to various welding techniques. The course is designed for students who have an interest in basic welding or possibly a career in the welding field. The course will include classroom and practical instruction in the following area shop safety, metallurgy (study of metals), tools \& equipment identification, blueprint reading, computer aided drafting, math \& measuring, effects of heat, welding positions, oxy-acetylene safety, oxy-acetylene cutting \& welding, shielded metal arc welding, shielded metal arc welding electrode identification, gas tungsten arc welding, gas metal arc welding, and plasma arc cutting.

\section{Goals:}

The student will:

1. Practice the rules for personal and group safety while working in a fabrication shop environment.

2. Demonstrate safe work habits on the job.

3. Demonstrate the ability to work well with others.

4. Learn and follow an orderly process to create a project from idea to finished product.

5. Learn and demonstrate mechanical skills.

6. Follow directions

7. Critically evaluate good workmanship

8. Apply problem-solving skills in the production of projects.

9. Understand how to design project plans by using mechanical drawing techniques

10. Employ math skills in working with measurements.

11. Know how to identify common metals, sizes, and shapes.

12. Know basic tool-fitting skills.

13. Know layout skills.

14. Know basic cold metal processes (e.g., shearing, cutting, drilling, threading, bending.).

15. Complete a metal project, including interpreting a plan, developing a bill of materials, selecting materials, shaping, fastening, and finishing.

16. Know how to properly set up, adjust, shut down, and maintain an oxy-fuel system.

17. Use welding tools and equipment, such as MIG, TIG, SMAW, to combine or join manufactured parts and products, resulting in a finished product that meets the standards of the American Welding Society or a similar industry. Operate and maintain fabrication tools and equipment safely and appropriately.

18. Use computers to design and produce welded products, write numerical control programs, and control robots.

III. Standards Taught in the Course:

Geometry standards 8.0, 9.0, 10.0, 11.0, 14.0, 15.0, 16.0, 20.0

Algebra standards 10.0, 15.0

Agriculture Mechanics Pathway standards B1.1, 1.2, 5.1, 5.2, 5.3, 5.4,7.1, 7.2,7.3,7.4, 7.5, 8.1, 8.2, 8.3, 8.4, 9.1, 9.2, 9.3, 9.4, 9.5, 9.6. 9.7

\section{Course Outline}

A. Basic Shop Safety

1. Housekeeping safety

2. Hand tool safety

3. Power tool safety

4. Personal protection gear

5. Arc and gas welding safety

6. Shop cleaning procedures 
B. Measurement and Layout

1. Common measuring tools

2. Units of measure

3. Layout tools and procedures

4. Area and volume calculations

C. Mechanical Drawings and Blue Prints

1. Mechanical sketching by hand

2. 3 Dimensional Computer Aided Drafting (Solids Modeling)

3. Reading and interpreting welding symbols and blue prints

D. Hand and Power Tools

1. Identification

2. Proper tool usage

E. Metal Materials

1. Identification of metal materials

2. Material properties and selection

F. Oxy-fuel Systems

1. Proper setup, usage, shutdown and maintenance

G Arc Welding and Cutting Systems

1. Operate and maintain SMAW, GMAW, and GTAW equipment safely and appropriately

H. Project Construction

1. Design, layout and construction of basic metal project

V. Scope and Sequence of the Course:

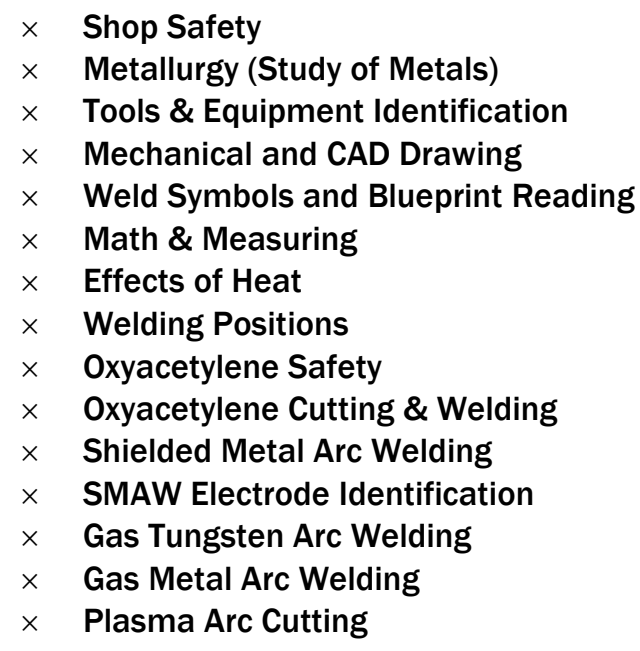

VI. Assessment and Standards for Student Performance

A. Written tests and quizzes that are short answer in format- $20 \%$

B. Performance based assessments such as demonstrations of skills, and projects completed-40\%

C. Written assignments to include worksheets, book assignments and drawings-20\%

D. Teacher observation of participation on a daily basis- $20 \%$

VII. List Standards Based Textbooks

Primary: Modern Welding. Althouse, Andrew D., Carl H. Turnquist, William A. Bowditch, and Kevin E. Bowditch.

Supplemental: Modern Metalworking

John R. Walker, The Goodheart-Willcox Company, Inc, 1985. 


\section{Apple Valley Unified School District Course of Study Description}

Course Title: Advanced Agricultural/Industrial Engineering

Grade Level: 11 th-12th grades

Check one: $\underline{X}$ Year Course/10 units credit

_ Semester Course/5 units credit:

Course Prerequisites: Students will need to have taken Intermediate Agricultural/Industrial Engineering.

\section{Course Description:}

This course expands student's knowledge of various welding techniques to a higher level and introduces them to the construction and fabrication of metal products. The course is designed for students who have basic welding skills. The course will include classroom and practical instruction in the following area: shop safety, metallurgy (study of metals), tools \& equipment identification, blueprint reading, computer aided drafting(CAD), computer aided machining(CAM), math \& measuring, effects of heat, welding positions, oxy-acetylene safety, oxy-acetylene cutting \& welding, shielded metal arc welding, shielded metal arc welding electrode identification, gas tungsten arc welding, gas metal arc welding, and plasma arc cutting.

\section{Goals:}

The student will:

1. Practice the rules for personal and group safety while working in a fabrication shop environment.

2. Demonstrate safe work habits on the job.

3. Demonstrate the ability to work well with others.

4. Learn and follow an orderly process to create a project from idea to finished product.

5. Learn and demonstrate mechanical skills.

6. Follow directions

7. Critically evaluate good workmanship

8. Apply problem-solving skills in the production of projects.

9. Understand how to design project plans by using mechanical and computer drawing techniques.

10. Employ math skills in working with measurements.

11. Know how to identify common metals, sizes, and shapes.

12. Know basic tool-fitting skills.

13. Know layout skills.

14. Know basic cold metal processes (e.g., shearing, cutting, drilling, threading, bending.).

15. Interpret scaled welding prints; gather design and materials information; perform calculations; and use the detail to plan, lay out, and produce parts or finished products.

16. Select and use appropriate welding tools, equipment, and inspection devices to manufacture parts or products.

17. Complete a fabrication, an assembly, or a repair by using appropriate techniques and processes.

18. Know how to properly set up, adjust, shut down, and maintain an oxy-fuel system.

19. Use welding tools and equipment, such as MIG, TIG, SMAW, to combine or join manufactured parts and products, resulting in a finished product that meets the standards of the American Welding Society or a similar industry. Operate and maintain fabrication tools and equipment safely and appropriately.

20. Use computers to design and produce welded products, write numerical control programs, and control robots.

\section{Standards Taught in the Course:}

Geometry standards 8.0, 9.0,10.0, 11.0, 14.0, 15.0, 16.0, 20.0

Algebra standards 10.0, 15.0

Agriculture Mechanics Pathway standards B1.1, 1.2, 5.1, 5.2, 5.3, 5.4, 5.5, 7.1, 7.2,7.3,7.4, 7.5, 8.1, 8.2, 8.3, 8.4, 9.1, 9.2, 9.3, 9.4, 9.5, 9.6. 9.7

\section{Course Outline}

A. Basic Shop Safety

1. Housekeeping safety

2. Hand tool safety 
3. Power tool safety

4. Personal protection gear

5. Arc and gas welding safety

6. Shop cleaning procedures

B. Measurement and Layout

1. Common measuring tools

2. Units of measure

3. Layout tools and procedures

4. Area and volume calculations

C. Mechanical Drawings and Blue Prints

1. Mechanical sketching by hand

2. 3 Dimensional Computer Aided Drafting (Solids Modeling)

3. Reading and interpreting welding symbols and blue prints

D. Computer Aided Machining

1.Plasma CAM

2.Tube bending

E. Metal Materials

1. Identification of metal materials

2. Material properties and selection

F. Oxy-fuel Systems

1. Proper setup, usage, shutdown and maintenance

G Arc Welding and Cutting Systems

1. Operate and maintain SMAW, GMAW, and GTAW equipment safely and appropriately

H. Project Construction

1. Design, layout and construction of advanced metal projects

\section{Scope and Sequence of the Course:}

$\times \quad$ Shop Safety

$\times \quad$ Metallurgy (Study of Metals)

$\times \quad$ Tools \& Equipment Identification

$\times \quad$ Mechanical and Computer Aided Drafting (CAD)

$\times \quad$ Computer Aided Machining (CAM)

$\times \quad$ Weld Symbols and Blueprint Reading

$\times \quad$ Math \& Measuring

$\times \quad$ Effects of Heat

$\times \quad$ Welding Positions

$\times \quad$ Oxyacetylene Safety

$\times \quad$ Oxyacetylene Cutting \& Welding

$\times \quad$ Shielded Metal Arc Welding

$\times \quad$ SMAW Electrode Identification

$\times \quad$ Gas Tungsten Arc Welding

$\times \quad$ Gas Metal Arc Welding

$\times \quad$ Plasma Arc Cutting

\section{Assessment and Standards for Student Performance}

A. Written tests and quizzes that are short answer in format- $10 \%$

B. Performance based assessments such as demonstrations of skills, and projects completed-40\%

C. Written assignments to include worksheets, book assignments and drawings $-10 \%$

D. Teacher observation of participation on a daily basis- $40 \%$

VII. List Standards Based Textbooks

Primary: Modern Welding. Althouse, Andrew D., Carl H. Turnquist, William A. Bowditch, and Kevin E. Bowditch.

Supplemental: Modern Metalworking

John R. Walker, The Goodheart-Willcox Company, Inc, 1985. 


\section{Computers and Software}

Once the courses had been changed then it was time to get the materials to teach the design and engineering aspect. This was the most difficult part of the whole project. With the budget cuts throughout the state it is not the easiest process to buy a lot of expensive equipment.

The most powerful portion of the new engineering courses is the computer solids modeling program SolidWorks. This program allows the students to virtually build any project idea down to the smallest detail in the computer. The software was not that big of a problem getting. There are several educational technology companies to get the software from with the cost around $\$ 3000$.

The computers were a little more challenging. We decided to go with laptop computers that can be brought out into the shop when they are needed instead of trying to use or create a computer lab. I talked with an educational suppler about what we were doing and he recommended the Gateway FX laptops. I got a quote for thirty of these laptops at around \$27,000 and submitted it to the Principal for purchase.

The quotes were into the Principal at the beginning of the school year thinking that it would not take that long to process the purchase order and receive the computers within the first few months of the school year. The students were doing mechanical drawing by hand for the first few months so we thought it was going to work out.

The problem came when the district office could not create the purchase order because the state budget had not been released. After waiting for four months, the purchase orders were finally able to be sent to the suppliers. Then once everything was ordered then it was a matter of waiting for everything to ship. 
Finally, after several delays the computers and software showed up at the end of November. Then it was time to get everything set up for student use. The next few pages are the steps and the pictures of the set up I did on the computers to make them all functional.

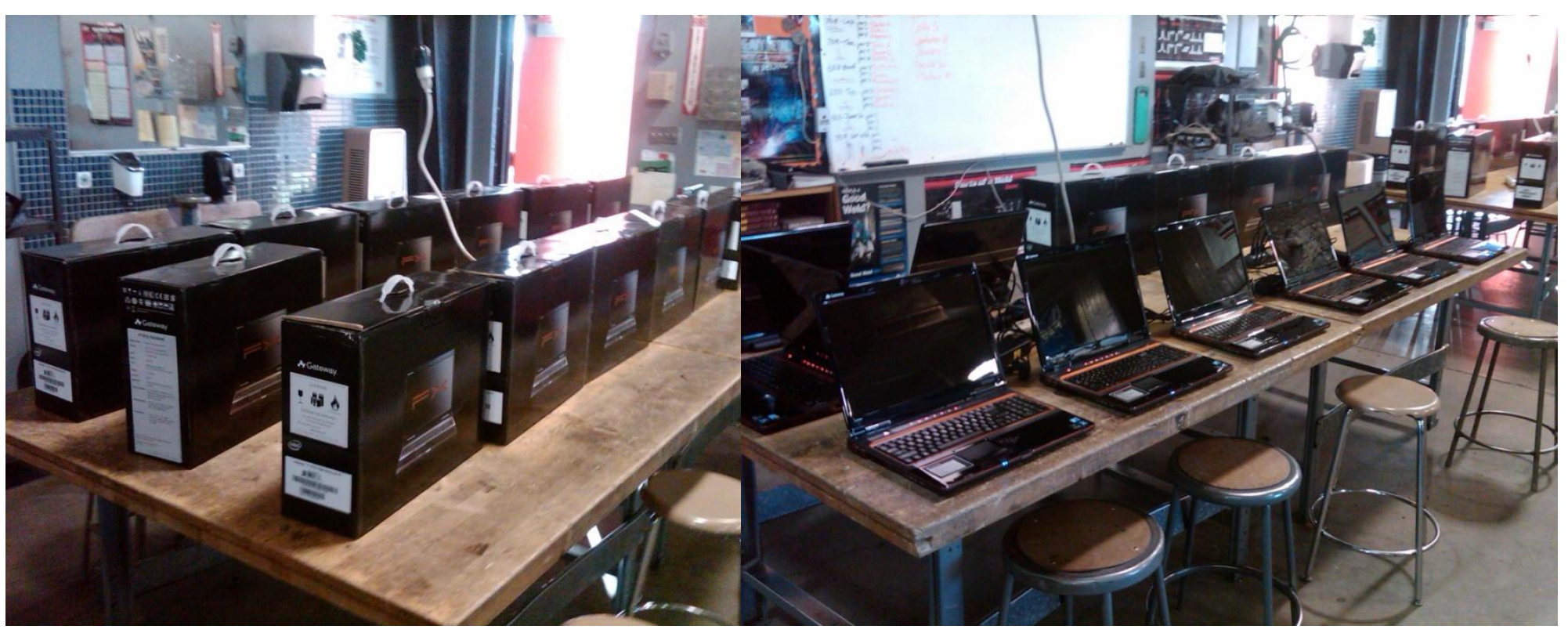

The first step was to get the computers unpacked, put together and turned on. Then the computers needed to be named and registered. I named the computers AGENG 1-29 and named the main computer Mr.Penfold's so they could be located on the network later. Once I got started doing this I realized I was in for a daunting task to get 30 computers configured because just getting them unpacked, turned on and named took over three hours. 

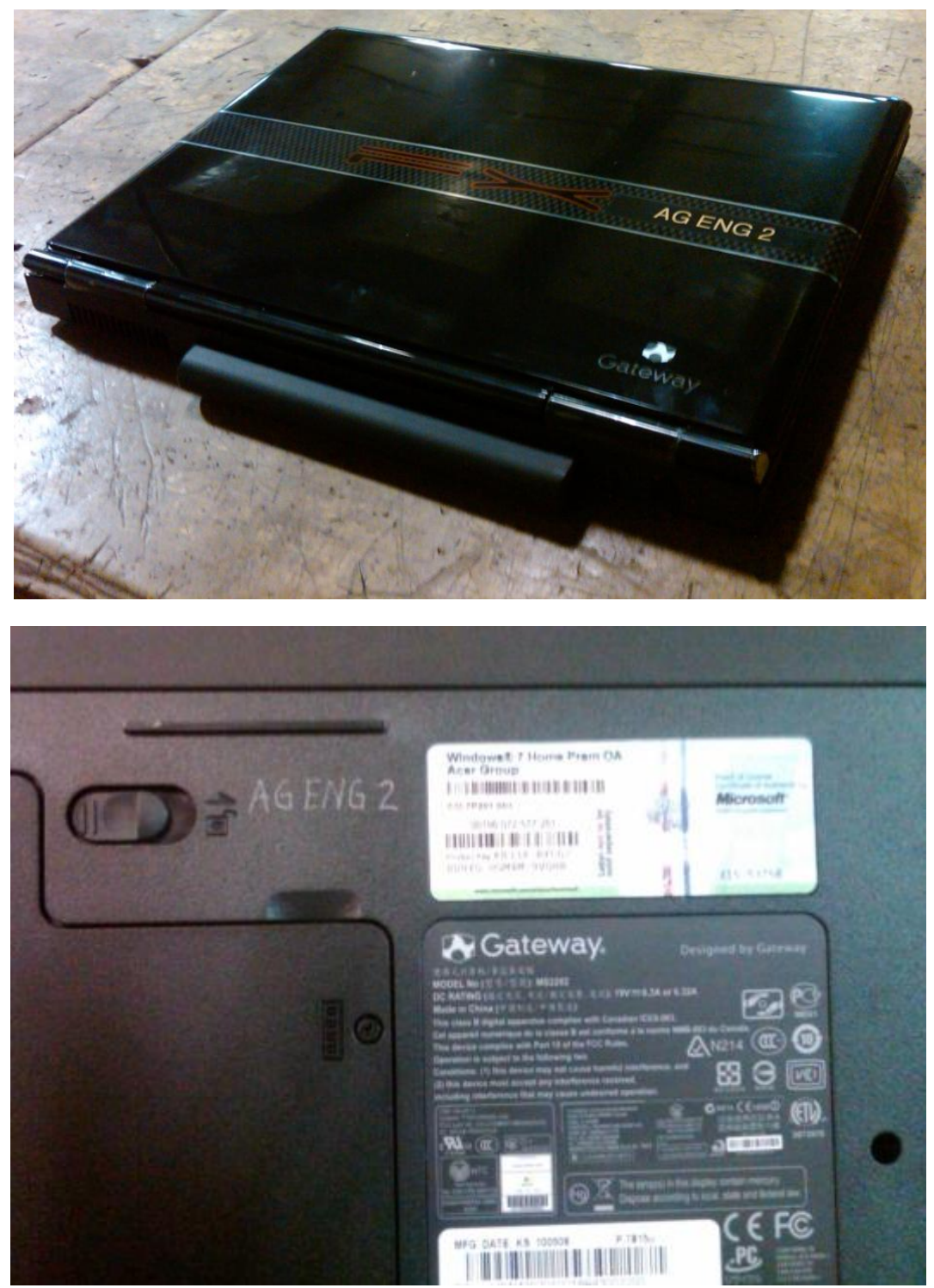

Once the computers had specific names they needed to be labeled with a label maker on the lid so each student could be assigned a number. Also, the names were engraved on the bottom to identify the computers if the labels get taken off.

With new computers there are a lot of programs that are previously installed before the owner gets them. A lot of the programs are useless but some of them can cause problems or be distracting to students. I went through the list of programs on the control panel settings and uninstalled certain programs like the Gateway games, Norton anti-virus trial offers, video web camera software, and any others that could be a problem. 


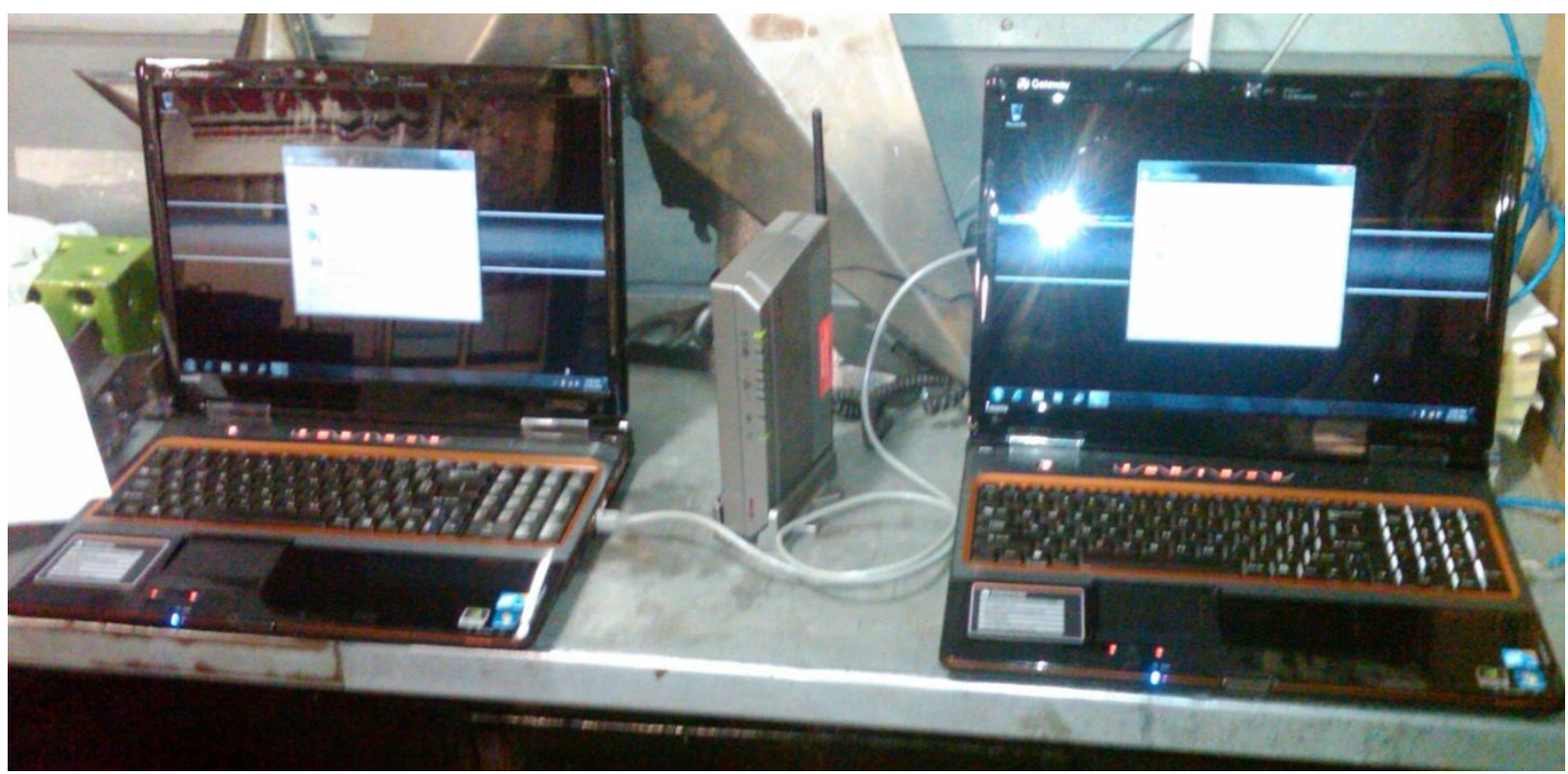

Now that the laptops had been cleaned of all of the unnecessary programs, it was time to install the SolidWorks program. Before installing the software the computers needed to be networked together by a wireless hub so they can communicate. To do this, all that was needed was a cheap wireless router that I happen to have laying around not being used anymore.

The reason they needed to be connected on a network was because the software is a license share type of an installation. This means one copy of the software can be installed on all of the computers and a master computer communicates with the others, through the network, and allows the software to open.

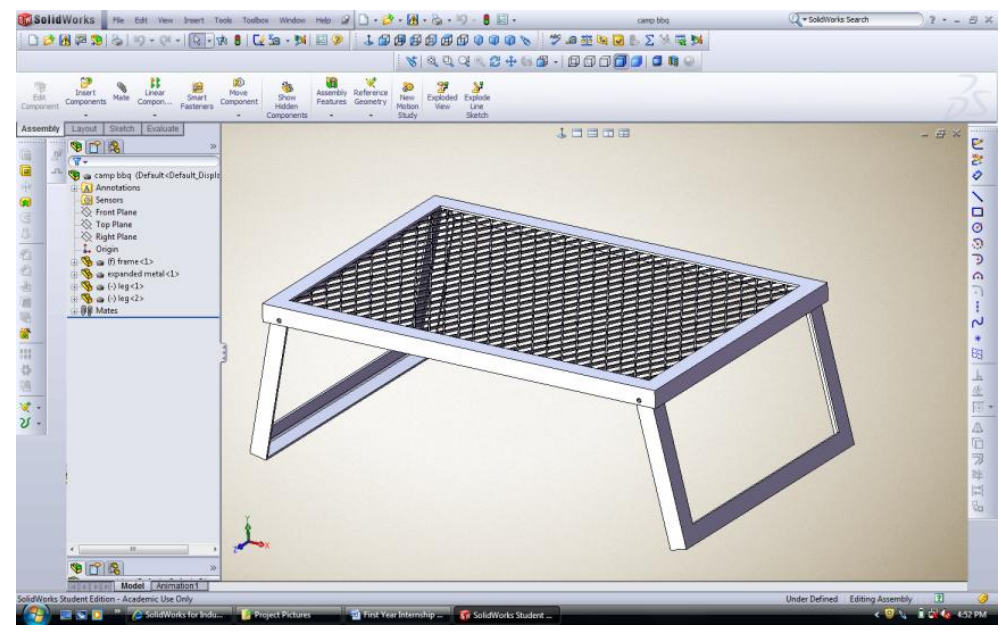



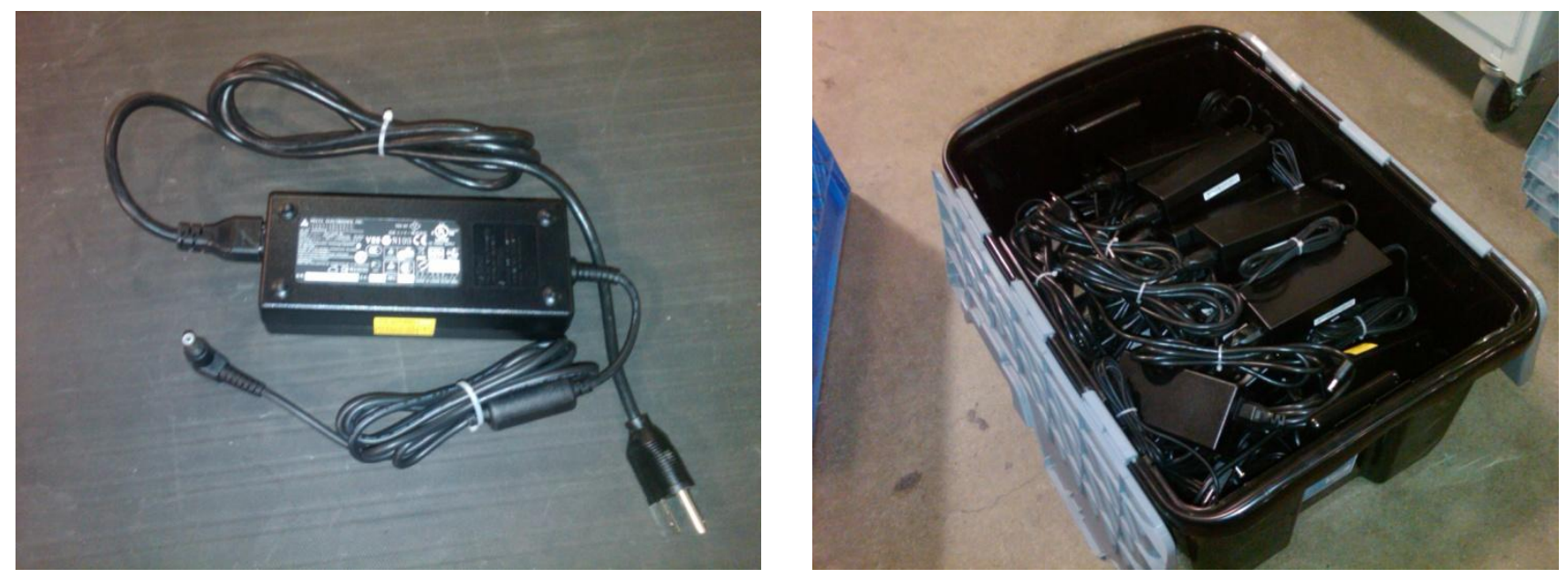

In order to keep the power cords neat and tidy, I zip tied the extra lengths so that they don't get tangled. I bought a plastic tub with closing lids to store the cords in so that they are in one easy location that will keep them clean.

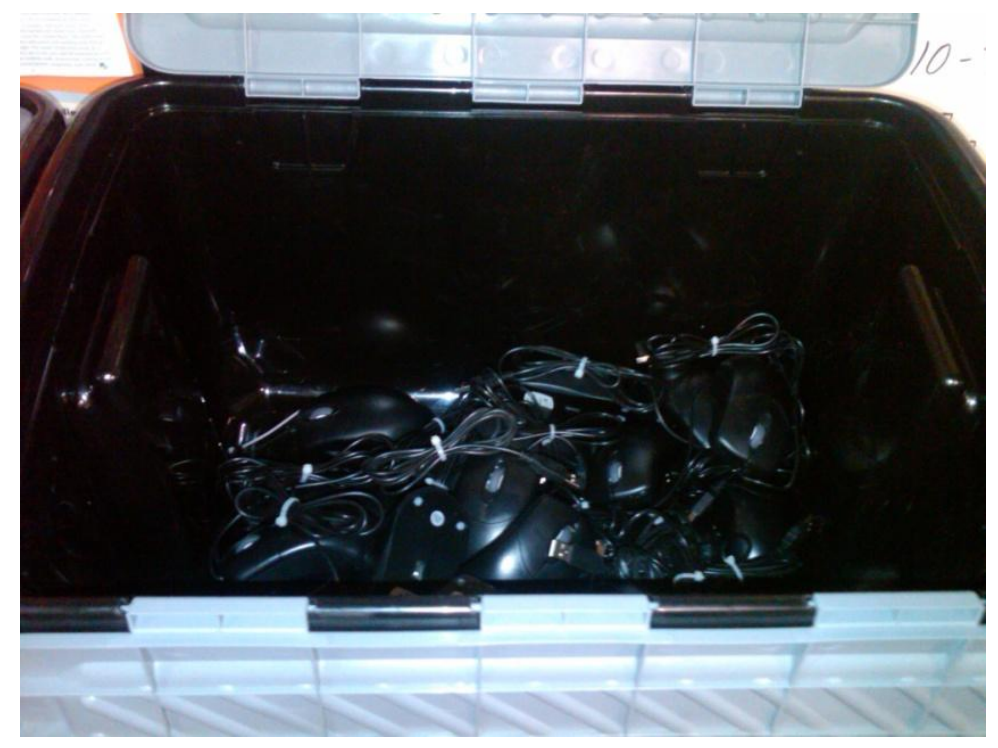

I also zip tied the cords on the optical mice for the same reason and put them in a separate tub for easy storage. 

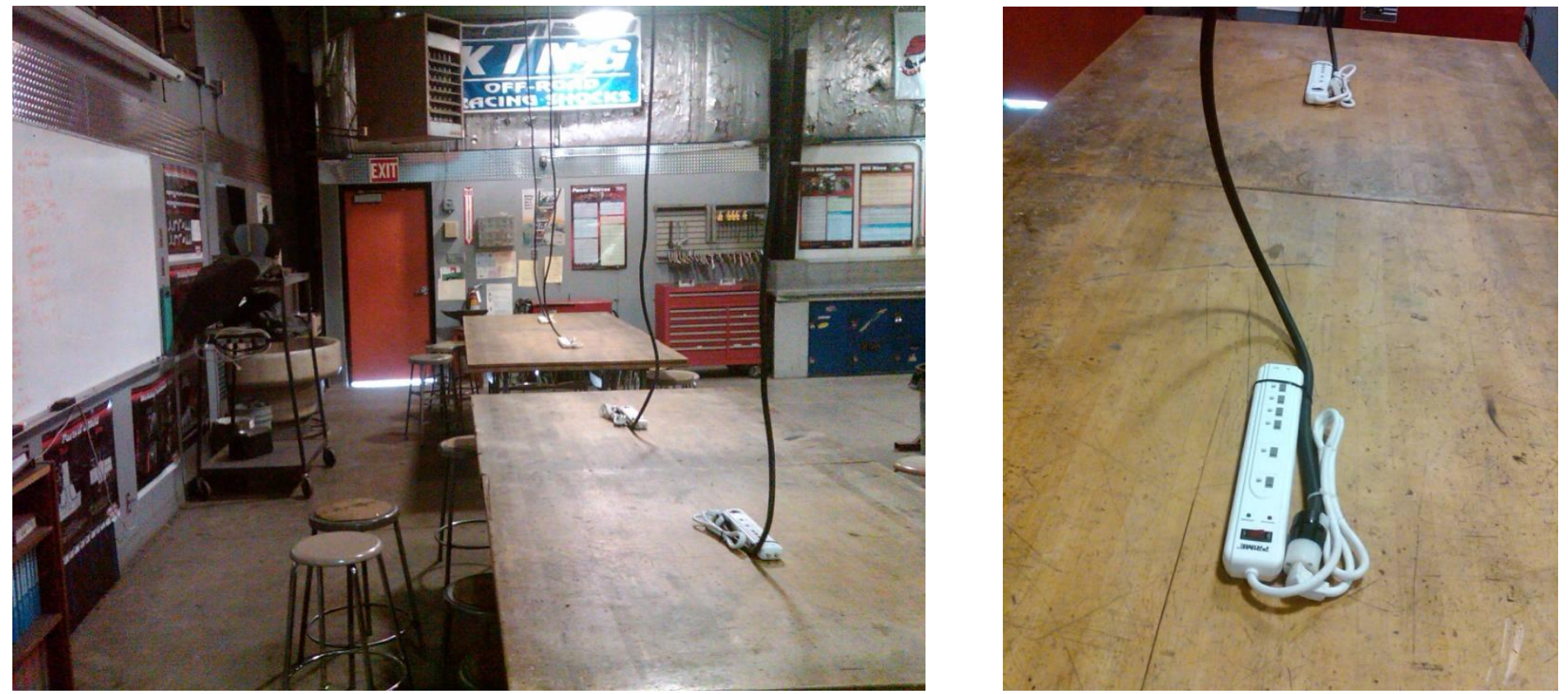

Another important step was to have electrical power accessible to charge 30 laptops at one time while the students worked. The solution I came up with was to have drop down extension cords installed and have surge protectors plug into them. I submitted a work request to the district electrician and he had the power ran and dropped down in a couple days. This is a lot safer and cleaner than having cords running along the floor for people to trip over.
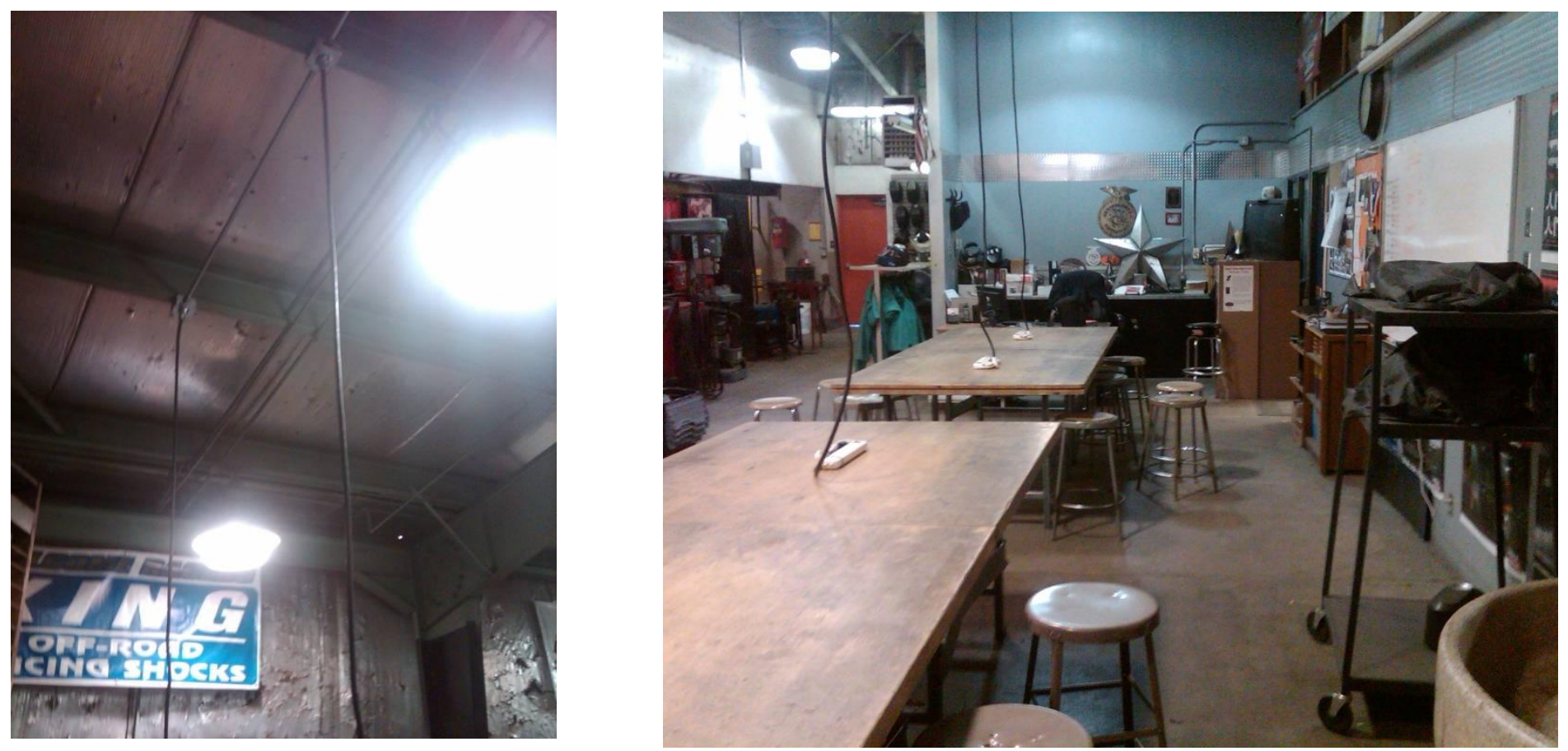


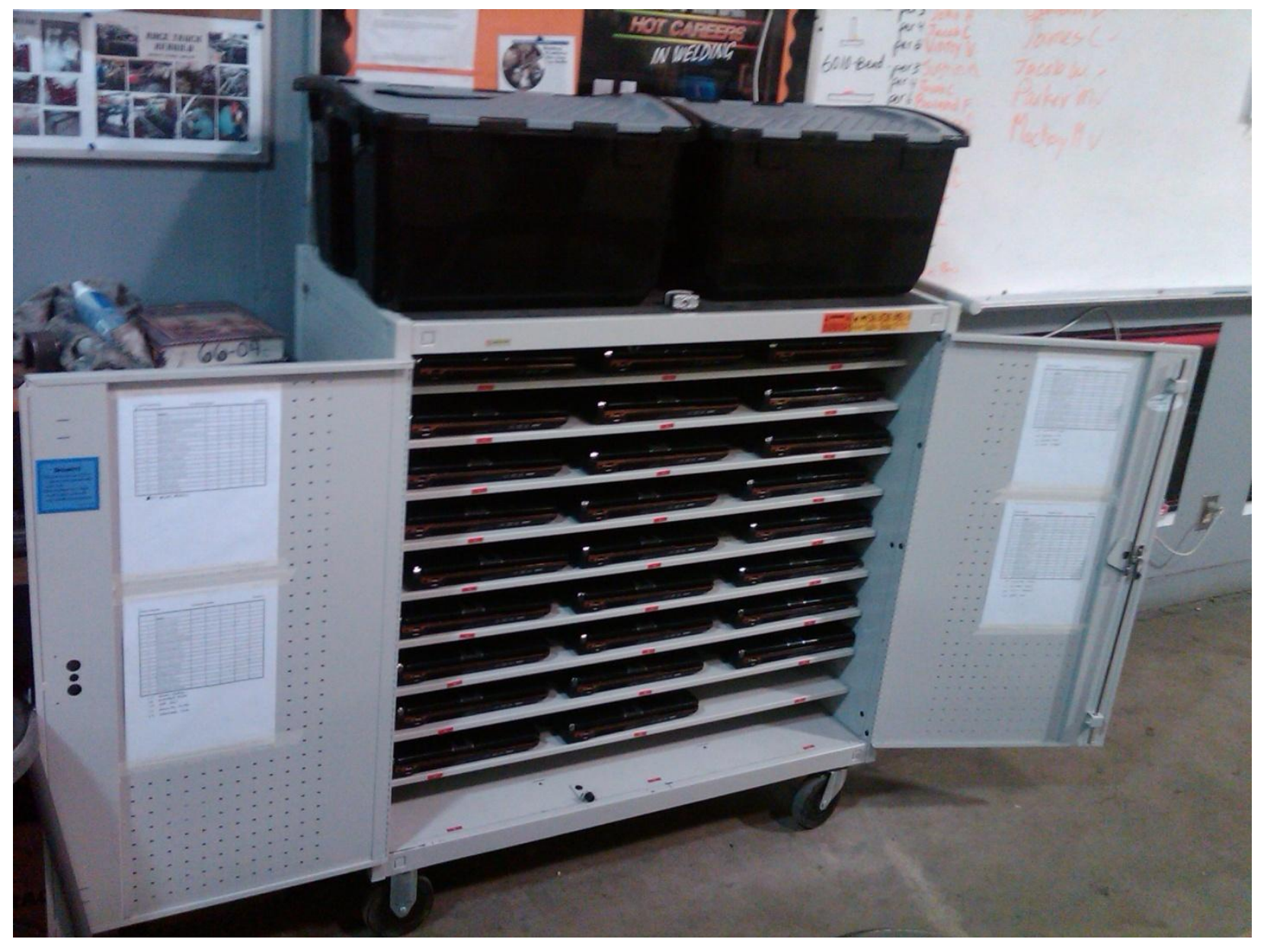

The best and easiest way to store laptop computers is in a locking rolling cart. I did some asking around and the Vice Principal knew of a cart that was not being used anymore because the computers went somewhere else. This worked out very well and it saved us from buying a new one. The shelves are labeled with numbers for each computer to go into. Also I taped a list of all the students and their computer numbers so they know who is assigned which number. 

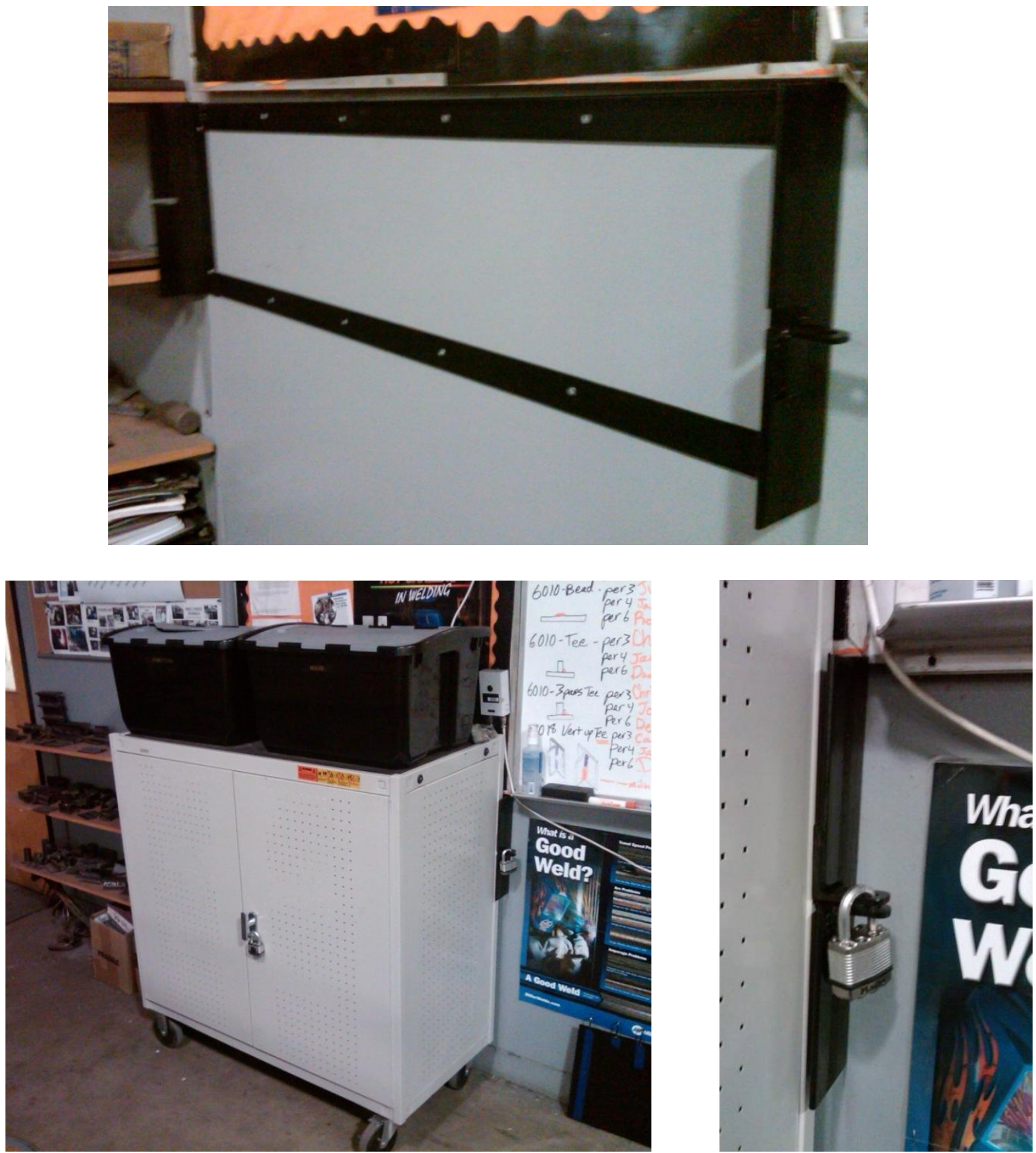

The cart itself locks up tight but the whole cart can be rolled right out of the shop loosing \$30,000 worth of equipment. So the students and I created a locking bracket that screws into the wall and secures the cart from moving. We made it so that the cart is easy to unlock and move around if needed. 


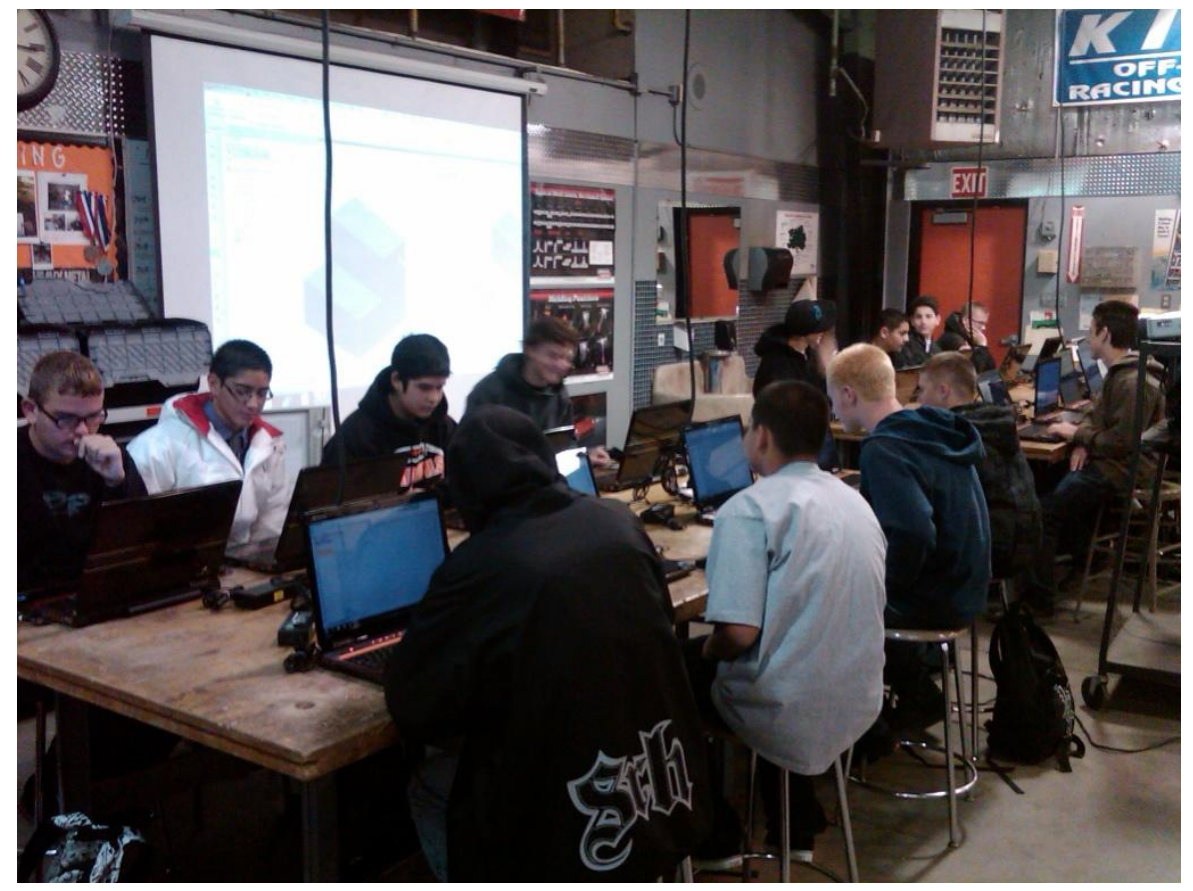

After many hours of setting up and organizing it all worked out very well. The key is having everything organized and easy to use. I had the students and their parents sign a user agreement with all the rules for using the computers. I have a specific routine for the students to follow which is a must for $9^{\text {th }}$ and $10^{\text {th }}$ grade students. They come into class and get their computers set up and are ready to work before the tardy bell rings.

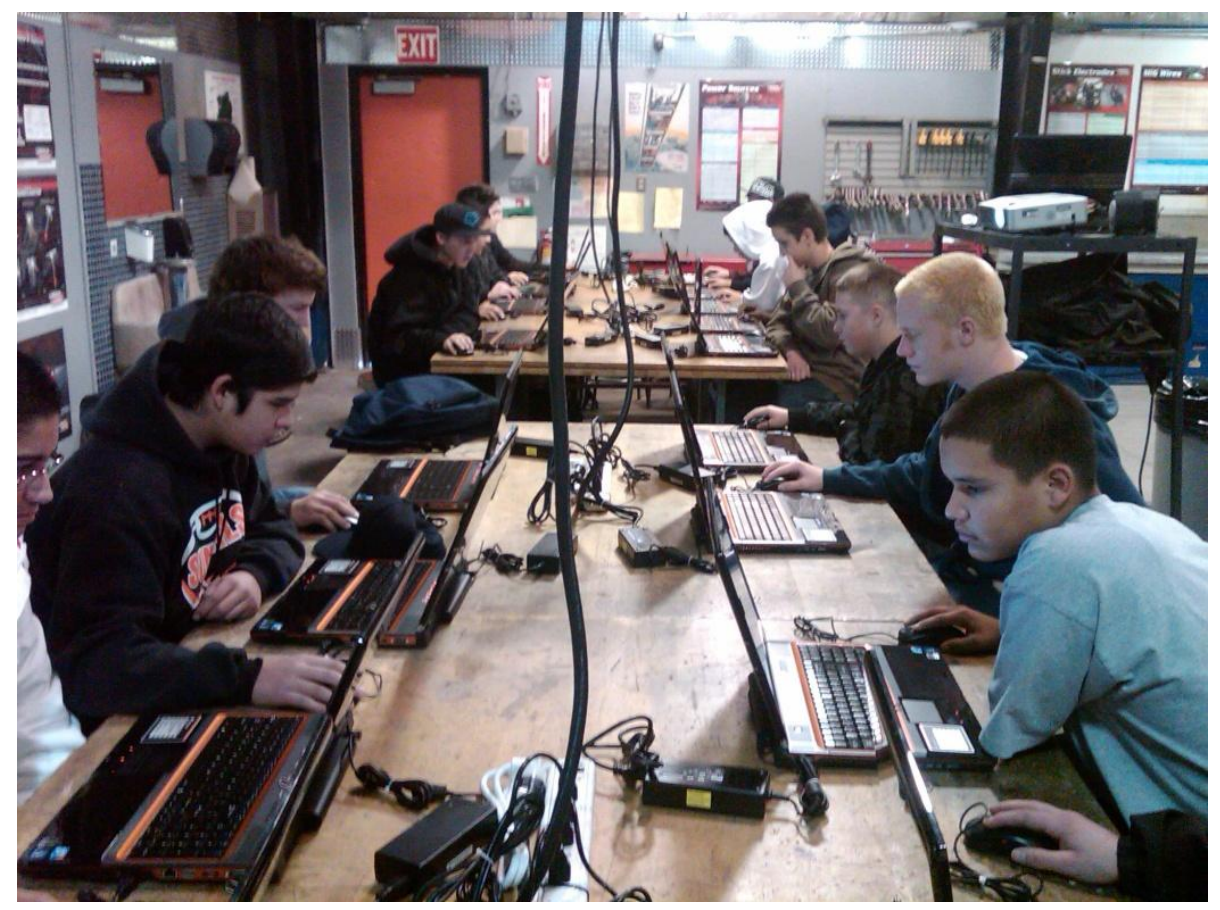




\section{Ag. Engineering Computer Agreement}

\section{Rules to be followed for computer use:}

1. No food or drink around the computers.

2. Do not use the computers with dirty or greasy hands.

3. When carrying the computers use both hands and have the lid closed.

4. Use only the computer that is assigned to you.

5. These computers are for work purposes only. These are not your personal computers.

6. Do not change any of the settings on the computer unless you are instructed to do so.

7. Do not plug i-pods or mp3s into computers to charge or play music.

8. Do not use computers to play or burn DVDs or CDs.

9. You are not permitted to use the internet on these computers.

10. Do not install any games or programs onto the computers.

11. You are responsible for properly shutting down and putting away the computers and all of its accessories.

12. Any miss use or damage to the equipment will result in restriction of the use of the computers and the parents and student will be charged for the replacement or repair to the equipment.

I have read and agree to all of the rules for the use of the Ag. Engineering Computers.

Student Name Printed

Student Signature

Date

Parent Name Printed

Parent Signature

Date 


\section{Assignment Organization and Delivery}

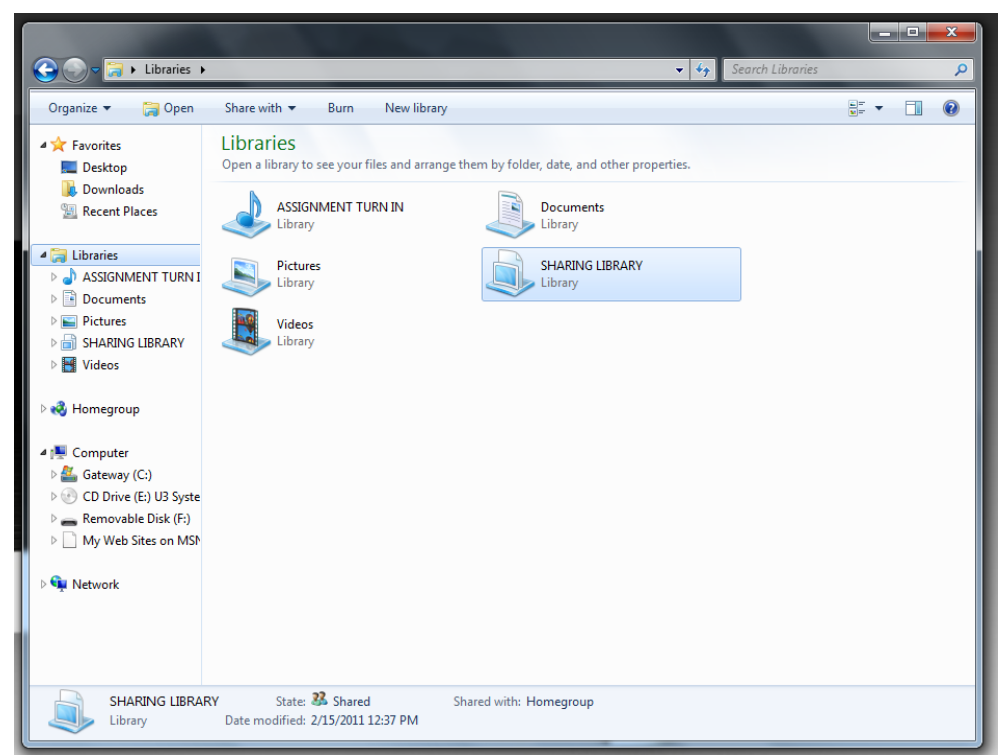

I deliver assignments to students using a paperless method. I create assignments using Word Documents or PDFs and copy and paste them into a shared public folder the students can access on our private wireless network.

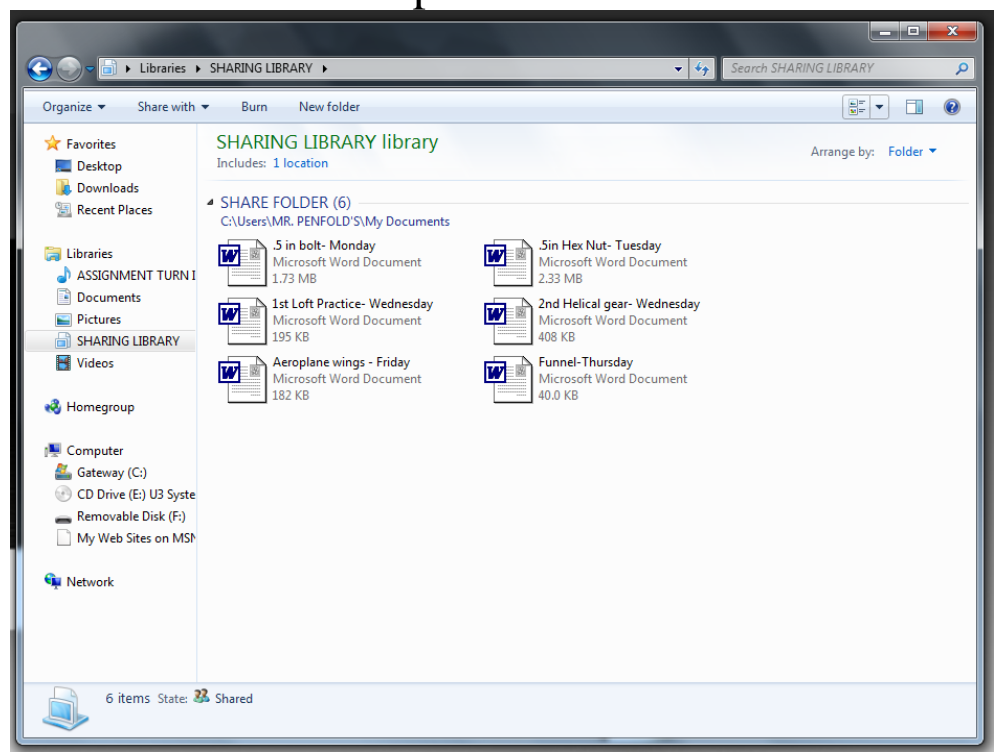

The students go into the Sharing Library and access the assignments in a read only format. I usually only keep a week's worth of assignments in the share folder and label what day each assignment was given. 


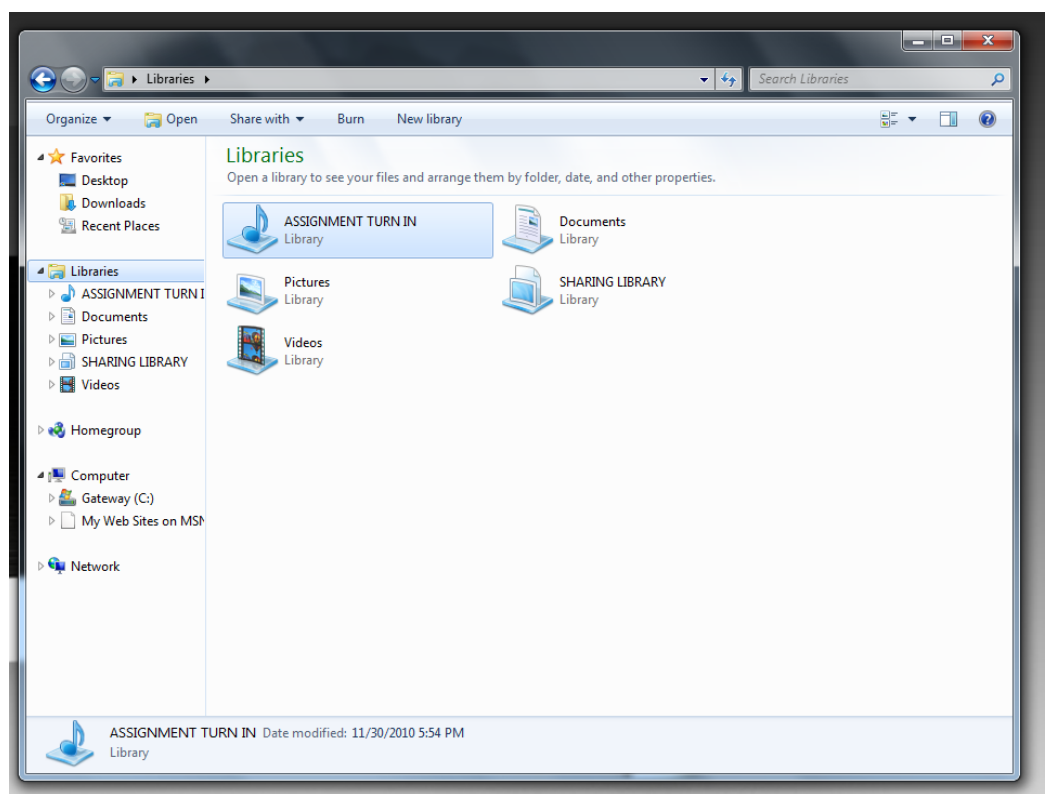

In order to turn in assignments the students access a public folder on my instructor computer and copy and paste their SolidWorks assignments here. This completely eliminates the use of paper and is much easier to organize lots of assignments.

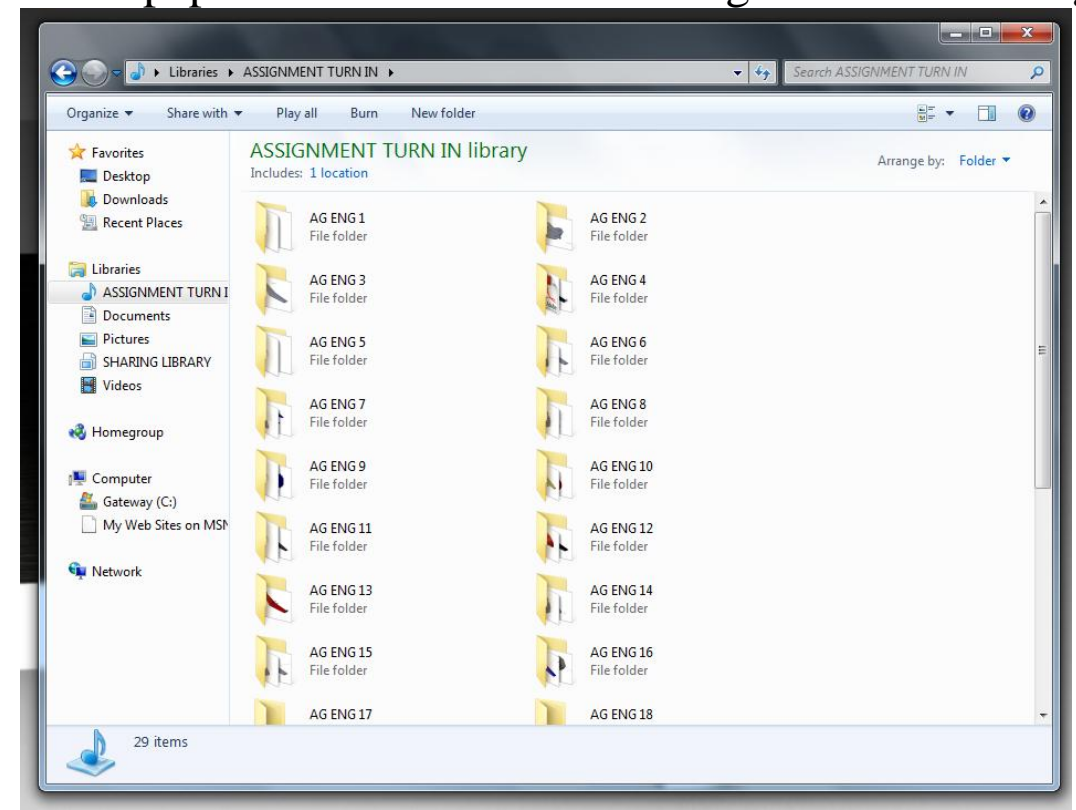

Each student drops their assignments into their specific computer number which is assigned to them. 


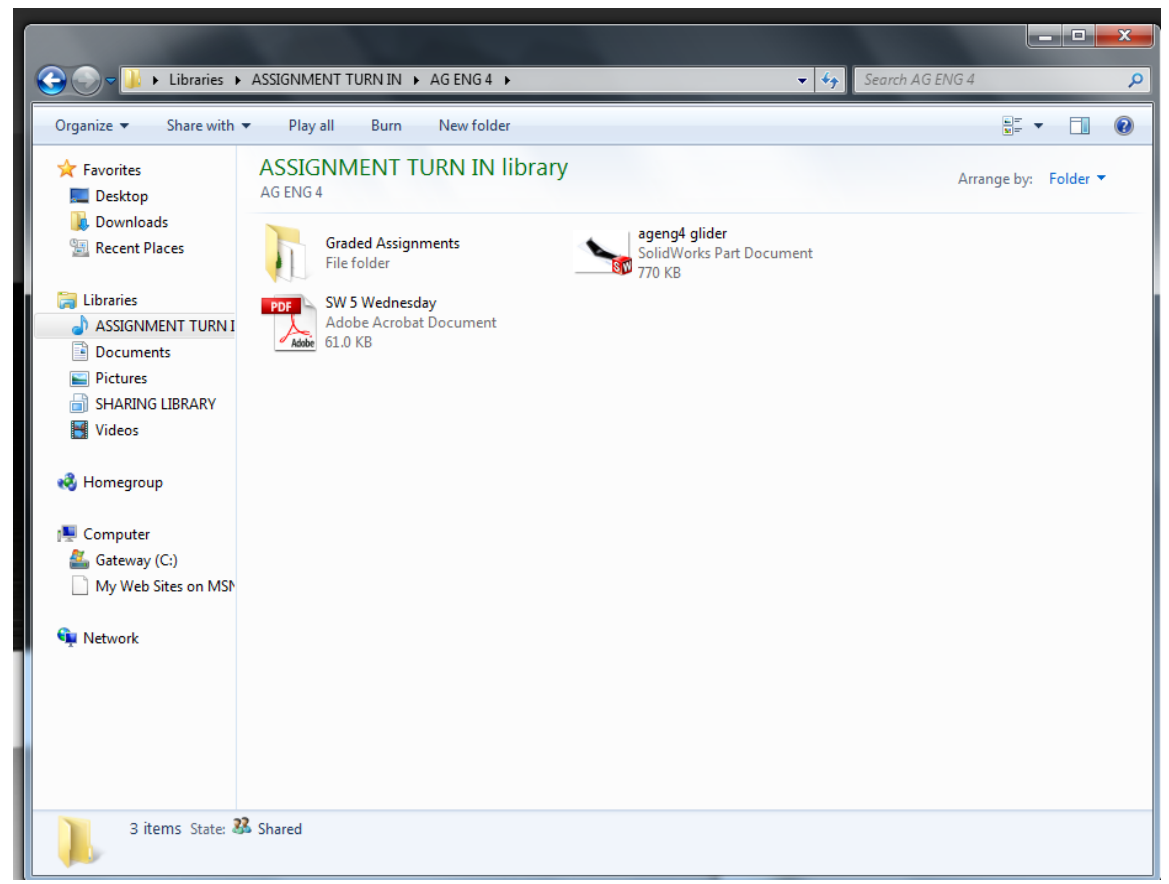

Once the students have dropped the assignment in the folder I will review the drawing and put a grade on it in the title of the part's name. If any student is absent and miss an assignment I drop the instructions or plans into this folder for them to make up when they have finished other assignments.

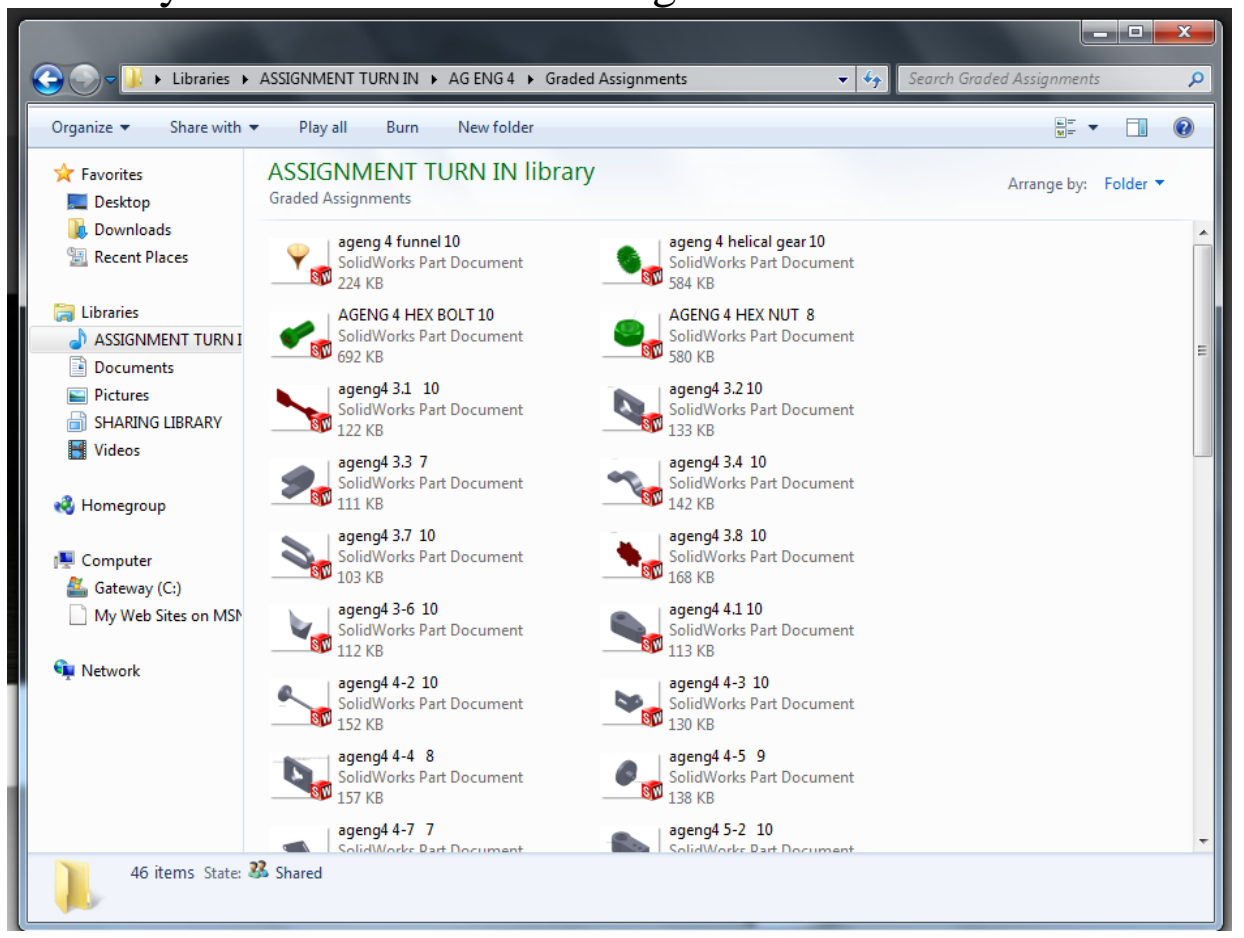

Once the student reviews their grade they drop that assignment into the graded assignments folder. This acts as an archive for them to go back to and review how to use a specific feature. 


\section{Curriculum}

Here are some examples of the curriculum I have created and compiled from various sources.

\section{Create $1 / 2 "$ Hex Bolt}

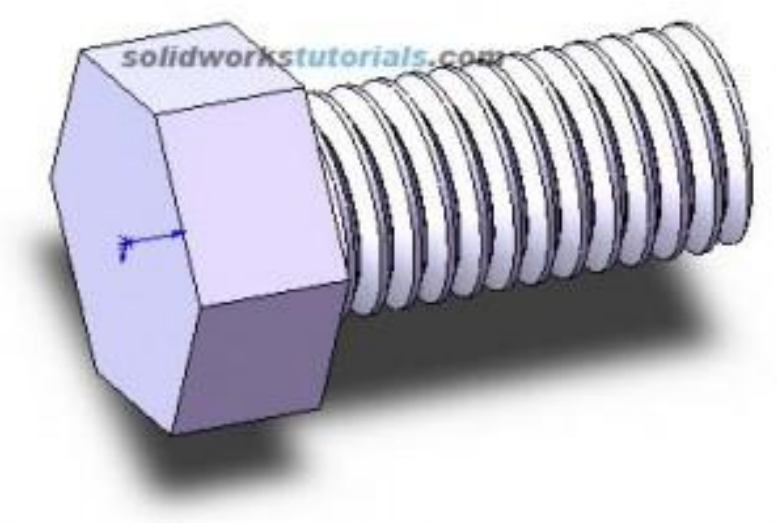

1. Sketch a polygon with 6 side, Tools $>$ Sketch Entities $>$ Polygon

$\begin{array}{lll}\text { Sketch Entities } & \square \text { Line } \\ \text { Sketch Tools } & \square \text { Rectangle } \\ \text { Sketch Settings } & \bigotimes \text { Parallelogram } \\ \text { Blocks } & \oplus \text { Polygon } & \text { set diameter to } 0.75 \mathrm{in} .\end{array}$

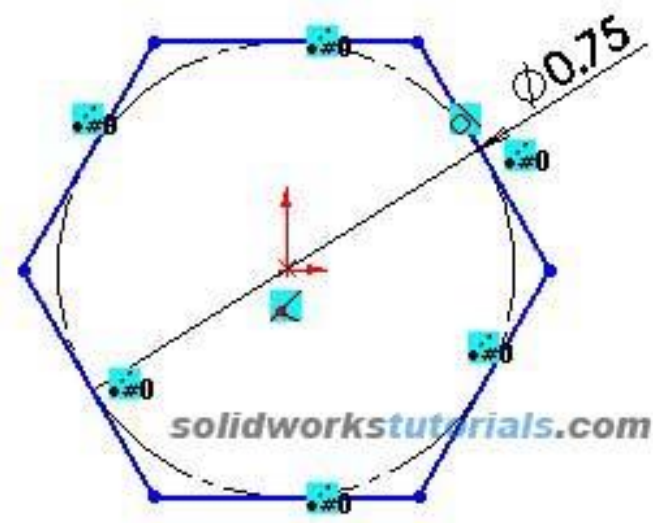


2. Extrude

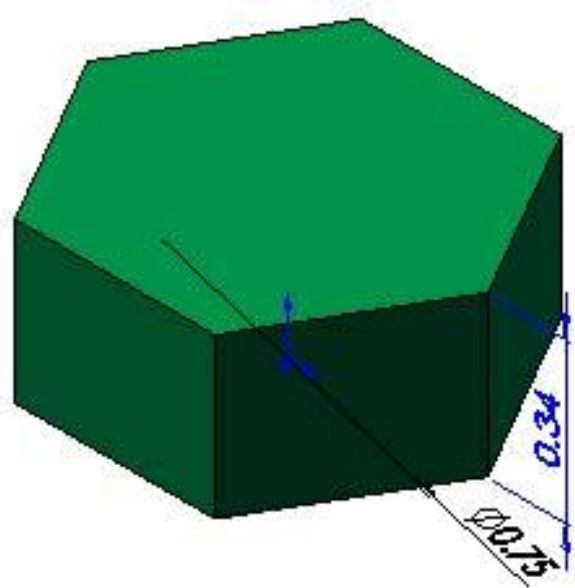

3. Create outside diameter for thread, sketch circle on top face, set diameter to $0.5 \mathrm{in}$.

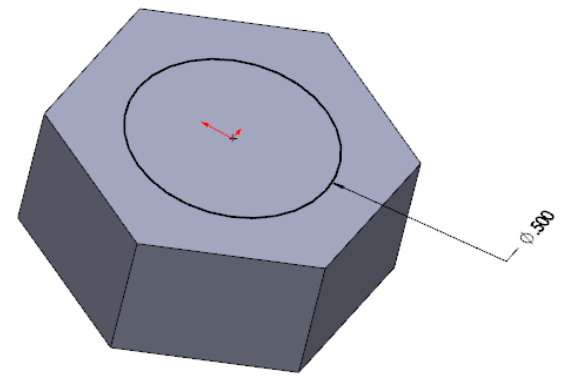

4. Extrude sketch to 1.1in.

5. Open a sketch on the end edge of thread shaft,

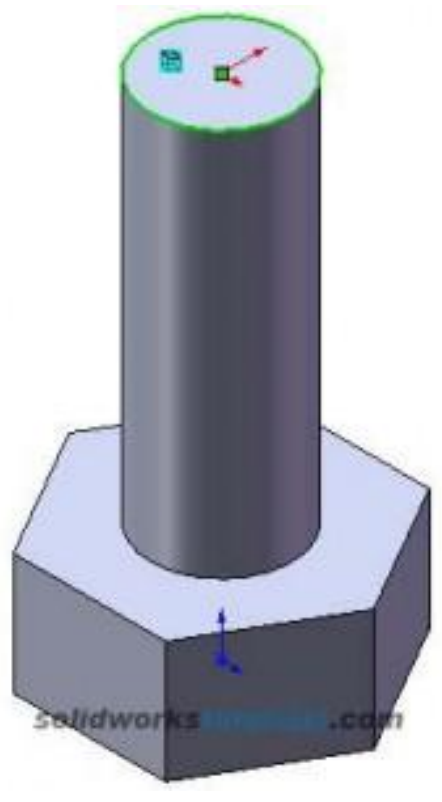
entities

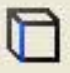

click convert 
6. Select Helix/Spiral feature 8 set height to 1.1 in, thread per inch=pitch $1 / 13$ in
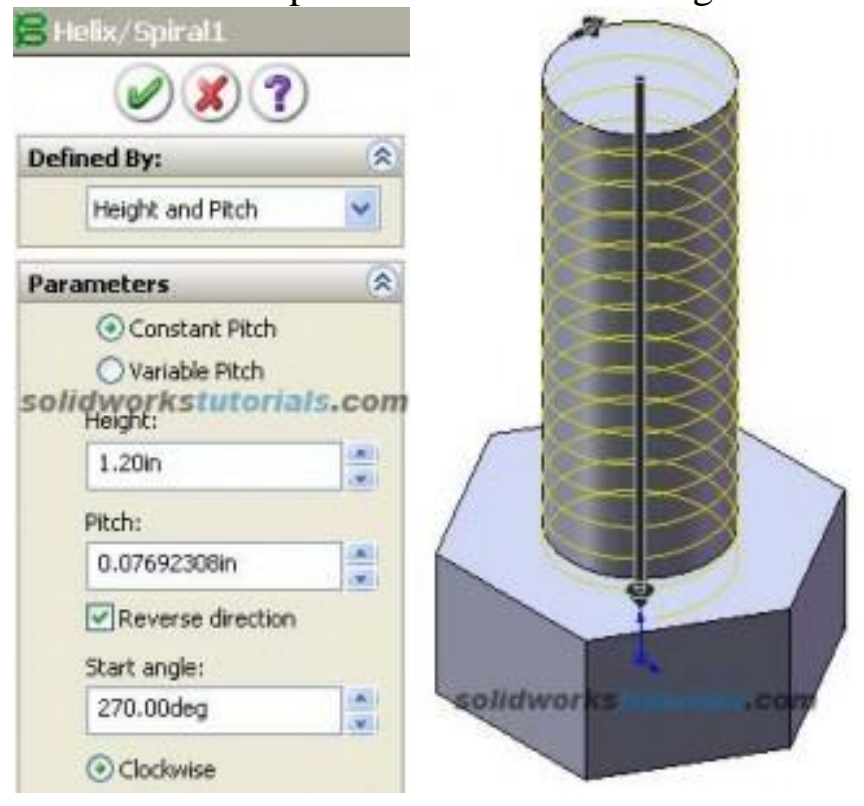

Ok.

7. Insert a new plane tangent to the start point of the helix.

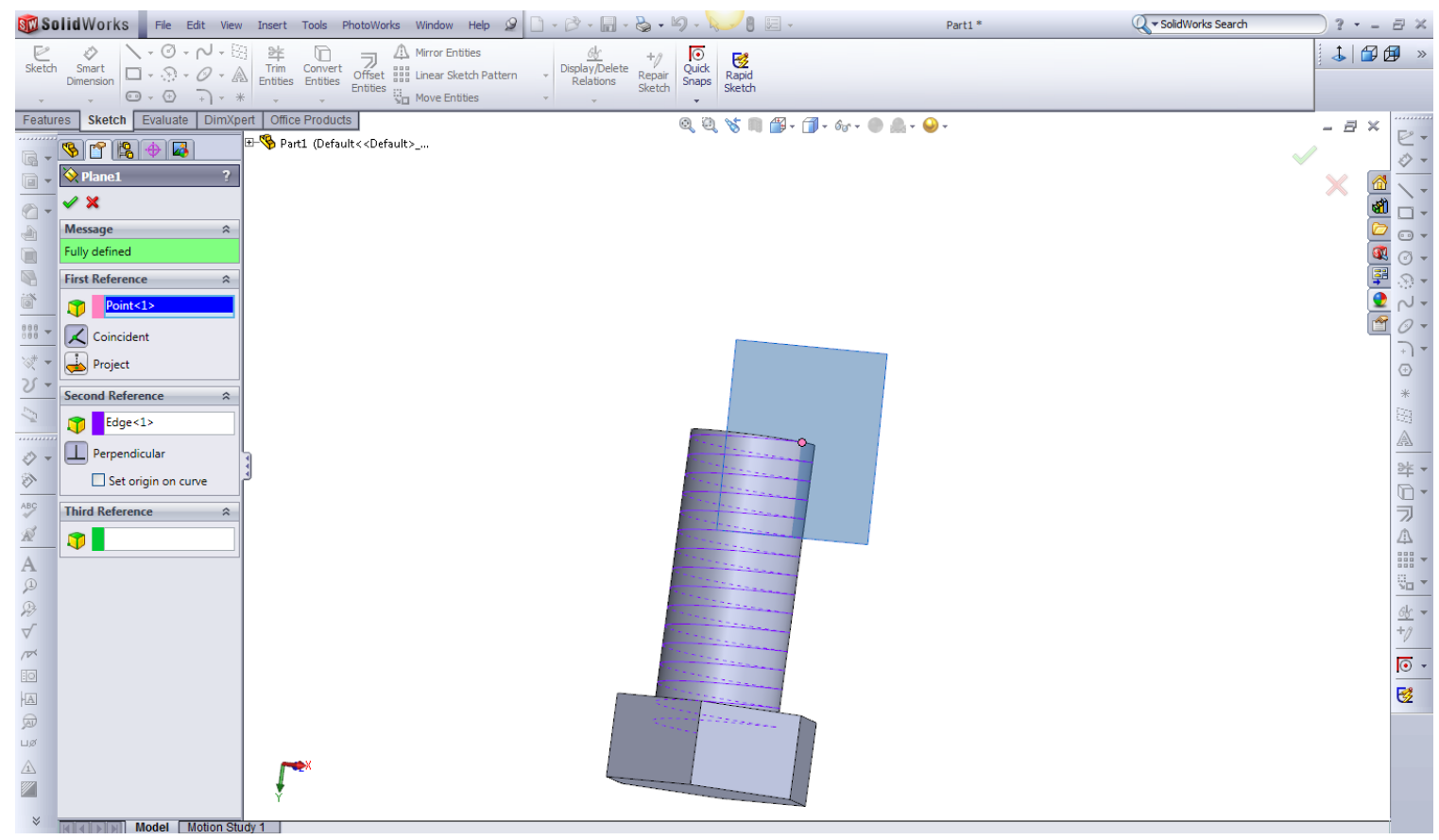


8. On the new plane sketch the thread profile.

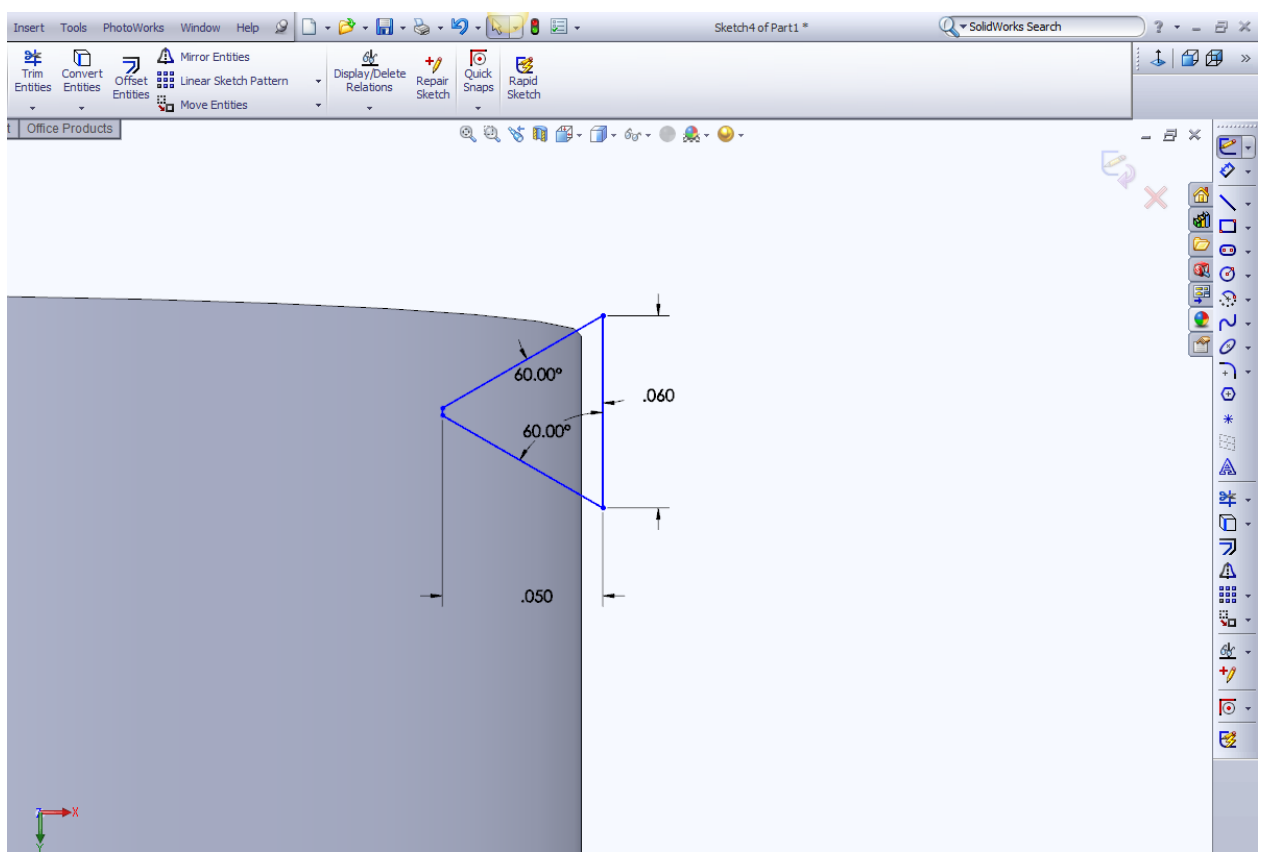

9. Click swept cut feature, select sketch profile as sketch and helix as a path, OK.

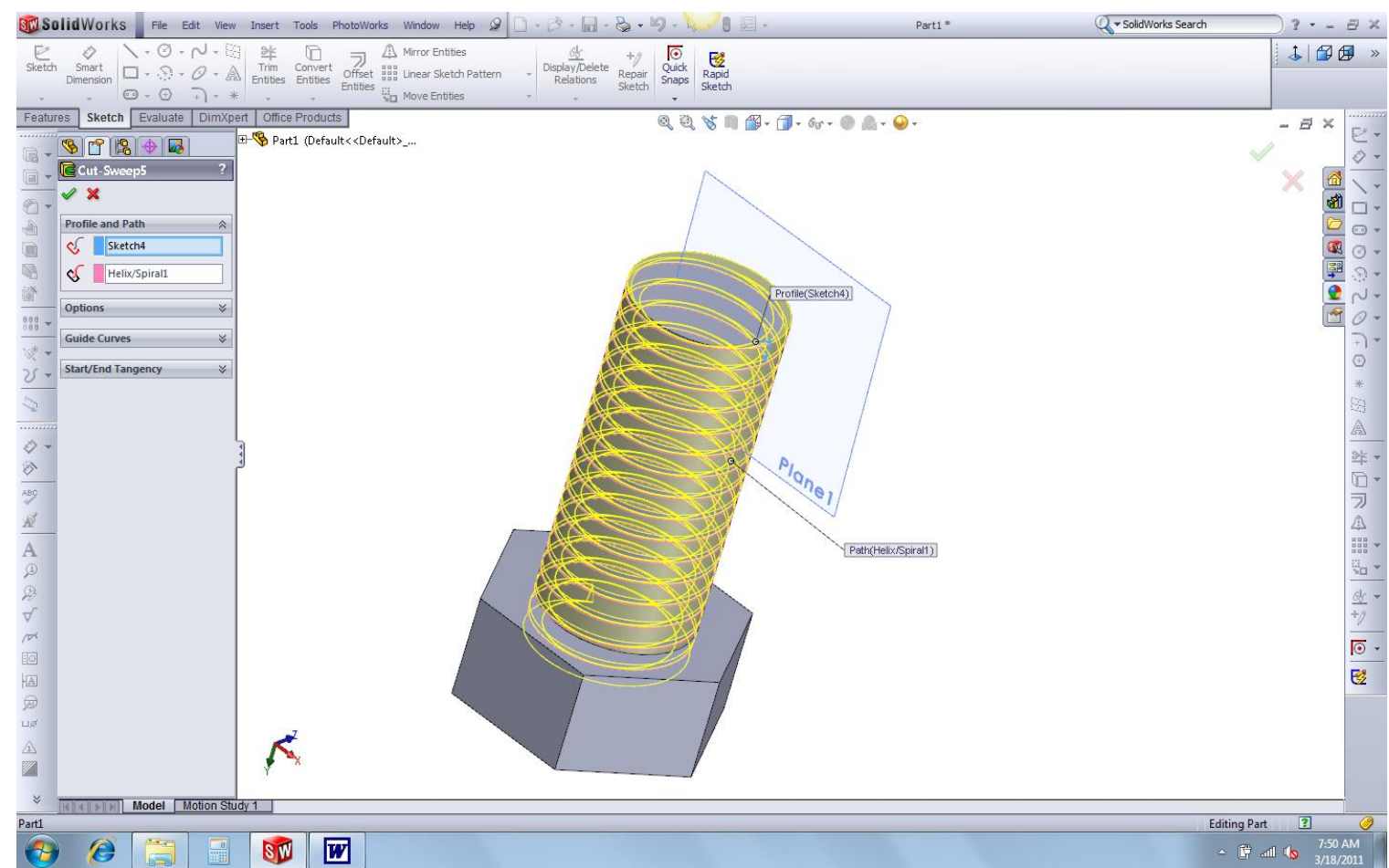


Done.

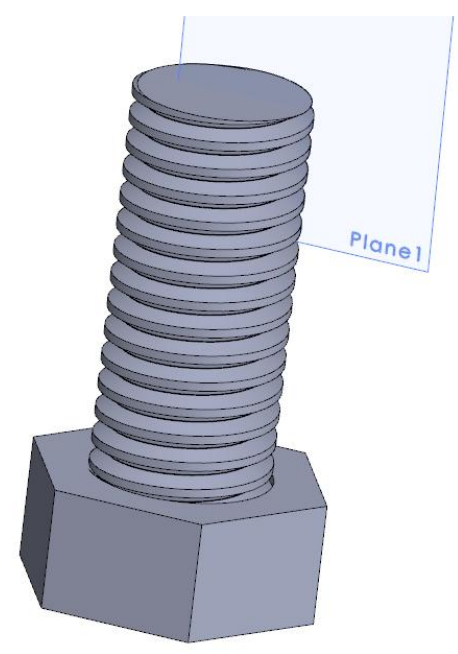

Extra credit: Add some detail to it.

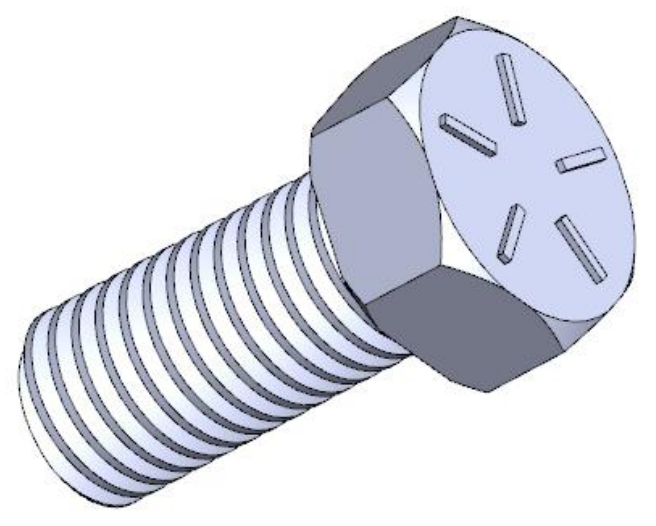




\section{Pencil Assignment}

Step 1. Wood Shape

-Open sketch on the right plane

-Draw a hexagon on the origin 0.25 " wide

-Draw a circle on the origin 0.08 " in diam.

-Extrude to 6" long

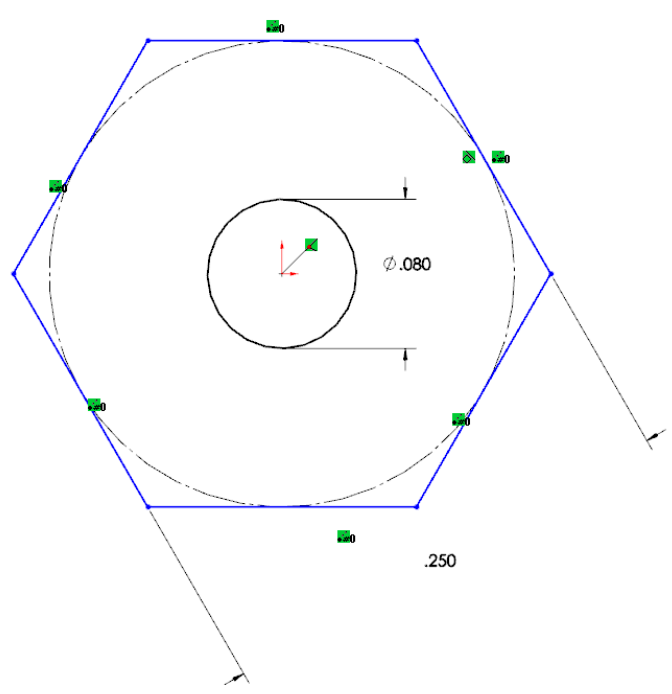

Step 2. Lead

-Open a sketch on the right plane

-Draw a circle on the origin with a diam. of 0.075 "

-Extrude to 6" long
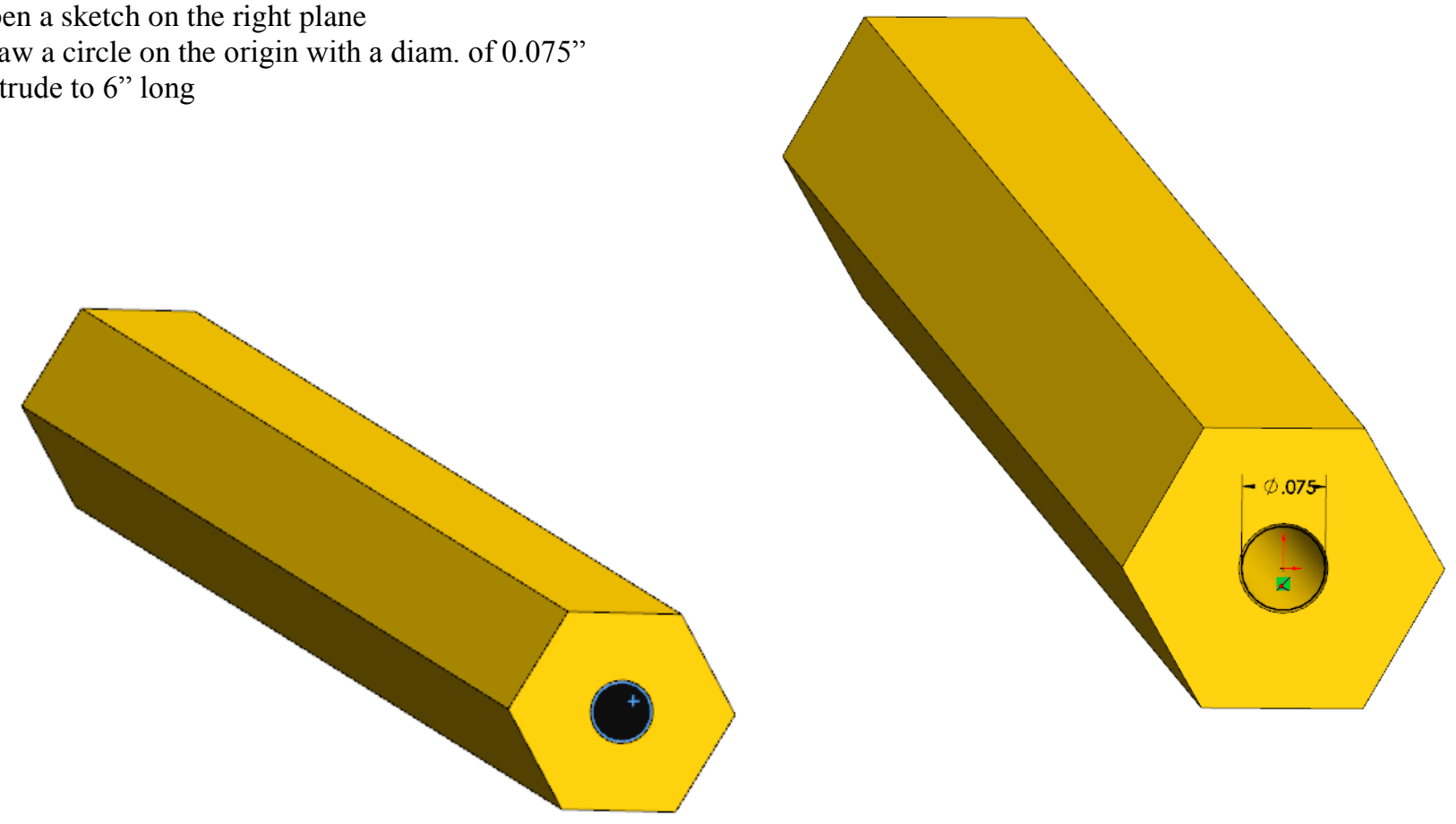
Step 3. Metal Collar

-Open a sketch on the right plane

-Draw a circle from the origin to the point of the hexagon or to a dimension of 0.289 "

-Extrude 0.50" long
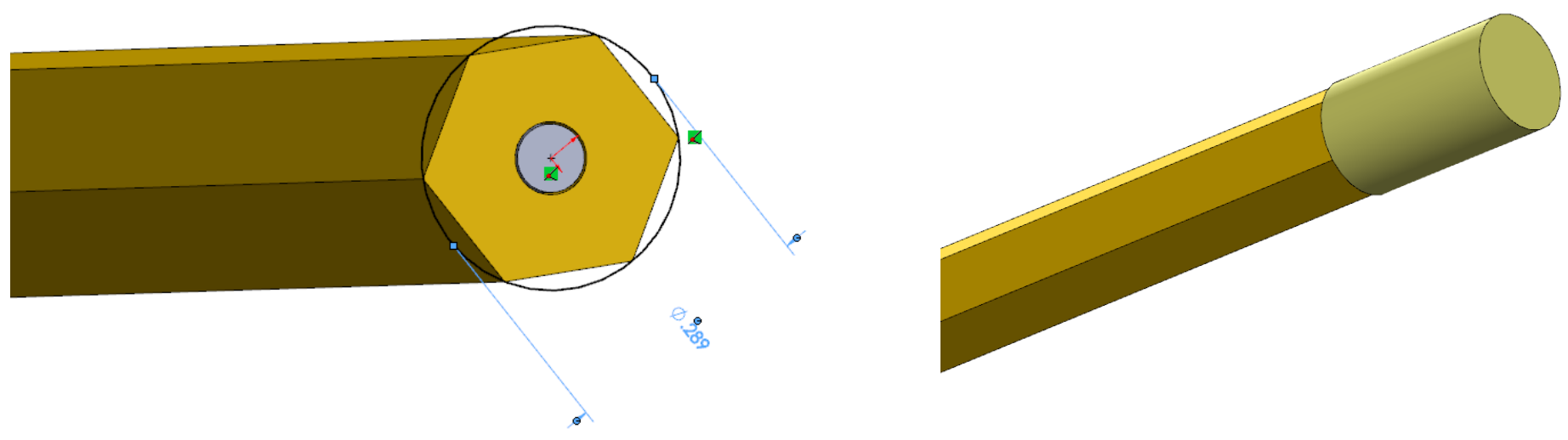

Step 4. Eraser

-Open a sketch on the end of the last extrusion

-Draw a circle from the center point to a diameter of 0.260 "

-Extrude to a length of $0.20 "$
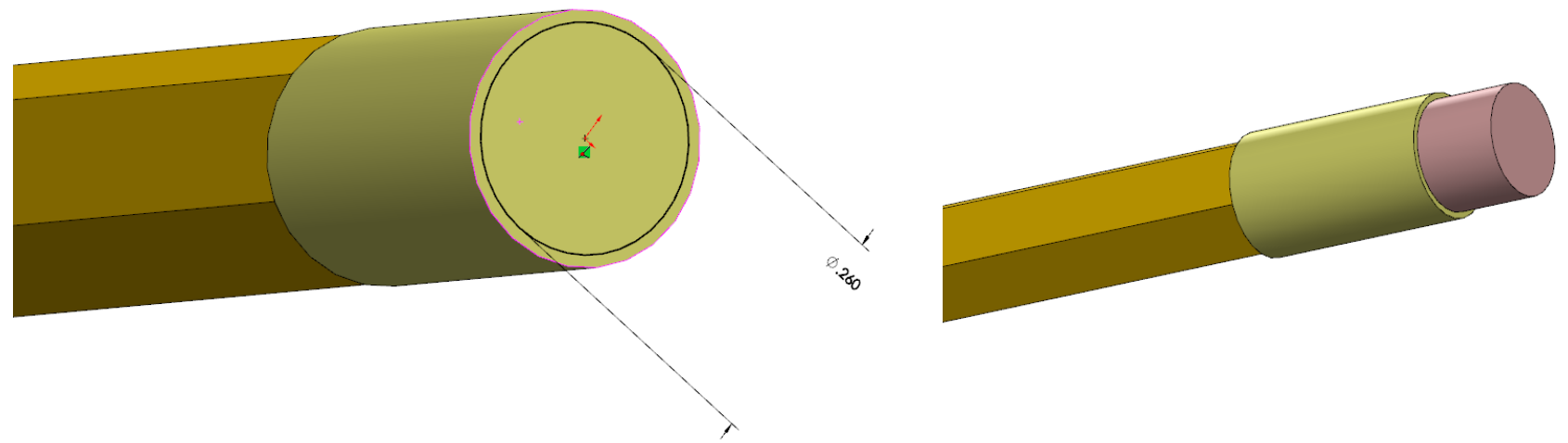

Step 5. Eraser Fillet

-Add a fillet feature with a radius of $0.02 "$

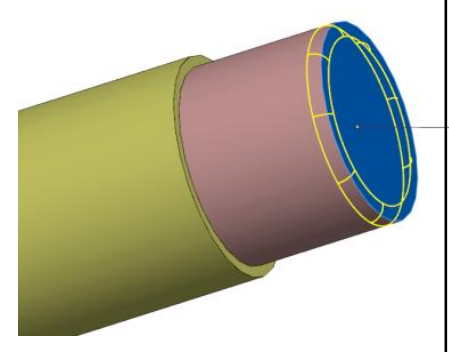


Step 6. Metal Collar Detail

-Open a sketch on the front plane

-Draw eight circles connecting the center points to the outer edge of the metal collar.

-Dimension each group 0.040 " from the ends

-Go to the view tab at the top of the page and select "temporary axis"
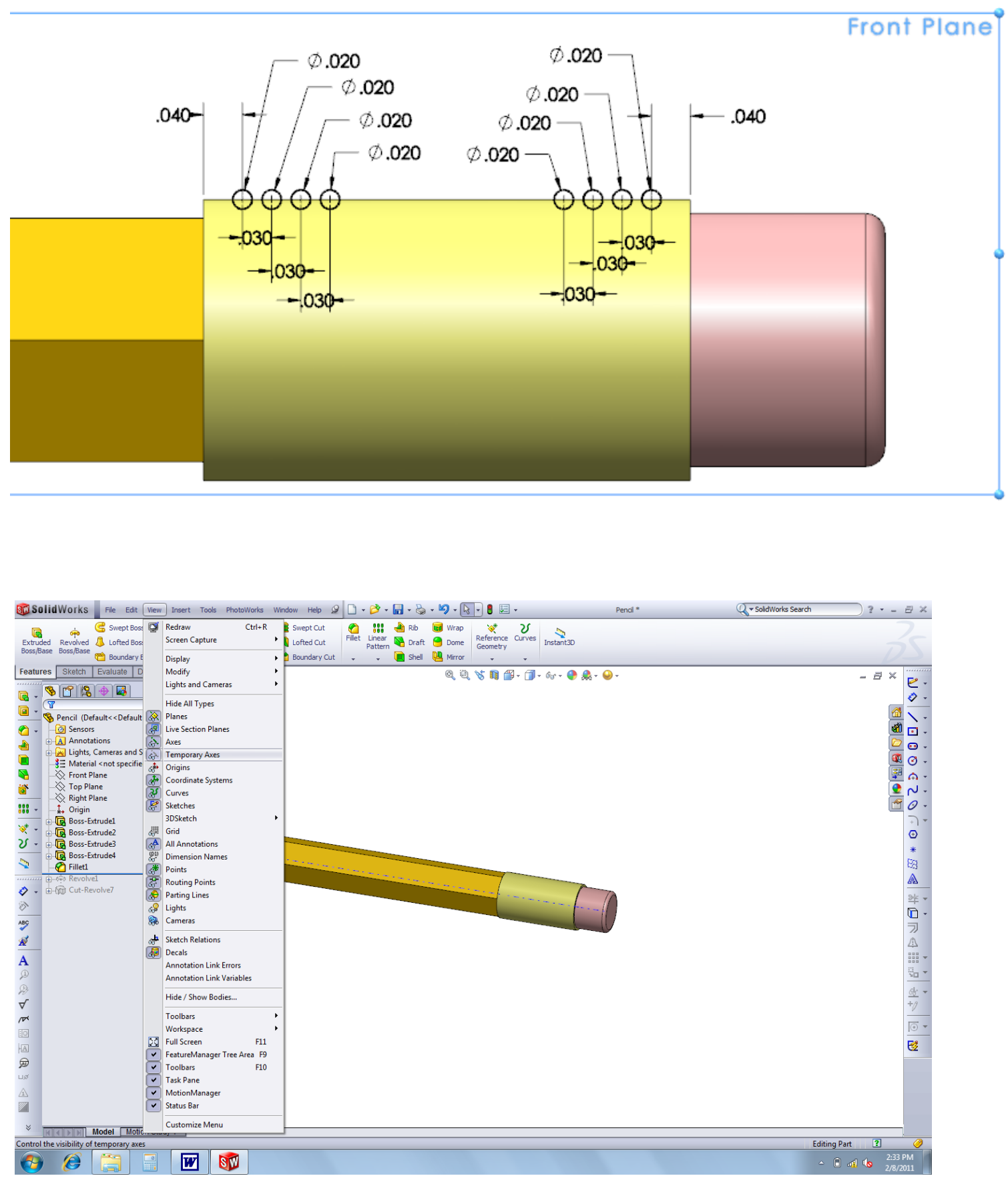
-Select the revolved boss feature from the tool bar.

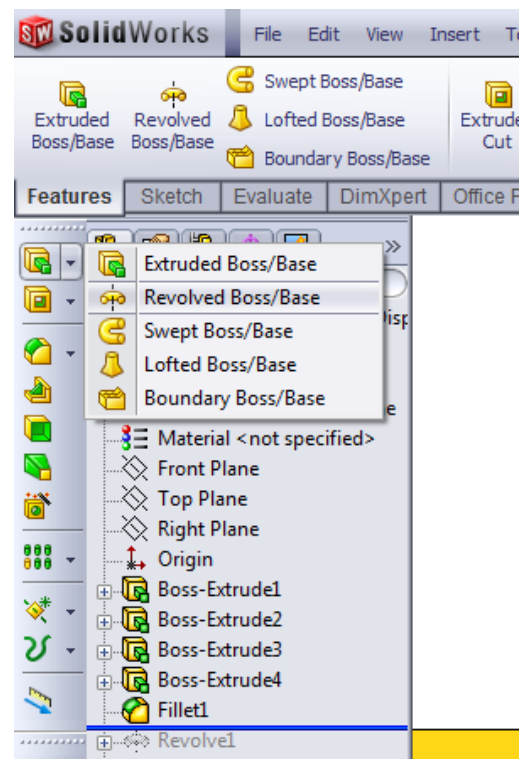

-First select the axis line of the pencil for the axis input box.

-Then select the eight circles in the select contours input box.

-Select the green check mark

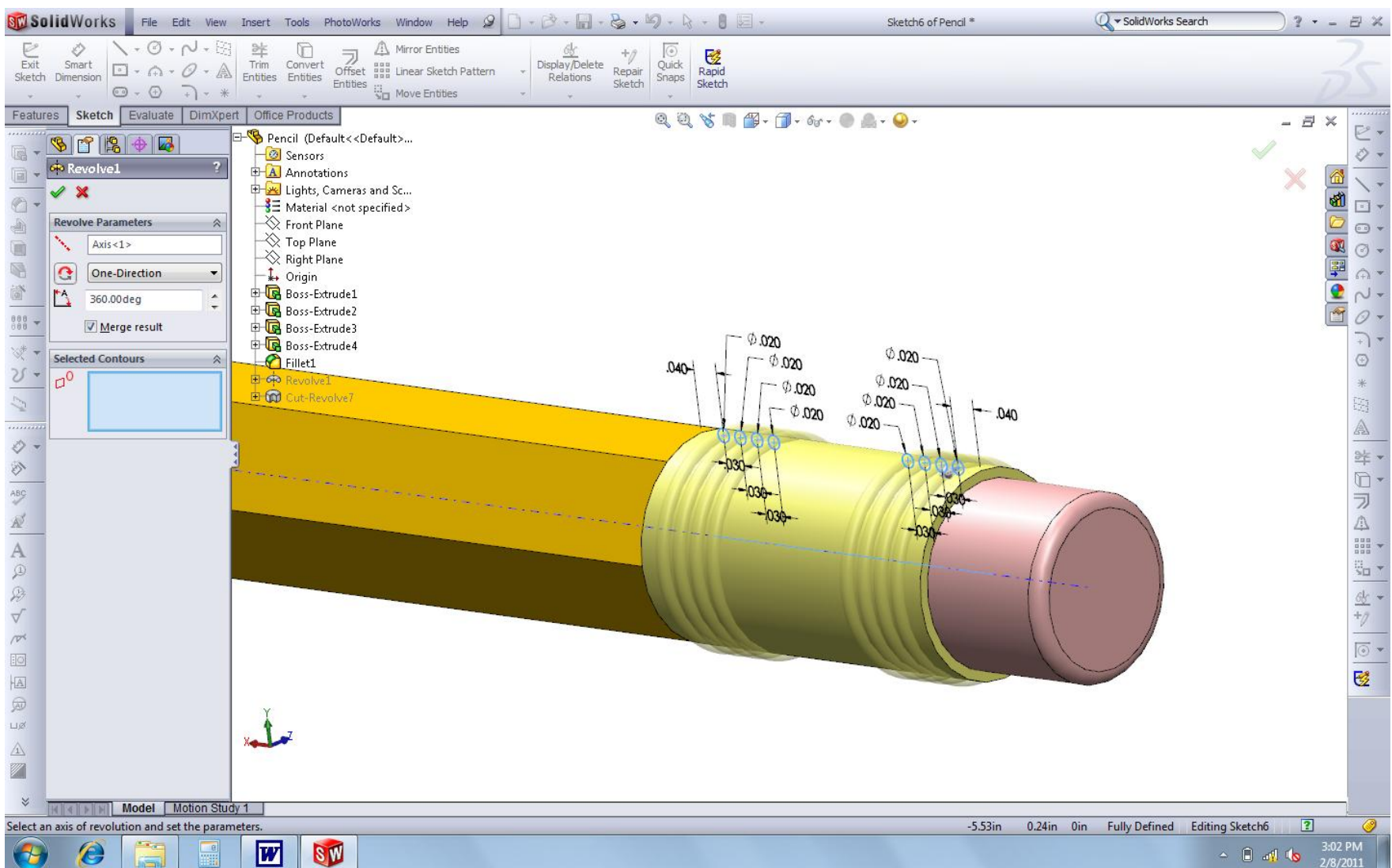


Step 7. Sharpening the pencil

-Open a sketch on the front plane

-Draw a triangle at the end of the pencil and dimension as followed:

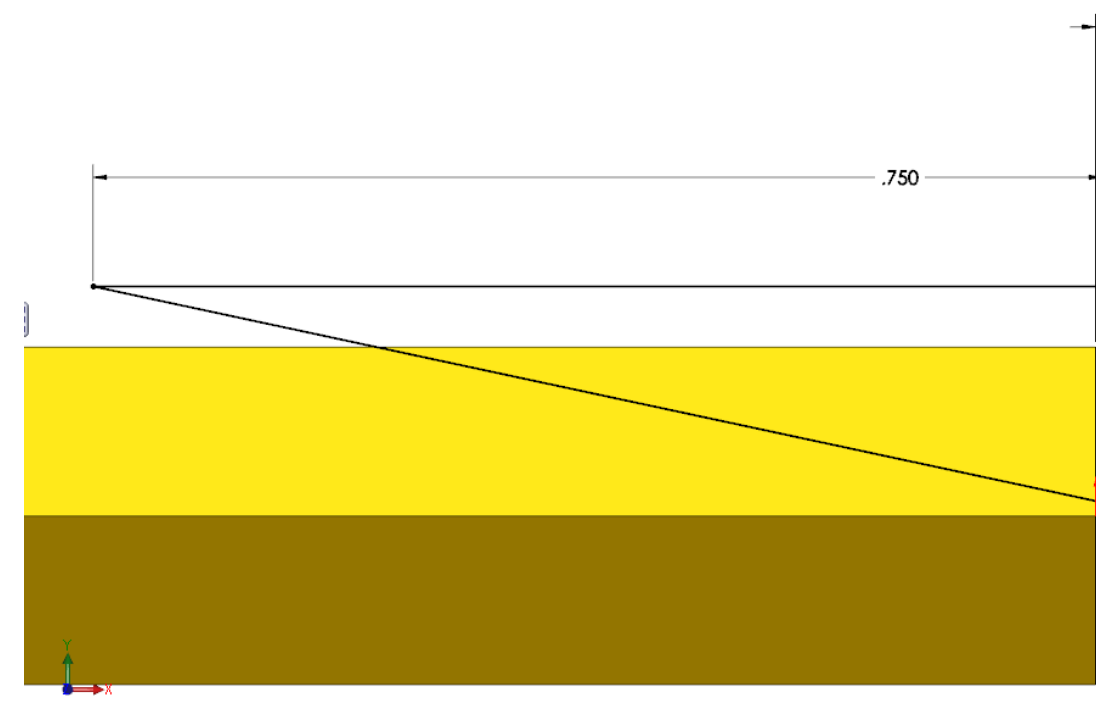

.005

.160

-Select revolved cut under the cut extrude features

-Select the temporary axis of the pencil in the axis input box.

-Select the triangle in the select contour input box.

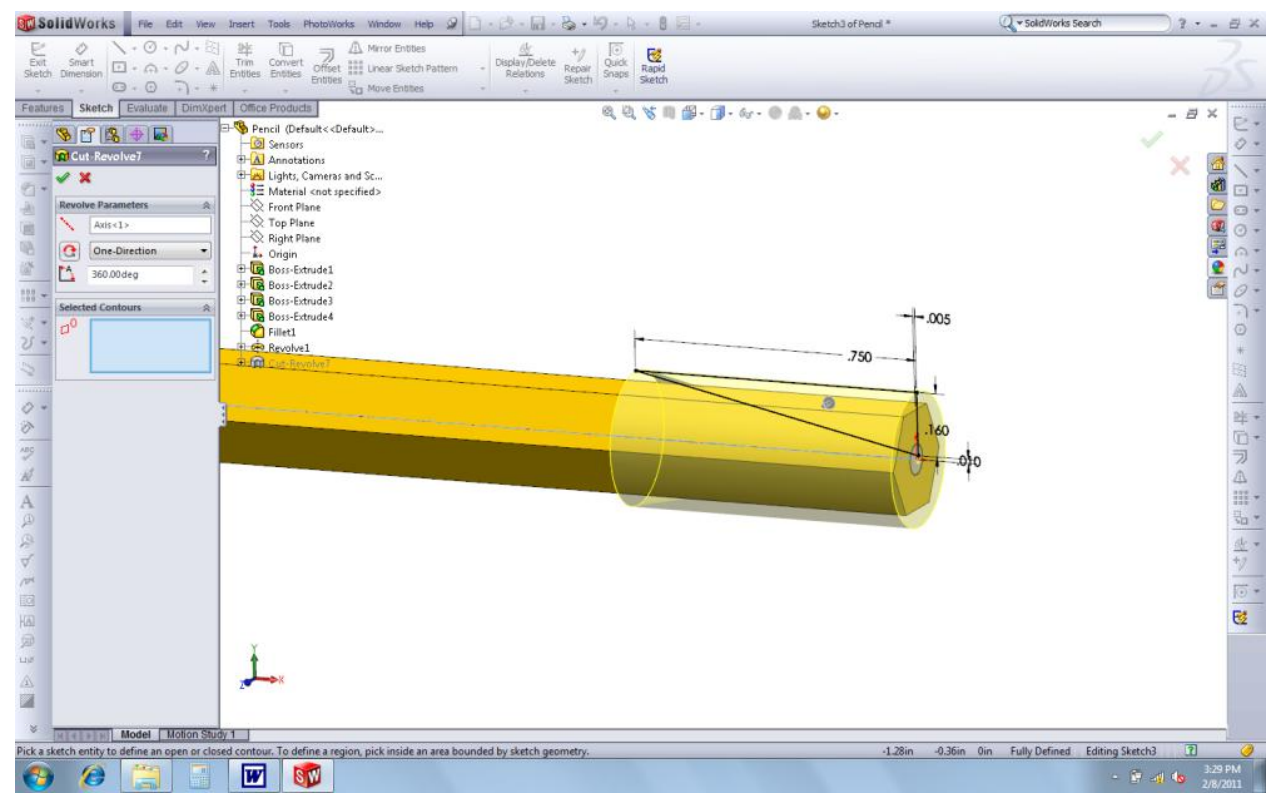

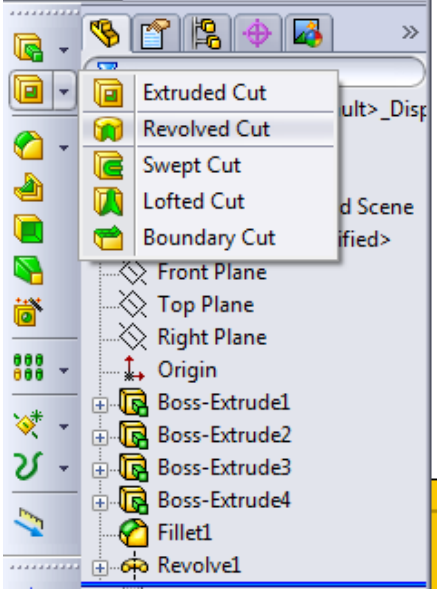




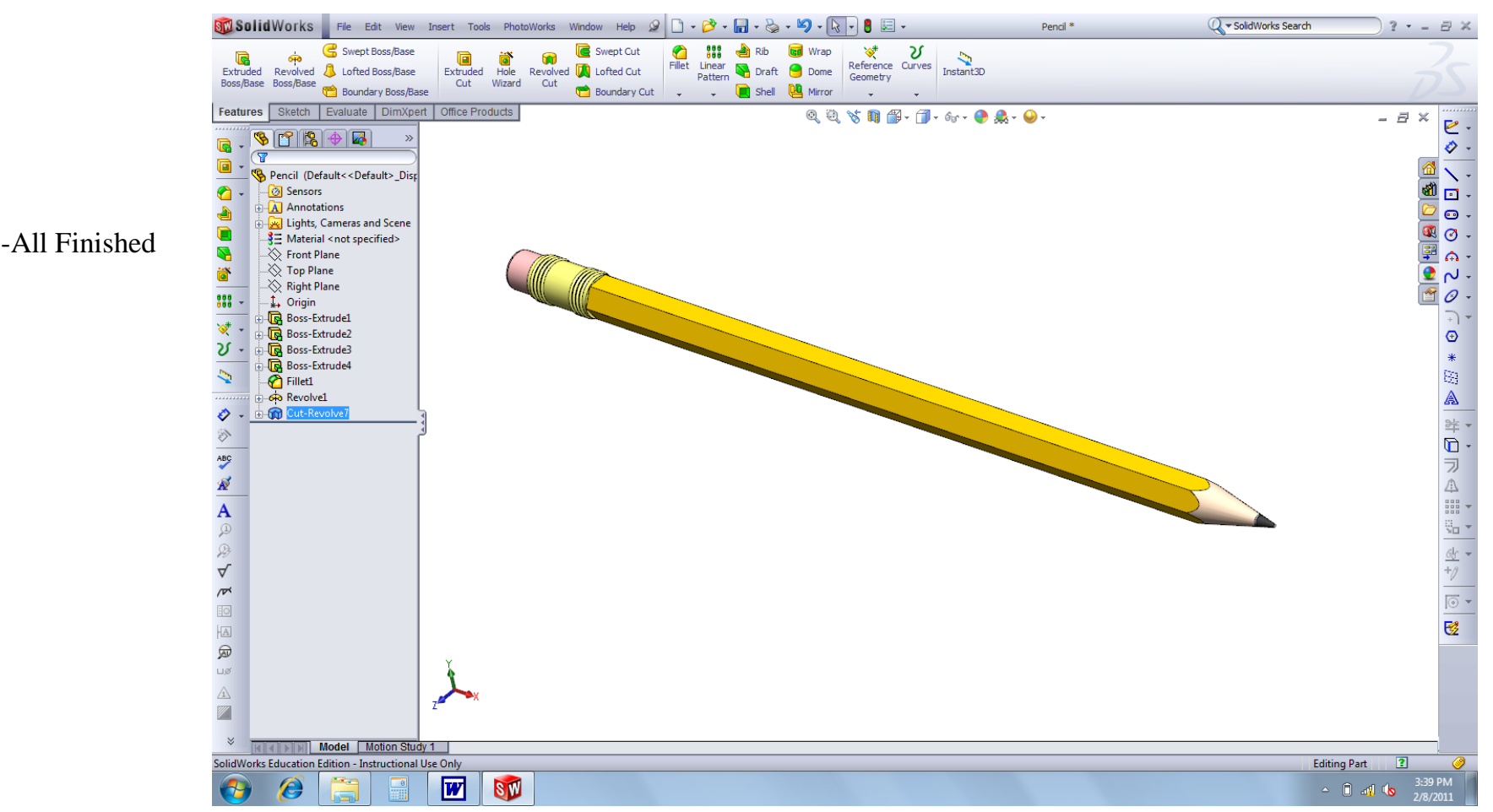

Extra Credit: if you can figure out how to put your name on the pencil as shown.

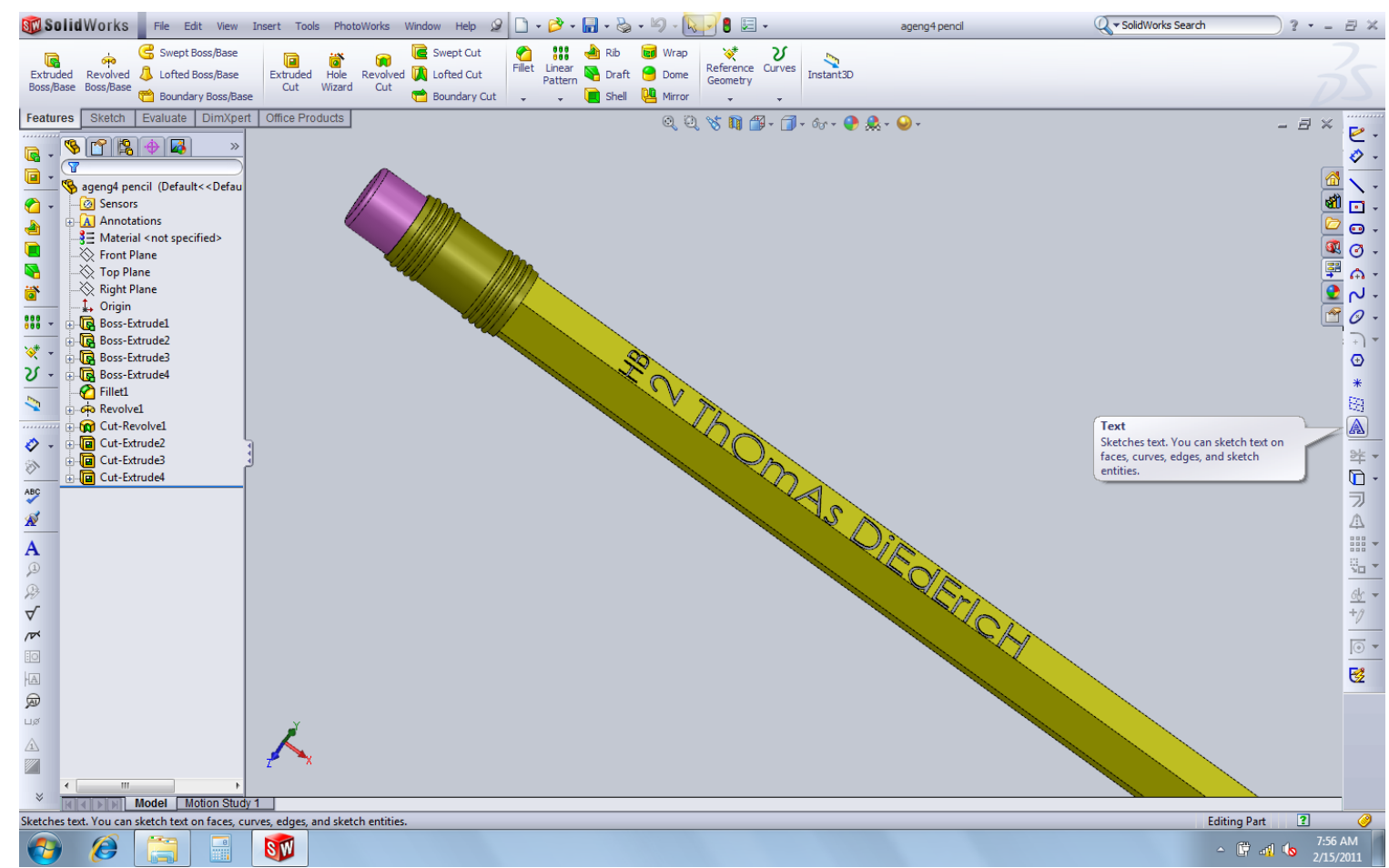




\section{Exercise 4-7 Blanked Cam Plate.}

A. 1. Start a new part file

Please click to enlange

B

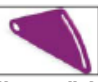

Please click

2. Change the units to MMGS, if needed.

3. Construct the blanked cam plate shown in figure A. All arcs are tangent to connected lines/arcs. Use construction lines as needed.

4. Apply dimensions and geometric relations to the sketch.

5. Extrude the profile into a solid part, as shown in figure B.

\section{Exercise 4-7A}

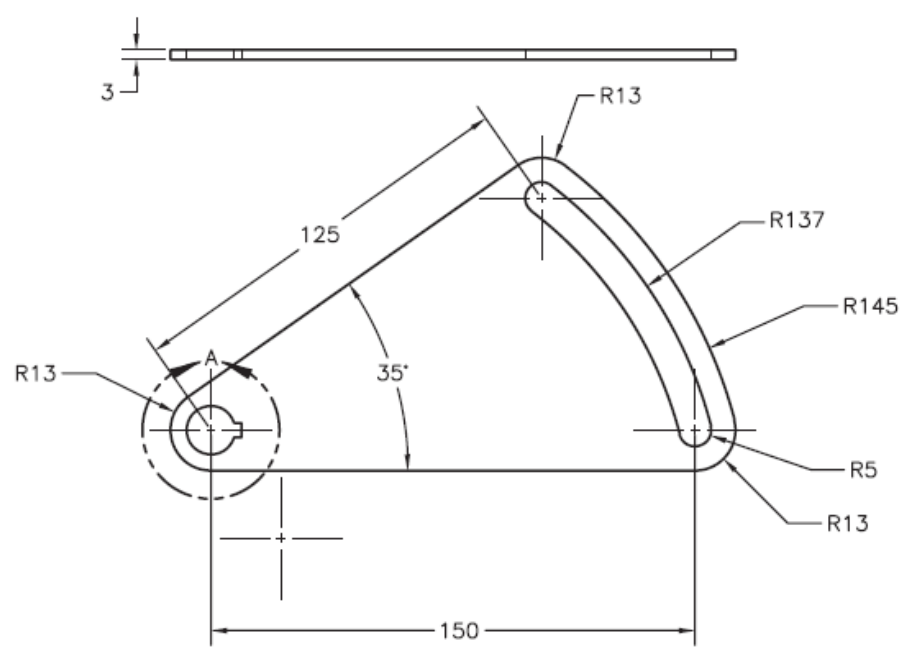

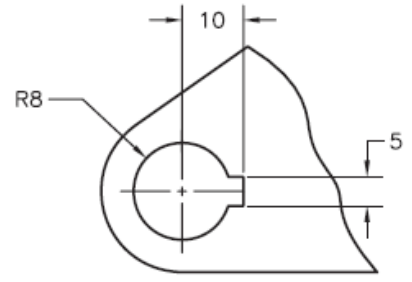

DETAIL A SCALE 2:1

\section{Exercise 4-7B}

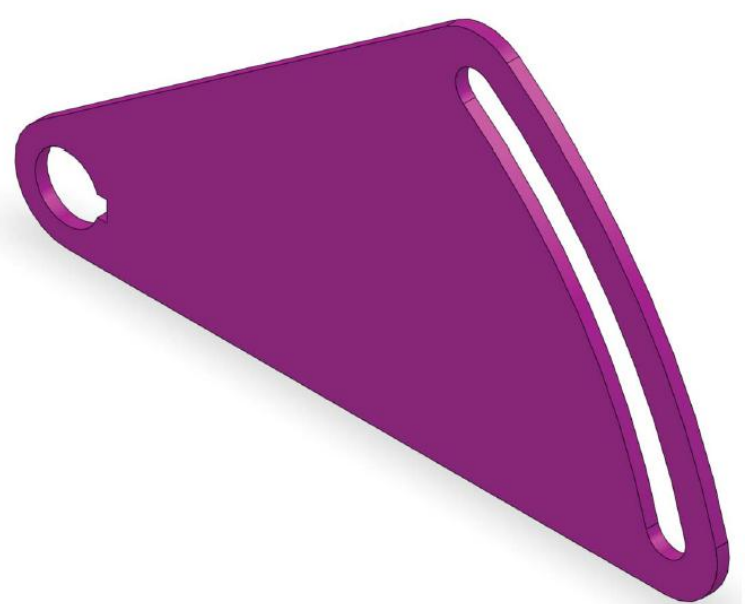




\section{Quality Criteria}

1) Curriculum and Instruction

2) Leadership and Citizen Development

3) Practical Application of Occupational Skills

4) Qualified and Competent Personnel

5) Facilities Equipment and Materials

6) Community, Business and Industry Involvement

7) Career Guidance

8) Program Promotion

9) Program Accountability and Planning

10) Student-Teacher Ratio

11) Full Year Employment 


\section{Quality Criteria One- Curriculum and Instruction}

The curriculum at Apple Valley High School's Agriculture Department has been organized and sequenced around career paths with clear performance standards leading to entry-level employment, job advancement, entrepreneurship, advanced education and training and personal use. Instruction is performance based and integrates academic knowledge and skills which reflect current and emerging technologies and practices in business, industry, and the home environment.

Quality Criteria-1.1

Our agriculture courses at Apple Valley High School meet this criterion by the incorporation of the core curriculum content standards infused with the existing curriculum in place. New courses such as the Plant and Soil Science course are created using the core cluster standards.

Evidence: Agriculture Course Outlines

Quality Criteria-1.2

The curriculum for the courses are in written form and include course descriptions, goals, objectives, outlines, course duration, instructional strategies, materials, texts, supplemental materials, software, performance standards, and evaluation procedures.

Evidence: Agriculture Course Outlines and Descriptions of Courses

Quality Criteria-1.3

The courses in agriculture at Apple Valley High School are structured into career pathways. Students choose which pathway to follow depending on their career interest. They will choose either Animal Science, Ag. Engineering, or Horticulture. Evidence: Agriculture Pathway Flowcharts and Course Outlines 
Quality Criteria-1.4

The agriculture curriculum and instruction provide Apple Valley High School students with career path information and planning strategies. A unit on agricultural careers is taught in every course.

Evidence: Agriculture Course Outlines

Quality Criteria-1.5

Every agriculture course meets the high school's graduation requirements either as a core class or elective units. The Agriculture Biology and Floral Design courses at Apple Valley High are UC approved courses receiving lab science credit for Ag. Bio and visual performing art credit for Floral.

Quality Criteria-1.6

The curriculum taught in the vocational education courses engage students in activities that enhance academic skills in math, science, communications, and technology.

Evidence: Every student is taught record keeping through the use of the record book. Science is a major aspect of the animal science pathway. Agriculture engineering applies mathematical relations and formulas including measurement and calculations in its curriculum.

Quality Criteria-1.7

Each course of study taught incorporates high order thinking skills and includes group and individual decision making and interpersonal skills.

Evidence: Judging team activities, class discussion topics, leadership activities and lessons.

Quality Criteria-1.8

The sequence of courses for each career path is identified through flowcharts for each pathway provided. Example: Agriculture Engineering pathway1.Introduction Agricultural Engineering 2. Intermediate Agricultural Engineering 3. Advanced Agricultural Engineering 4. ROP Welding Technology.

Quality Criteria-1.9

Courses taught in the Apple Valley High School Agriculture Department follow a logical sequence which is consistent with the State Agriculture Education Implementation Guidelines. The students must take introductory courses before advanced courses can be taken. The pre-requisites for each course are strictly enforced.

Evidence: Course of Study Descriptions 
Quality Criteria-1.10

The instruction of the agriculture courses are competency-based, current and relevant in content and reflect the knowledge and skills required in the career path. Evidence: The career cluster performance standards are identified in the curriculum and course descriptions and the courses are based off of competency type assessments.

Quality Criteria-1.11

All students in the agriculture department are required to use computers throughout their instruction whether it is the e-record book, PowerPoint presentations, or $\mathrm{CAD} / \mathrm{CAM}$ instruction. The department has over 60 laptop computers available for students to use at any given agriculture class during the day.

Quality Criteria-1.12

Apple Valley High School Agriculture Department instruction, activities, and materials do not discriminate students based on gender, race, disabilities, or disadvantaged. All instructors at Apple Valley High School are required to send any information home in two different languages. The district offers translation assistance to fulfill this requirement.

Evidence: Newsletters sent home to parents.

Quality Criteria-1.13

All courses at Apple Valley High School and the Agriculture Department meet the needs of all students, especially those with learning needs resulting from academic and economic disadvantages, and mental, emotional, and physical disabilities. Students that have IEP's receive as much assistance as they need whether it is through personal aides or modified teaching strategies. All teachers at Apple Valley have specific training on using modified teaching strategies in order to accommodate learning disabilities.

Evidence: Student IEP's, CLAD certifications, lesson plans.

Quality Criteria-1.14

There are resources available at Apple Valley's Agriculture Department to ensure students succeed in their courses. Examples include all lecture materials given on a LCD projector using PowerPoint or other type of presentation program. These presentations are available to be printed out for students if their IEP's require it. The use of Quizdom assessment tools are used in conjunction with lectures to ensure student understanding of the material. Also many tangible models are used 
to demonstrate concepts and the use of a digital presenter is used for dissections and to analyze objects.

Quality Criteria-1.15

Many courses at Apple Valley High School articulate with the local junior college, Victor Valley Community College. An example is the ROP Welding course that articulates to VVC's Welding 50 course.

Evidence: Agreement forms between the school and colleges.

Quality Criteria-1.16

The agriculture department utilizes business and industry sponsored resources and support, such as guest speakers, equipment, demonstrations, field trips, student scholarships, partnerships and placement opportunities.

Evidence: Thank you letter to South West Gas for the donated welder, Pictures of students on field trips and demonstrations, Student's record books on job placements. 


\section{Quality Criteria Two- Leadership and Citizenship Development}

Students at Apple Valley High School's Agriculture Program develop leadership, citizenship, interpersonal, and employment skills by participating in community service projects and cooperative individualized and competitive instructional activities. The students achieve this by participating in the intra and extracurricular activities involved with the FFA. FFA is $25 \%$ of their academic grade and must attend a minimum of 12 activities to fulfill the grade requirement.

Quality Criteria-2.1

The Apple Valley FFA Charter has been applied for and exits since 1967. Apple Valley's charter number is 321. Apple Valley High School Agriculture Department is located in Apple Valley Unified School District in San Bernardino, California. Evidence: Current FFA roster for Apple Valley High School.

Quality Criteria-2.2

All students that are enrolled in agriculture courses at Apple Valley are also entered into the R-2 as FFA members. All of the agriculture courses offered at Apple Valley require students to participate in FFA. $25 \%$ of the student's grades are dependent on their involvement in the FFA.

Evidence: Course of study for each course, FFA roster and enrollment forms.

Quality Criteria-2.3

Every course taught in agriculture at Apple Valley High School includes at least one unit of instruction on the FFA organization and its activities.

Evidence: Course of study for each course and unit plans.

Quality Criteria-2.4

The current FFA Advisor for Apple Valley High School is an Agriculture Instructor employed by the district and is verified by the programs R-2 enrollment report.

Evidence: District employment records, R-2 report. 


\section{Quality Criteria Three- Practical Application of Occupational Skills}

The students in Apple Valley High School's Agriculture Department receive practical application of occupational skills through classroom simulation of worksite experiences, community based learning and entrepreneurship. These practical experiences are combined, coordinated, and evaluated with the classroom instruction.

Quality Criteria-3.1

Students participate in Supervised Agriculture Experiences which is 25\% of the graded criteria of each course. Students must have a viable project in place and have expenses and hours recorded in their record book to fulfill this grade requirement.

Evidence: Course Outlines, Student Record Books.

Quality Criteria- 3.2

Students that have off campus SAEs are visited by their instructor at least two times throughout the school year. A school vehicle is a available for all instructors to use to visit students. If teachers use personal vehicles or incur personal expenses they are reimbursed.

Quality Criteria- 3.3

All students that have an SAE project have completed a business agreement or similar document to plan their experience.

Quality Criteria- 3.4

Apple Valley High School has a school farm/ laboratory facility for students to keep projects at if they cannot keep them at home. There are farrowing facilities for students to engage in market hog breeding projects. Also the high school greenhouse is fully rebuilt and an apple orchard planted for student to have horticulture projects on campus. 


\section{Quality Criteria-3.5}

Students with special needs usually have their SAE projects at school so that the teachers can assist them while they work with their projects. The most common type of project for students with special needs is the meat bird project that goes on in the late spring. The several students work together to raise $50-100$ chickens for 6-8 weeks. Each student takes a pen of three to the fair to show and sell. This type of project works well because of the teamwork involved. 


\section{Quality Criteria Four- Qualified and Competent Personnel}

All agriculture teachers at Apple Valley High School are competent and qualified with the appropriate occupational proficiency.

Quality Criteria- 4.1

Each instructor holds a valid California Single Subject Teaching Credential in the appropriate areas.

Evidence: Copies of the credentials.

Quality Criteria- 4.2

Each teacher has a minimum of 3000 hours of occupational experience in agriculture as required by the Agricultural Teaching Credential.

Quality Criteria- 4.3

Instructors at Apple Valley use a variety of teaching strategies and materials to effectively teach all types of learners especially special needs learners. The use of practical and hands on teaching is extremely effective as well as the student group work assignments.

Evidence: Teacher lesson plans, class observations.

Quality Criteria- 4.4

Both agriculture teachers are CATA members and attend professional development meetings and conferences in the sectional, regional and state levels throughout the year. Teachers are reimbursed for personal expenses incurred by participating in professional development activities.

Quality Criteria- 4.5

Our administrative staff at Apple Valley High School is involved with the professional development activities in the career technical areas of our school. Our Principal has attended State convention and was nominated for the State Star Administrator Award by winning the regional level. He also attended the Educating for Careers conference with the rest of the career technical teachers.

Quality Criteria- 4.6

Both CATA member teachers attend the fall and spring regional meetings, at least four sectional meetings, and the summer conference annually. 


\section{Quality Criteria- 4.7}

The department chair always attends the State CATA Conference every year and gathers information at the conference and shares with other teachers within the department.

Quality Criteria- 4.8

The department chair person calls for department staff meetings at least twice a month to discuss events and issues in the agriculture department. 


\section{Quality Criteria Five- Facilities, Equipment and Materials}

The facilities, equipment, instructional materials and supplies at Apple Valley High School's Agriculture department are safe, organized and contain emerging technology used in the industry.

Quality Criteria- 5.1

Facilities, equipment, and materials are comparable to those currently used by businesses and industry. The agriculture classroom is the most technologically advanced classroom in the school. It contains LCD projector, big screen LCD TV for the school farm video camera system, digital presenter, Quizdom assessment tools, ultra-sound equipment, video microscopes, and 30 laptop computers. The green house building is updated with automated control systems and all new coolers and heaters. The agriculture engineering shop is fully equipped with many industry standard equipment including: welders (10 Stick, 7 MIG, 4 TIG, 4 OxyAcet., and 2 gas powered multi-process welders), ironworker, sheet metal shear, sheet metal brake, horizontal band saw, plasma cutter, Plasma CAM, drill press, many handheld power tools from Milwaukee Tool and 30 laptop computers with SolidWorks and Plasma Cam Software.

Evidence: Advisory committee approval

Quality Criteria- 5.2

All facilities are kept neat and organized by students and instructors. The school farm is managed by a student laboratory manager who oversees the up keep of that facility.

Quality Criteria-5.3

Facilities, equipment and instructional materials are regularly maintained, replaced, and repaired to meet the local state and federal health and safety rules and regulations. The district risk management official frequently inspects our facilities and equipment for safety. The school maintenance department fixes the needed repairs along with the instructors for each of our facilities.

Quality Criteria- 5.4

All facilities on campus including the agriculture department are ADA compliant to accommodate the needs of special populations. 
Quality Criteria- 5.5

The instructional material are adapted or supplemented to meet the needs of special populations.

Evidence: Typed lecture notes/ handouts, Ear phone/microphone for hearing impaired

Quality Criteria- 5.6

There is adequate storage for all materials and equipment. The department recently purchased three 8'x 40' storage containers for the storage of fair equipment, student projects, metal storage, and other supplies. 


\section{Quality Criteria Six- Community, Business and Industry Involvement}

Individuals from the community, industry and post-secondary institutions help guide and support the program by serving on the advisory committee. The agriculture instructors use the advice given from these individuals to design and develop classes and curriculum to meet the needs for students graduating and entering the work force or post-secondary education.

Quality Criteria- 6.1

Apple Valley's Agriculture Advisory Committee consists of industry representatives, college professors, community members, high school staff and administrators, parents, and students.

Quality Criteria- 6.2

The advisory committee minutes contain the advice and criticism given by the members and verify that the program is working to meet their needs.

Quality Criteria- 6.3

The minutes for the advisory meetings for the last five years are on file and also the program's five year plans that are created each year are constantly reviewed and added to.

Quality Criteria- 6.4

Career technical staff actively participates in the advisory committee meetings. Quality Criteria- 6.5

The advisory committee meets at least twice a year. They meet once in the fall and once in the spring.

Quality Criteria- 6.6

The advisory committee addresses special populations and their specific needs at the meetings. 


\section{Quality Criteria- 6.7}

A record of the recommendations given at the meetings is on file with the school/district administration because our principal and other district staff are on the committee and attend the meetings. 


\section{Quality Criteria Seven- Career Guidance}

Career technical staff and counselors ensure that the students enroll in the career technical program that they are interested in or would be good at.

Quality Criteria- 7.1

Ninth grade students receive counseling when they enter high school to see what program they would be interested in taking. Once the students are in the career technical classes the instructors further counsel the students on what interests them and lets them know of other programs the student might be good at or interested in.

Quality Criteria- 7.2

Information is given from CTE teachers to counselors to help them with counseling students to the correct program.

Quality Criteria- 7.3

CTE instruction includes, career planning, employability skills, articulation options and provides students with information relevant to their career path goals. Students complete the student data sheets when entering into the agriculture program and plan out their four year plan. This helps guide the students to an end goal for their high school education to prepare them for what is next after high school.

Quality Criteria-7.4

Students in career technical courses are made aware of the $2+2$ articulation agreements with the local community colleges.

Quality Criteria- 7.5

Each year the students review their student data sheets and four year plans and make modifications to their career goals and course choices. 


\section{Quality Criteria Eight- Program Promotion}

Apple Valley's Agriculture Program promotes its self to inform students, parents, counselors, other teachers, administrators, board members, community members, and business and industry representatives, of the options, advantages, and availability of career technical education programs.

Quality Criteria- 8.1

The program of work indicates a plan for promotional and recruitment activities and public relations throughout the year.

Quality Criteria- 8.2

Promotional activities are conducted throughout the year to inform students, parents, counselors, other teachers, administrators, board members, community members, and business and industry representatives of the students' achievements and merits in the program.

Evidence: Green hand/Chapter degree ceremony, Chapter meetings, Awards banquet, School Board presentations.

Quality Criteria- 8.3

Promotional materials including a program brochure and poster board presentation have been developed to publicize the agriculture program and FFA organization.

Quality Criteria- 8.4

Programs have been developed to help students overcome financial barriers in participating in program activities. The students that cannot afford to finance a fair project can apply for an interest free loan through a program US Bank has set up for our agriculture department.

Quality Criteria- 8.5

Promotional activities are conducted annually with the elementary and middle schools to recruit students into the program. We participate in the High School Awareness Night where students and parents come to the high school to see what our school has to offer. We also host tours for high school classes so students know what is available for them to enroll in. 


\section{Quality Criteria Nine- Program Accountability and Planning}

Apple Valley High School and its career technical courses are assessed each year to make sure that they are meeting the needs of students and the program objectives.

Quality Criteria- 9.1

Following the completion of agriculture courses the students are assessed on a performance based assessment that measures students' performance in the application of vocational and academic skills and knowledge of occupational tasks.

Quality Criteria- 9.2

A yearly site program improvement plan has been completed and filed with Jack Havens our regional supervisor.

Quality Criteria- 9.3

A comprehensive five year program plan has been filed with the regional supervisor.

Quality Criteria- 9.4

A graduate follow up report is completed after seniors graduate from the program and the results are shared with the advisory committee.

Quality Criteria- 9.5

The agriculture program budget contains long-term plans for funding future facilities and equipment. Both agriculture instructors are familiar with the funding sources and help the district personnel allocate funds for the career technical programs. 


\section{Quality Criteria Ten- Student-Teacher Ratio}

A quality vocational program is dependent on maintaining a student teacher ratio that ensures effective instructional and safe working conditions. At Apple Valley High School and under the current economic conditions it is very difficult to hold the proper student teacher ratios.

Quality Criteria- 10.1

The career technical classroom based courses at Apple Valley do not meet the 25 to 1 ratio. The ratio is more like $35-40$ to 1 . However, in the agriculture engineering shop most of the classes meet the 20 to 1 ratio for shop based courses.

Quality Criteria- 10.2

The total number of students taught per day in class exceeds 60 students per teacher. A closer number would be 80 or 90 students if intro classes count as .5 per person. 


\section{Quality Criteria Eleven- Full Year Employment}

Effective instruction in Agriculture Education extends far beyond the regular school day/year.

Quality Criteria- 11.1

The district shall provide adequate teacher time to conduct the year-round activities for the agriculture program. One of our agriculture teachers receives a summer stipend for supervising projects over the summer months.

Quality Criteria- 11.2

In addition to any preparation period provided to teachers, a supervision period shall be provided. This is defiantly not the case at Apple Valley. There are already more students that want to take agriculture courses then there are teachers to teach it. We would like to hire another agriculture teacher to teach horticulture and agricultural biology and then it might be possible for a teacher to have a project supervision period. 


\section{Supporting Materials}

Table of Contents

a. Student Data Sheet

b. Permanent Vo-Ag Student Record

c. Course outlines

d. Daily grade sheets from each class taught

e. Project Visit Forms

f. Wall chart of SOE visits

g. SOE Summary by individual student

h. Board Approved department SOEP policy, procedures and operations

i. Program of Work

j. Board approved policy statement pertaining to FFA as an integral part of the Ag program

k. Recruitment Program

1. Chapter Scrapbook

m. Summer activities schedule

n. Sample of Vo-Ag follow up survey form

o. Up to date file on status of graduates

p. Vo-Ag comprehensive plan

q. Advisory committee minutes for current year

r. Completed student program plan

s. Proficiency Standards

t. Copy of teaching credentials

u. Calendar of department/chapter activities

v. Daily $\operatorname{logs}$ for current year

w. List of expected professional growth activities

x. Current year's R-2 report

y. Extended contract

z. Completed travel plan submitted to administration

aa. CATA membership card

bb.Meeting reports submitted to administration

cc. Wish list 
ee. Advisory committee agendas for current year

ff. Advisory committee charter and bylaws

gg.Operating budget for $\mathrm{Vo}-\mathrm{Ag}$

hh. VEA district allocation

ii. Department budget process

jj. Department chairperson duties

kk. Chart of responsibilities

11. Substitute teacher procedure and plans

$\mathrm{mm}$. Proficiency for Vocational Agriculture Students

nn. 2+2 articulation agreement

oo.Reimbursement for personal expenses 


\section{a. Student Data Sheets}




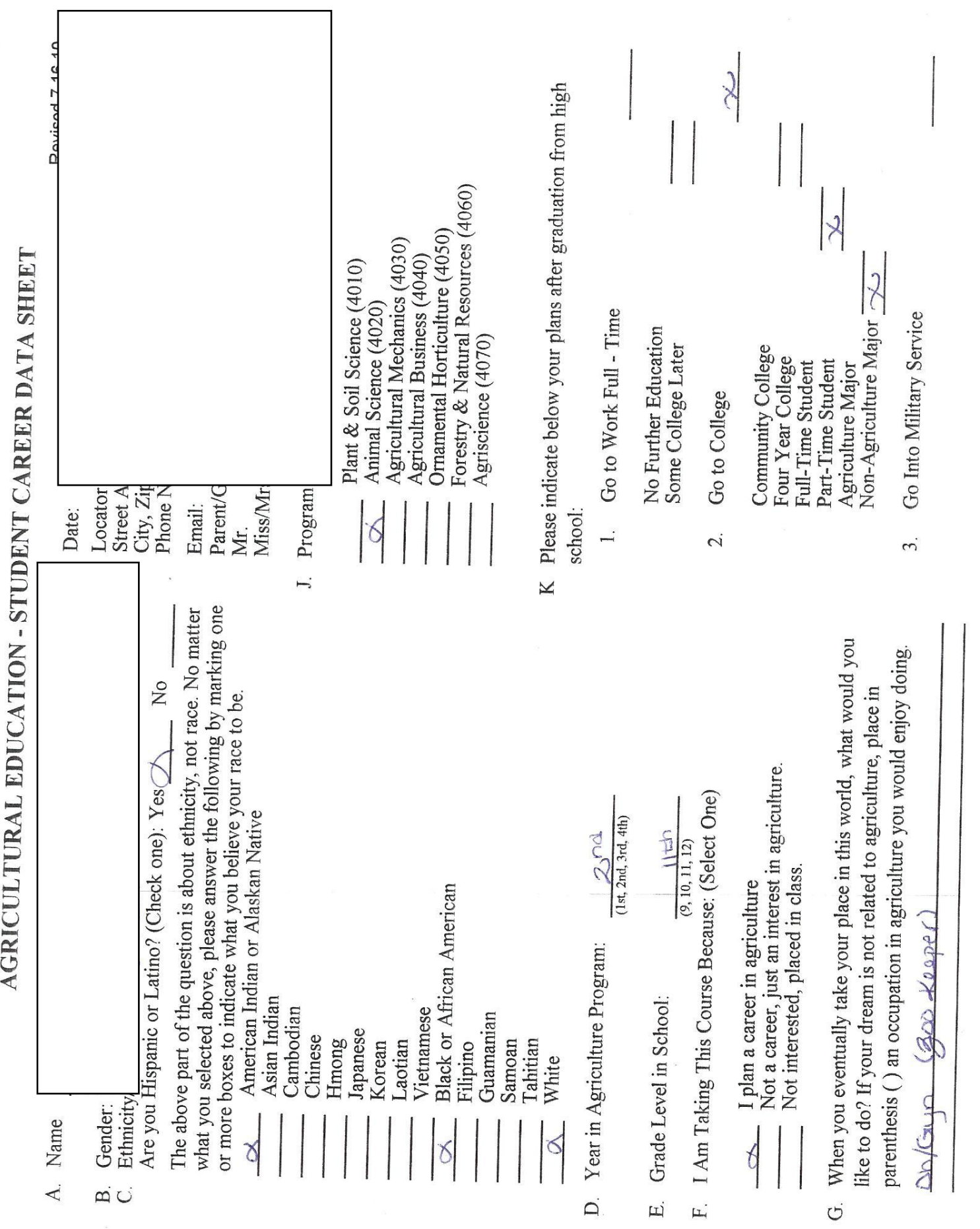




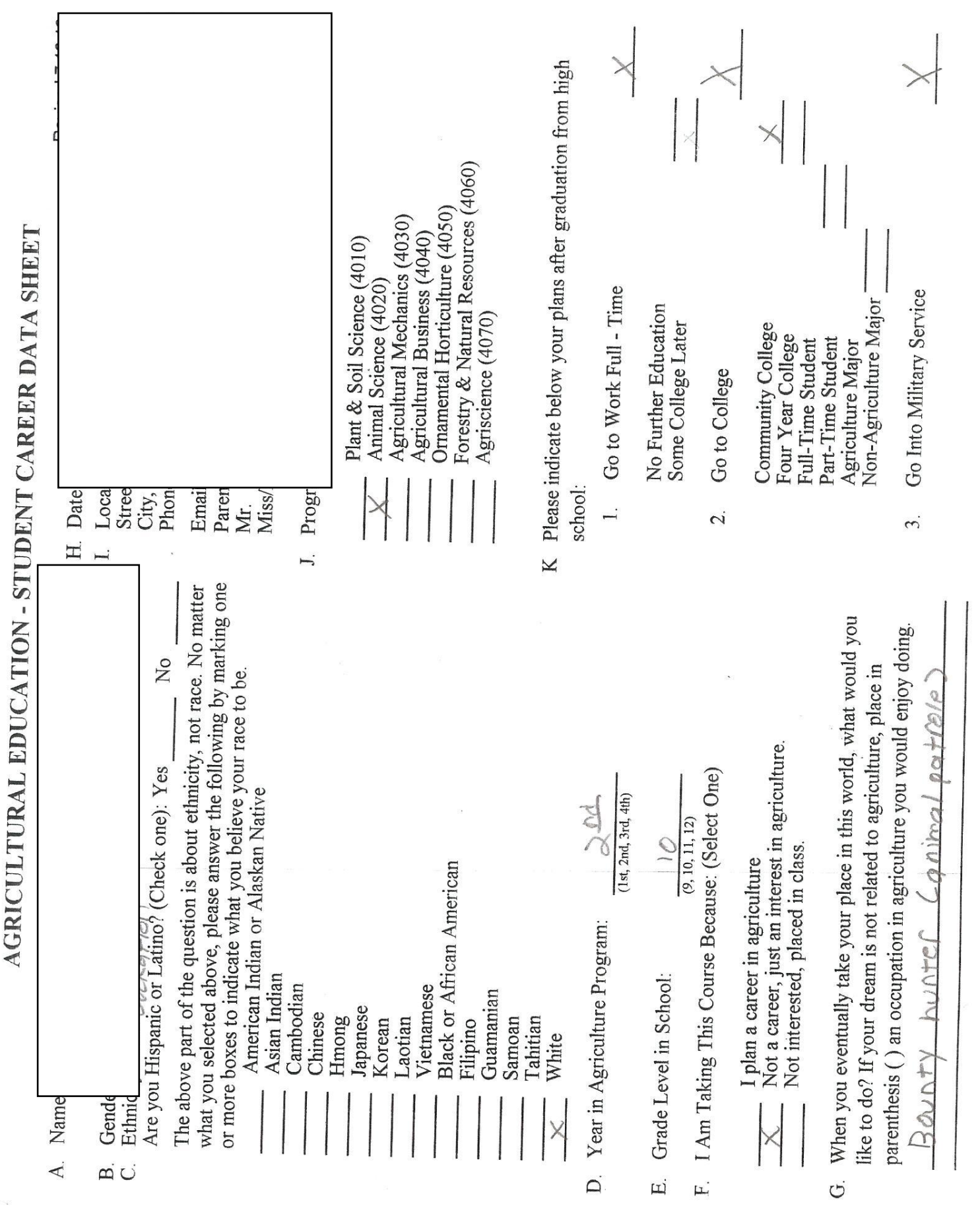




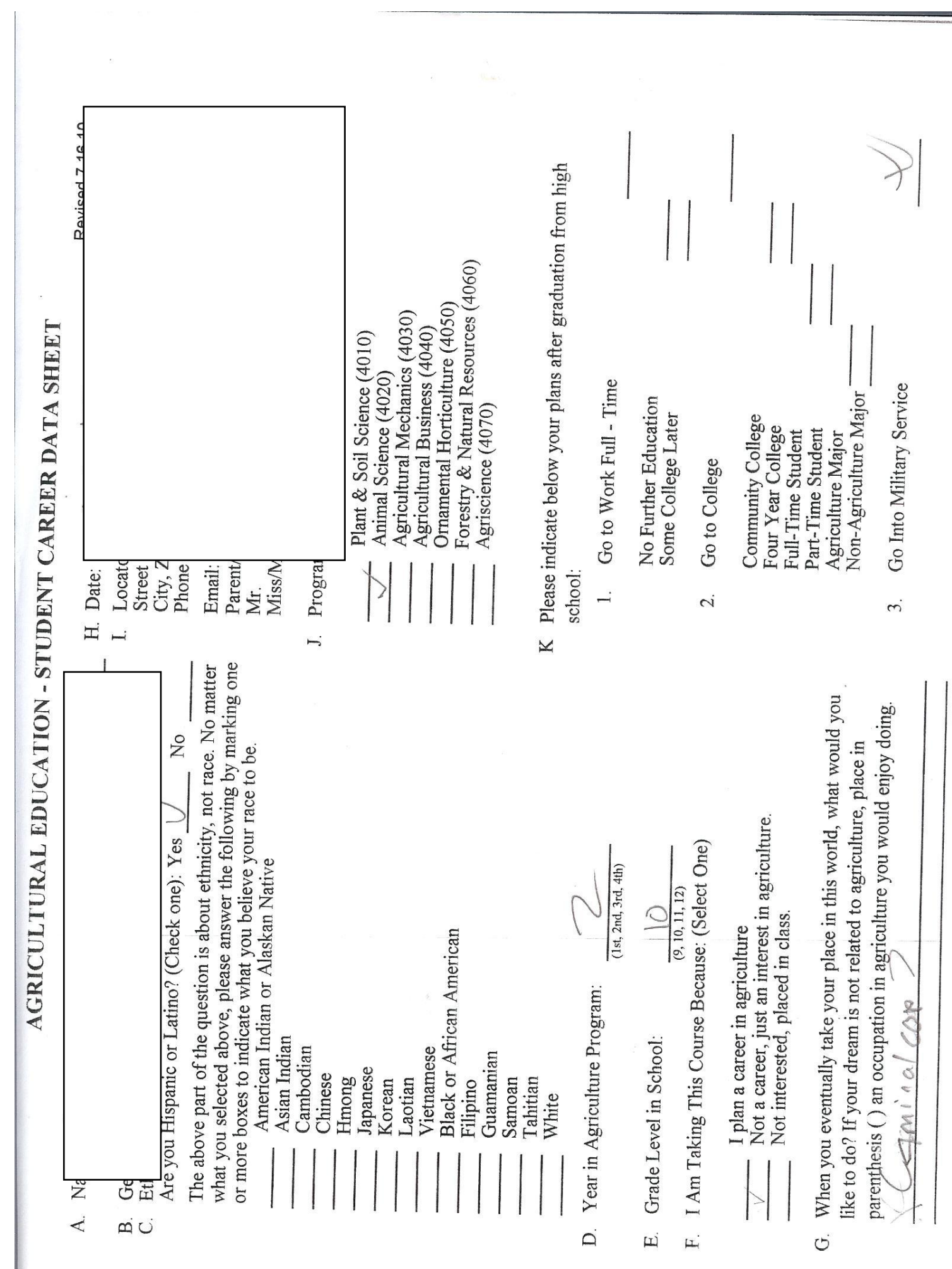




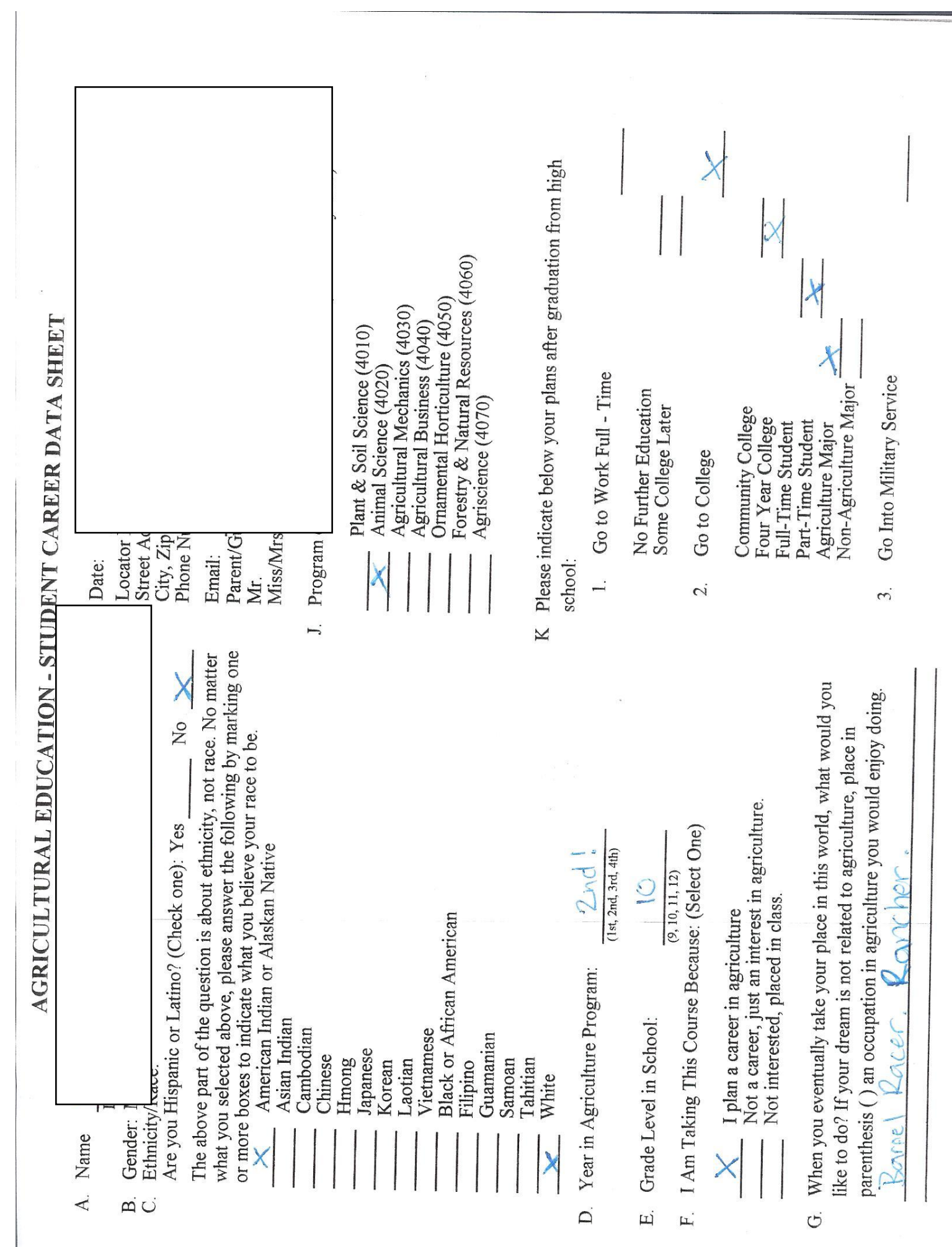




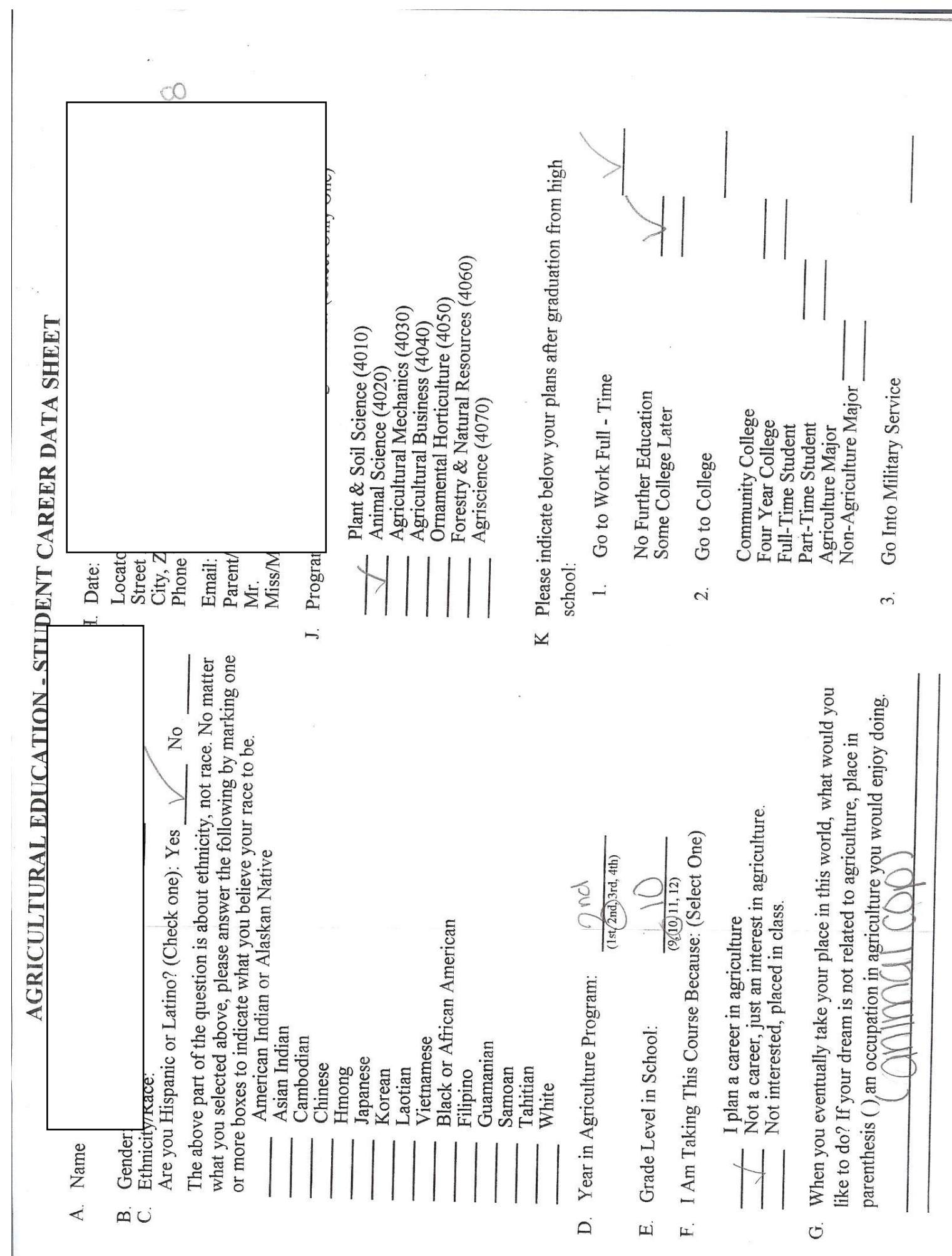




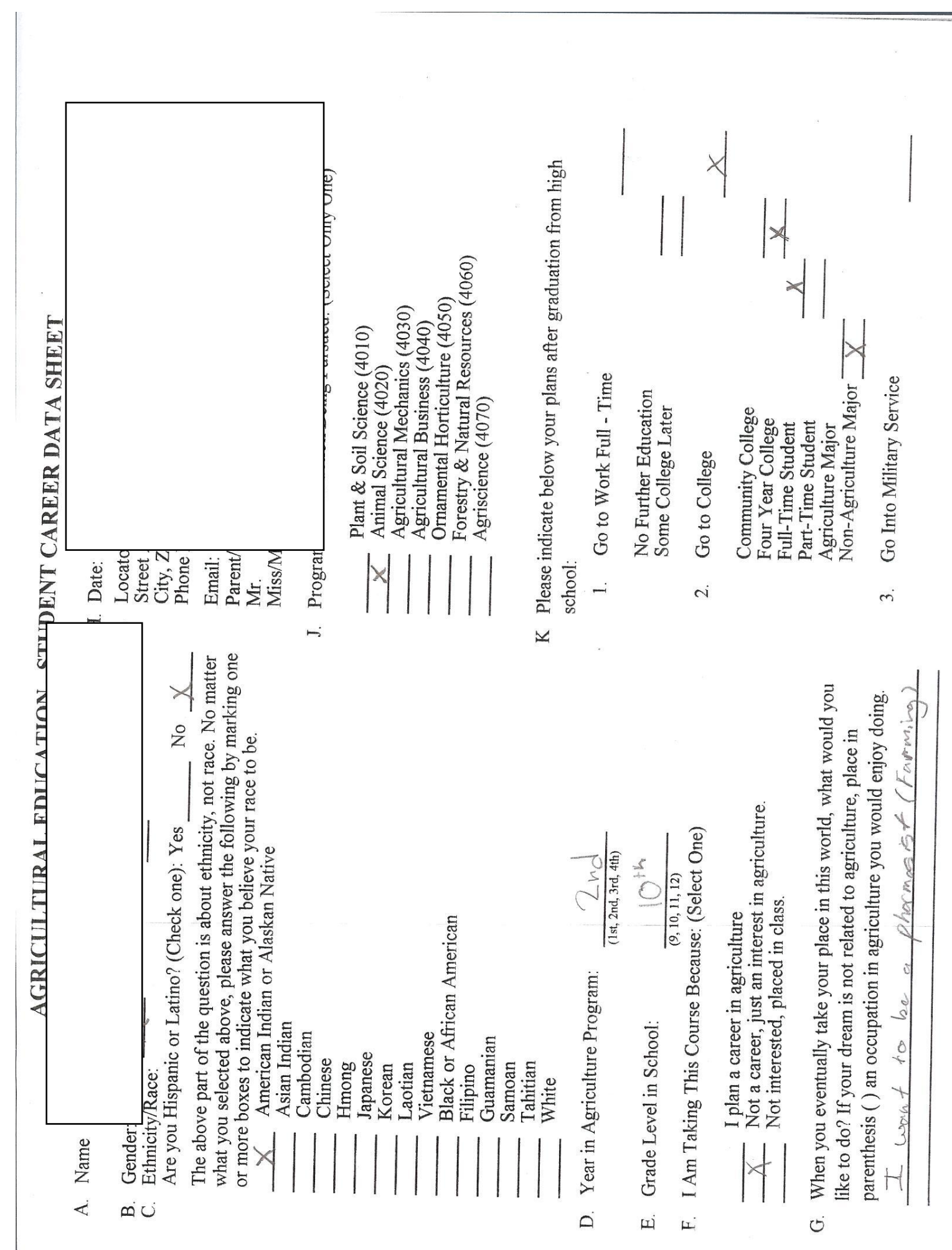




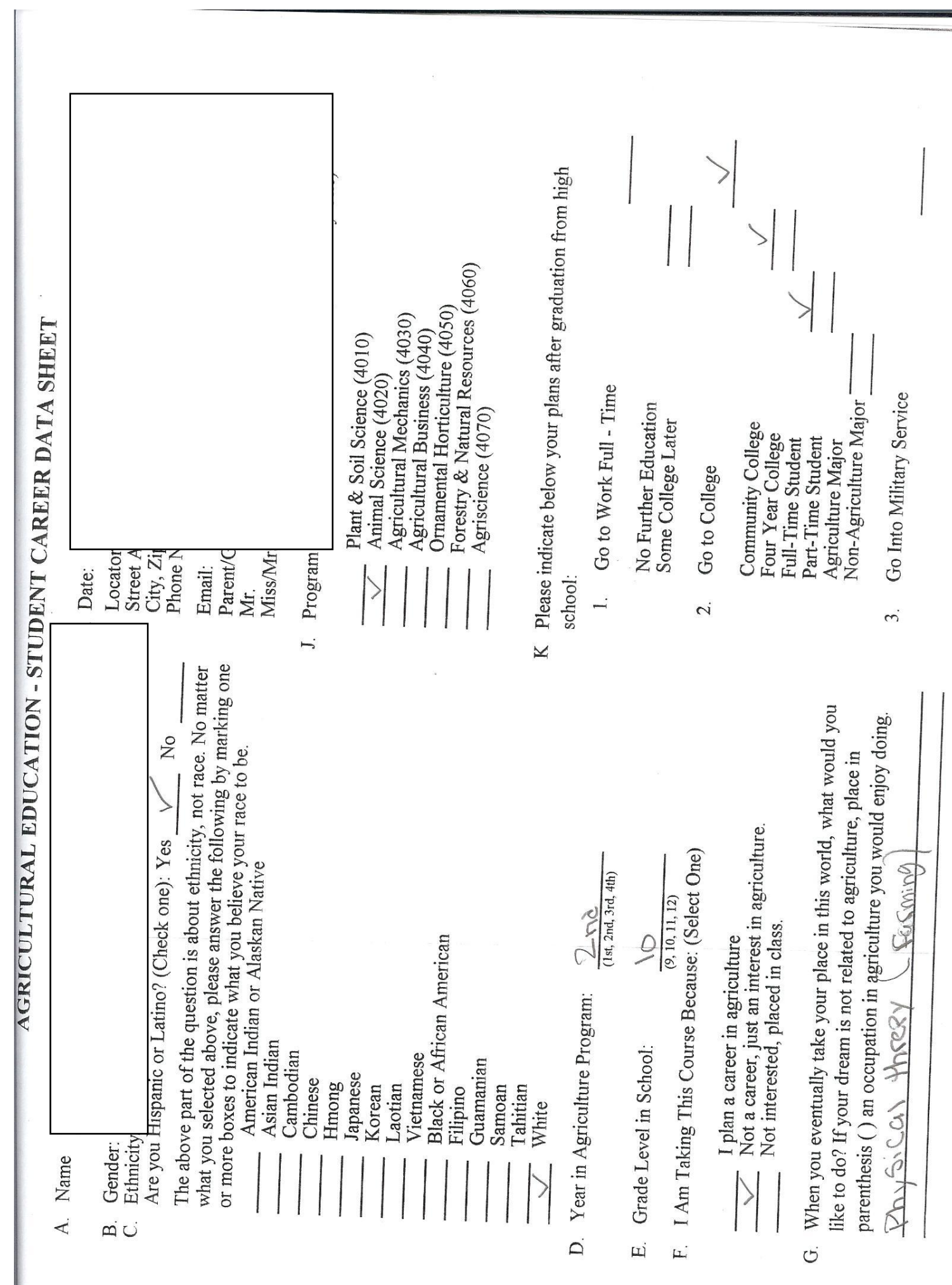




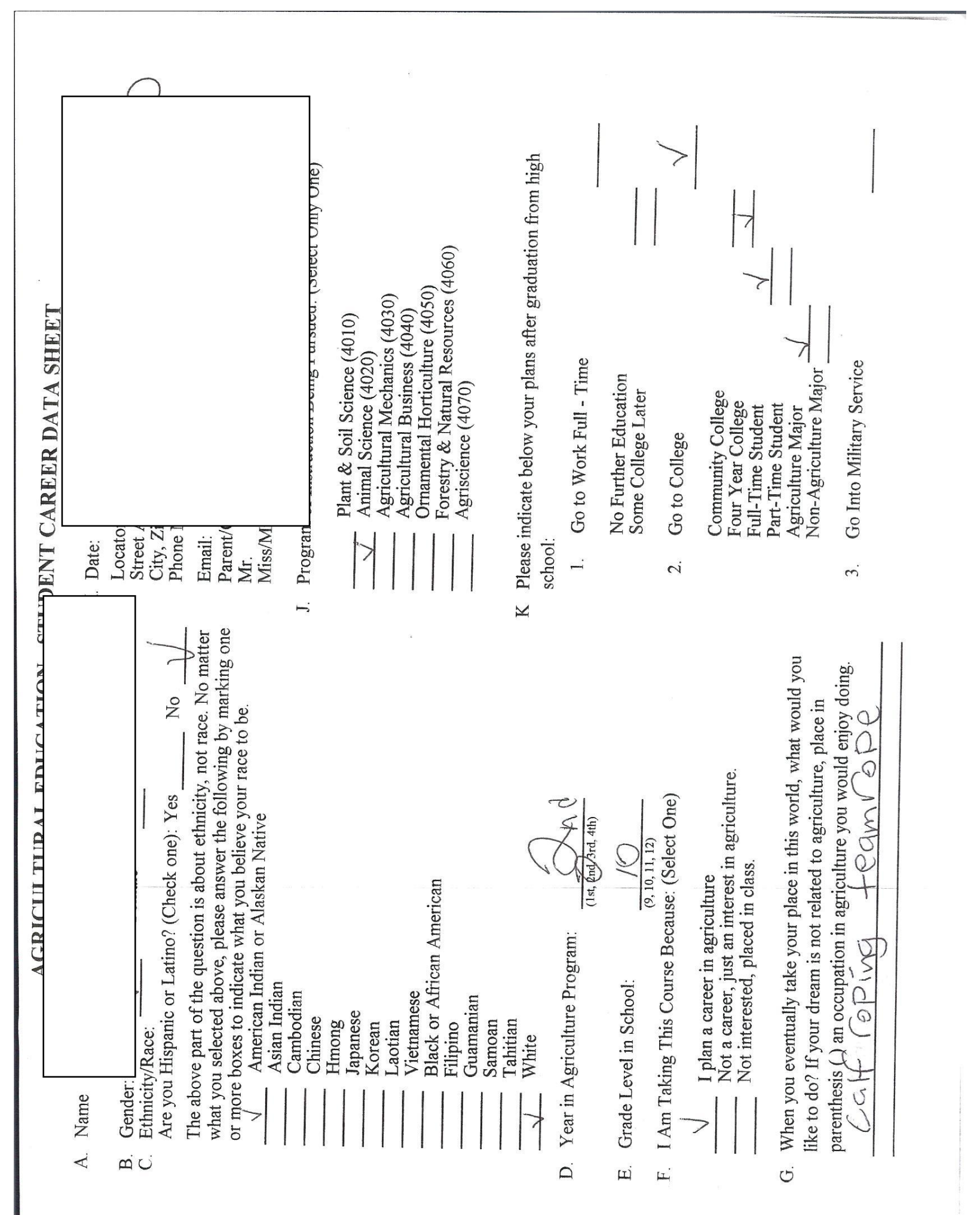




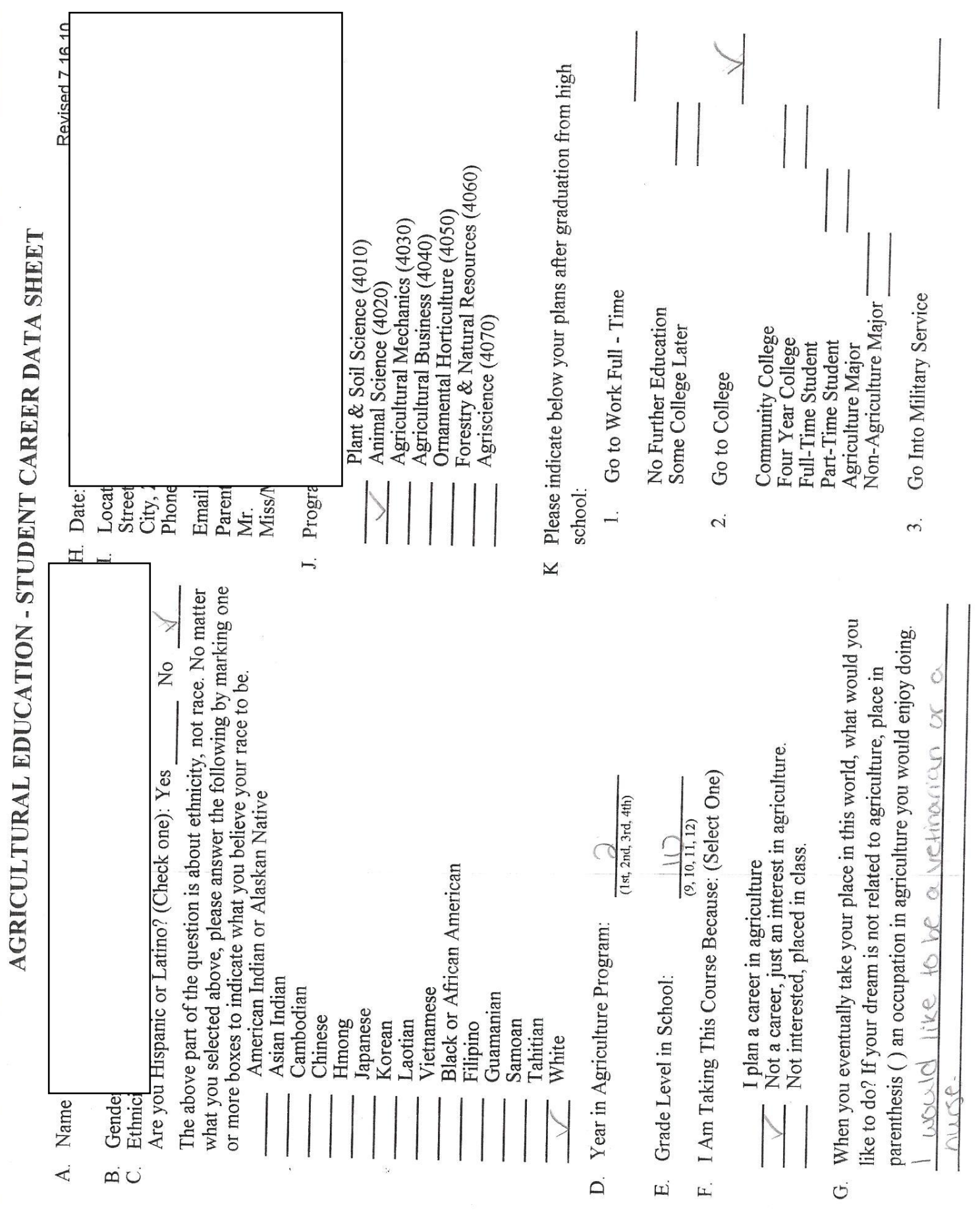



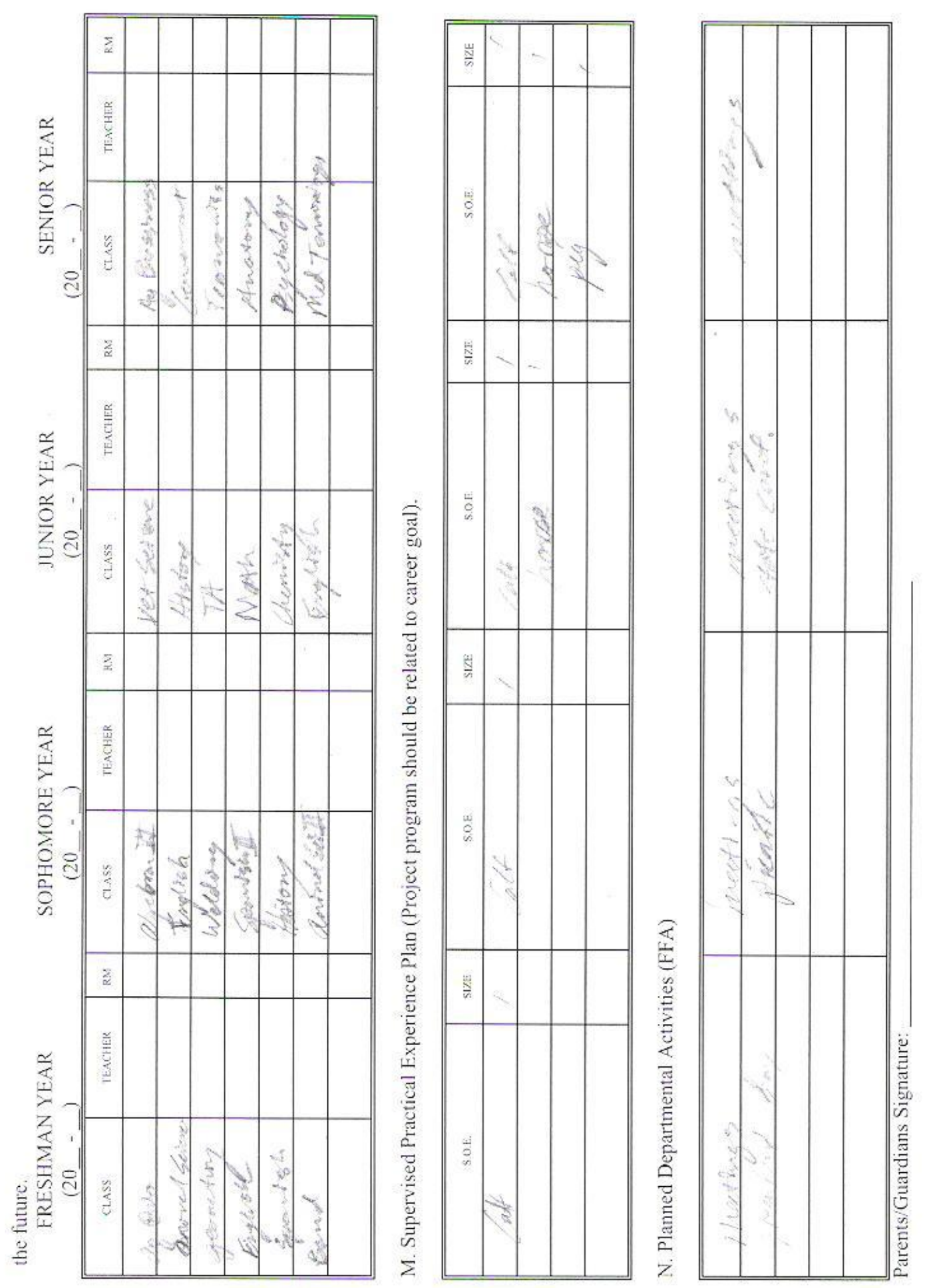

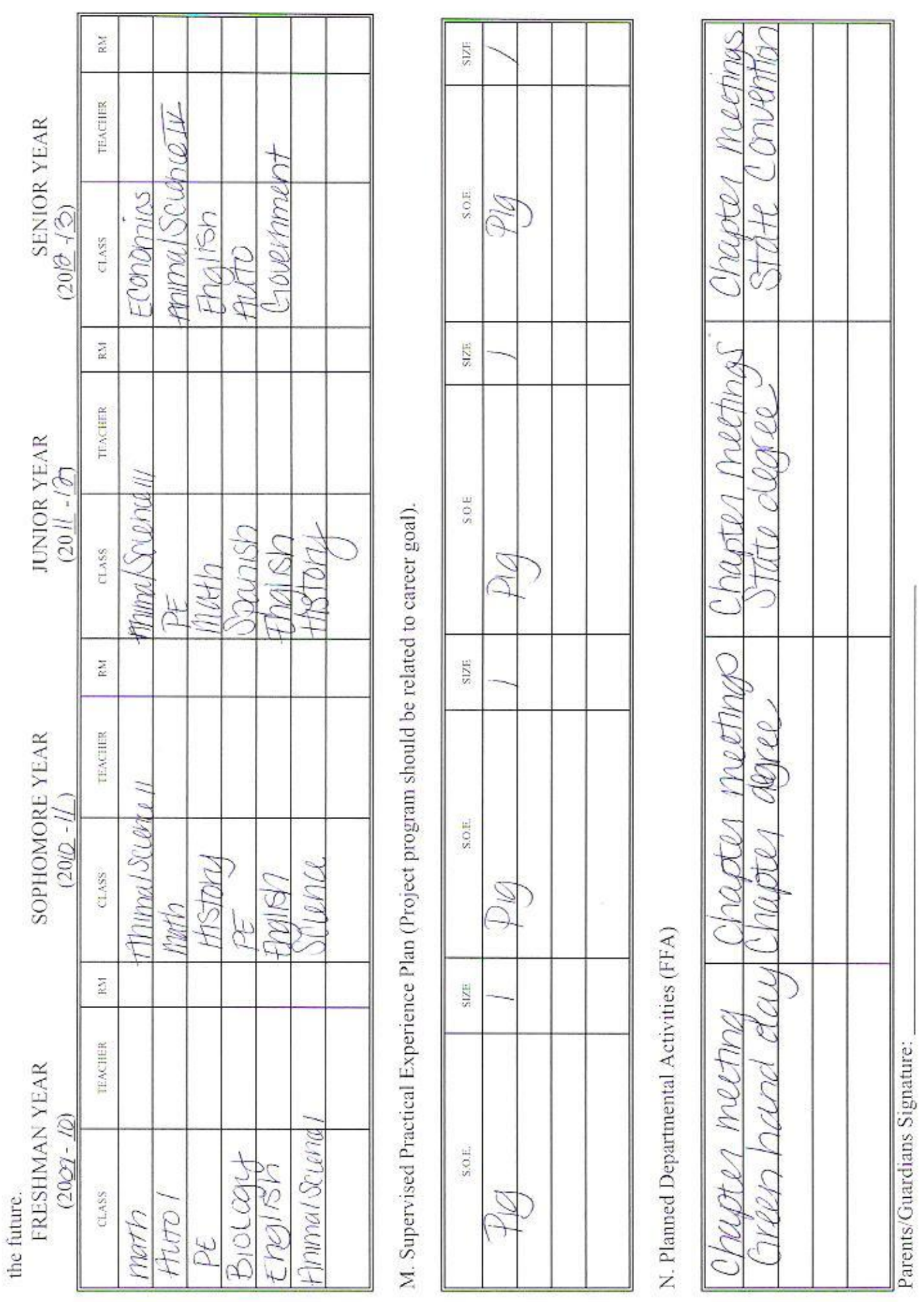

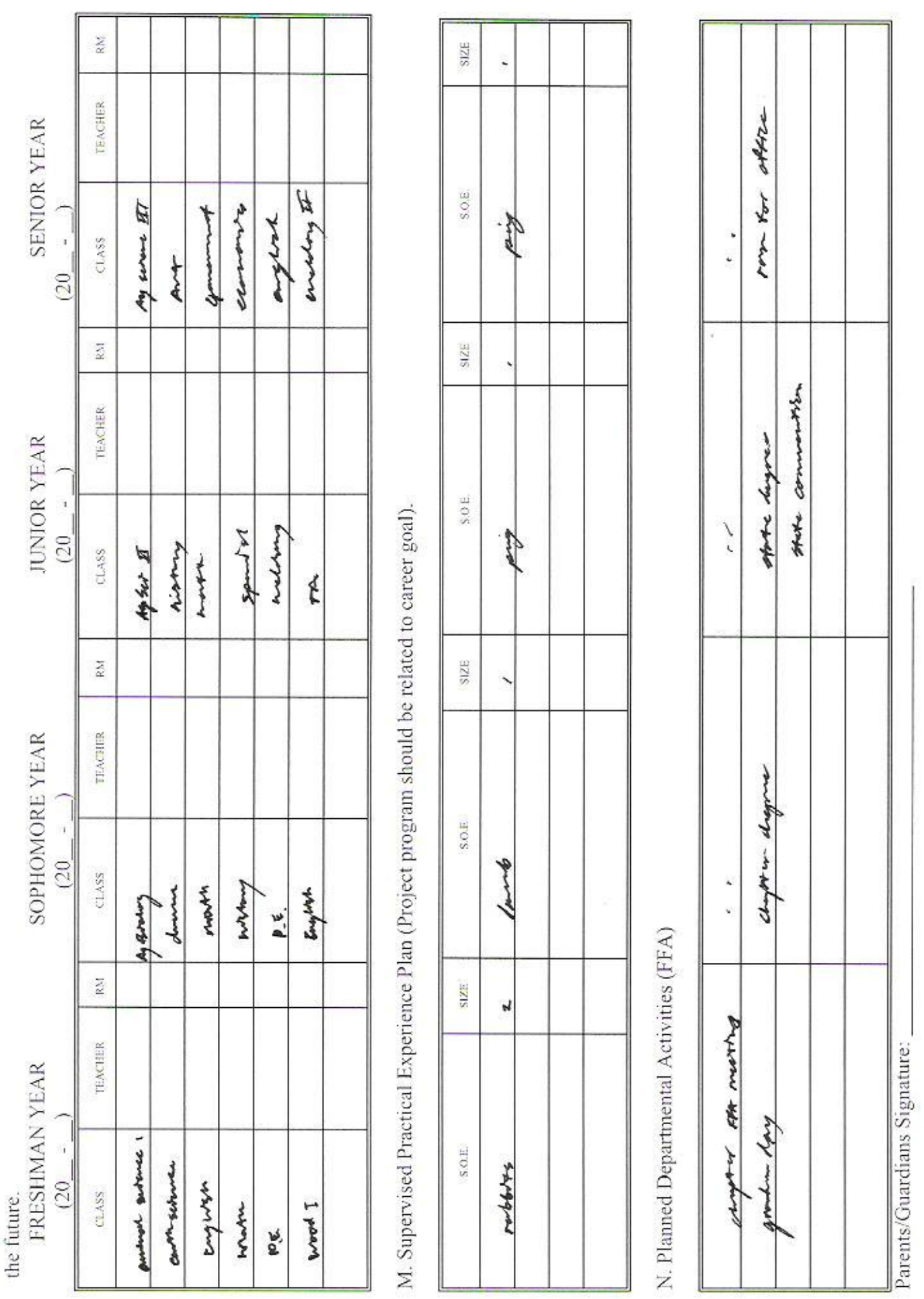

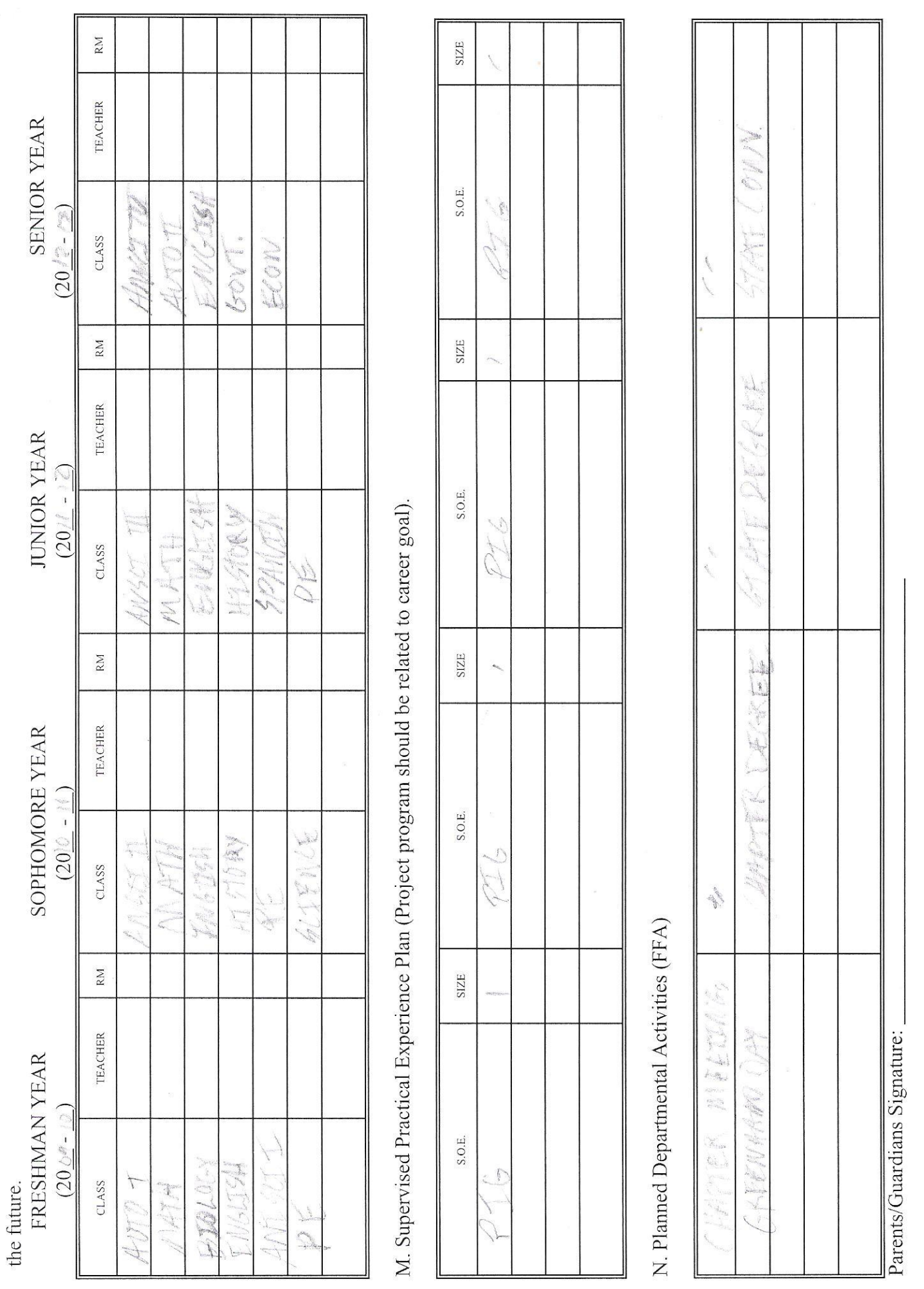

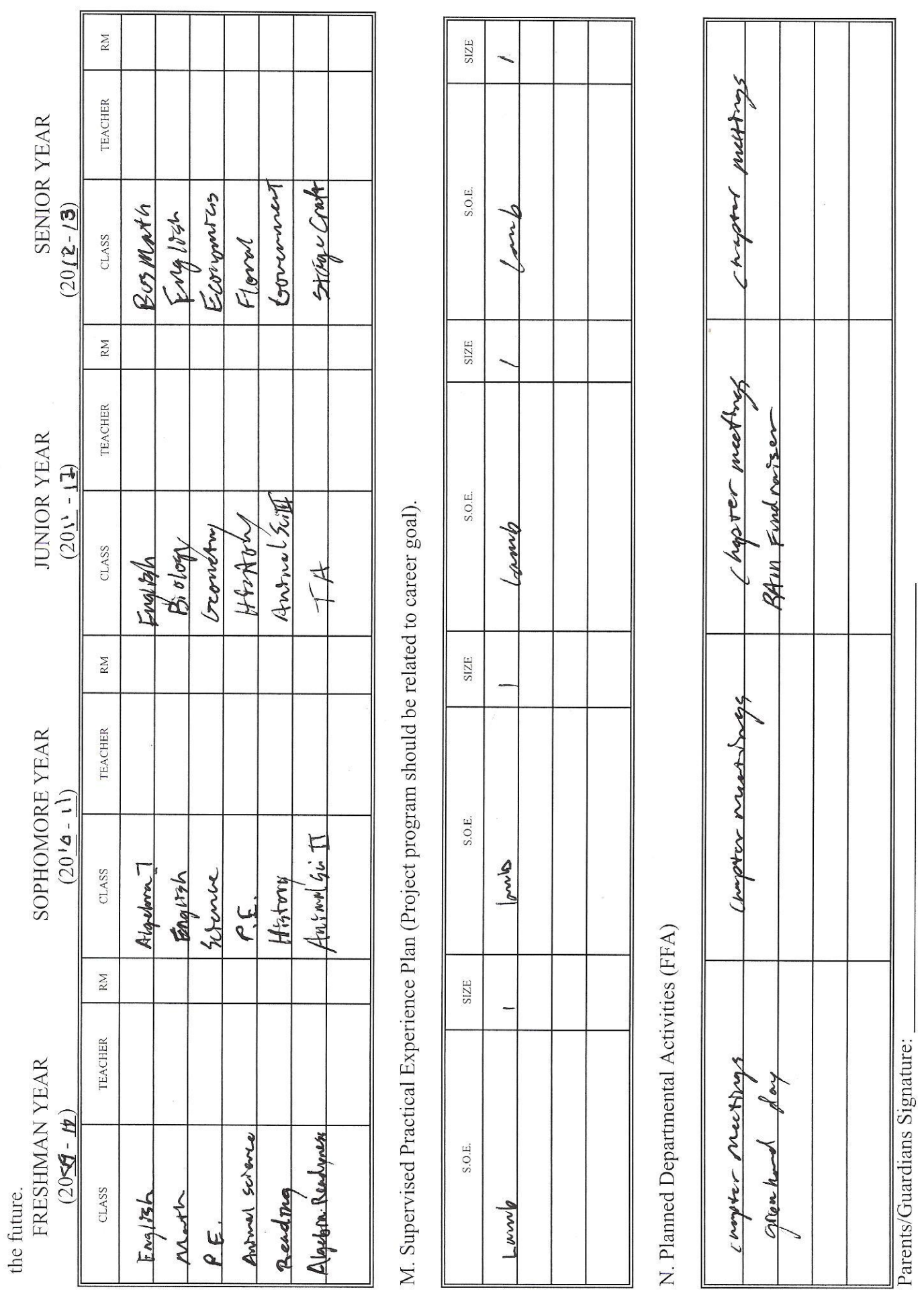


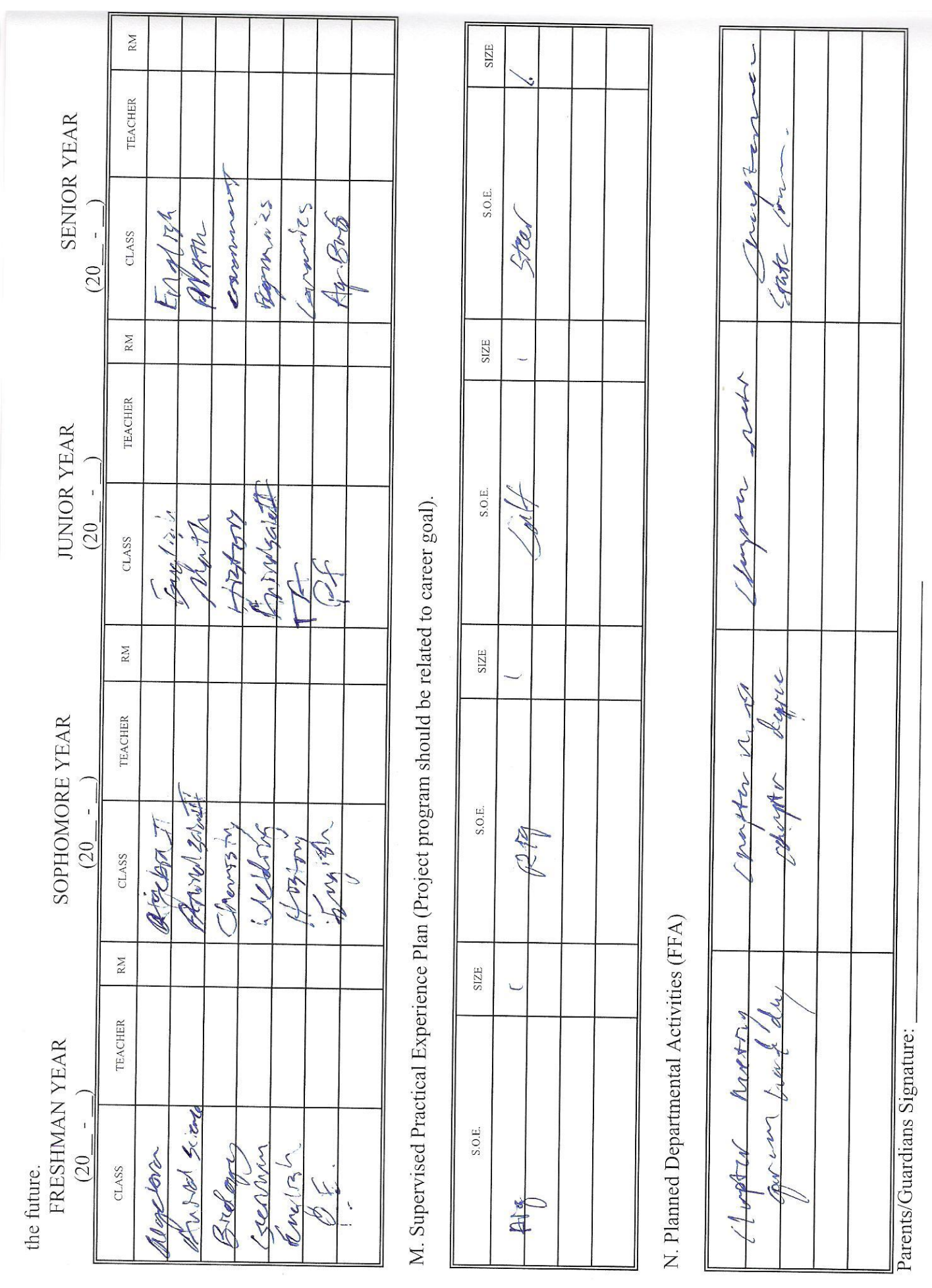



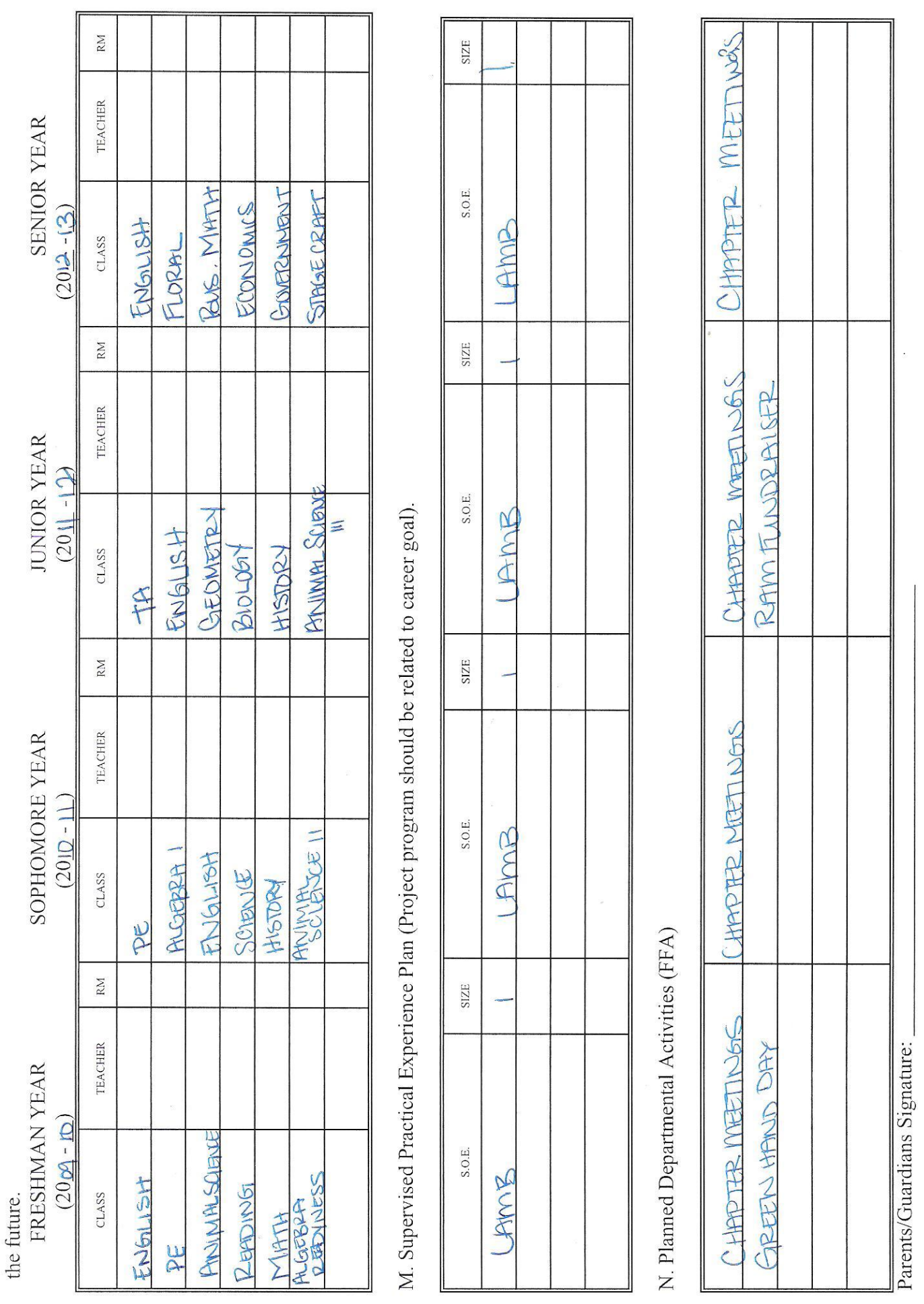

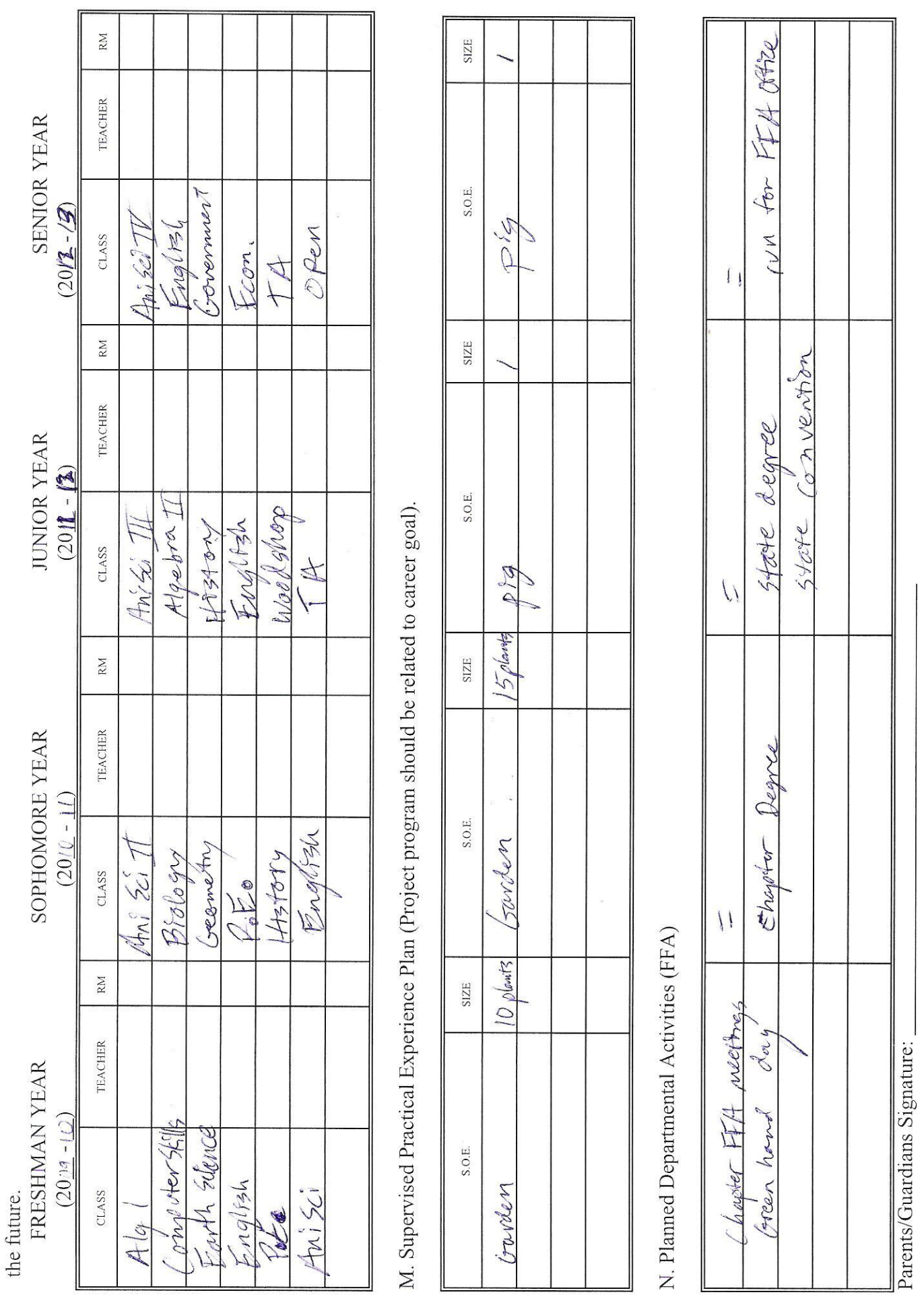

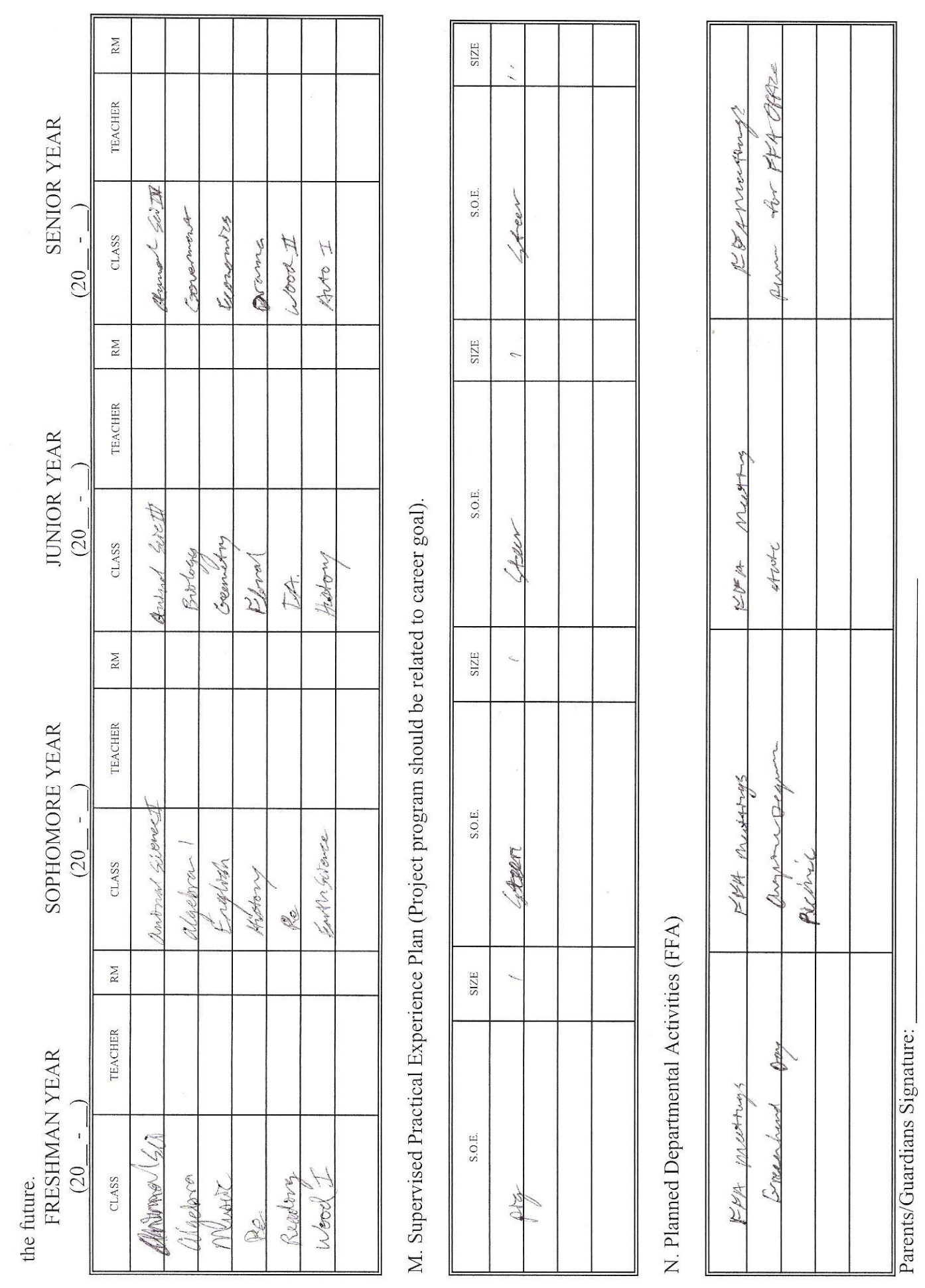

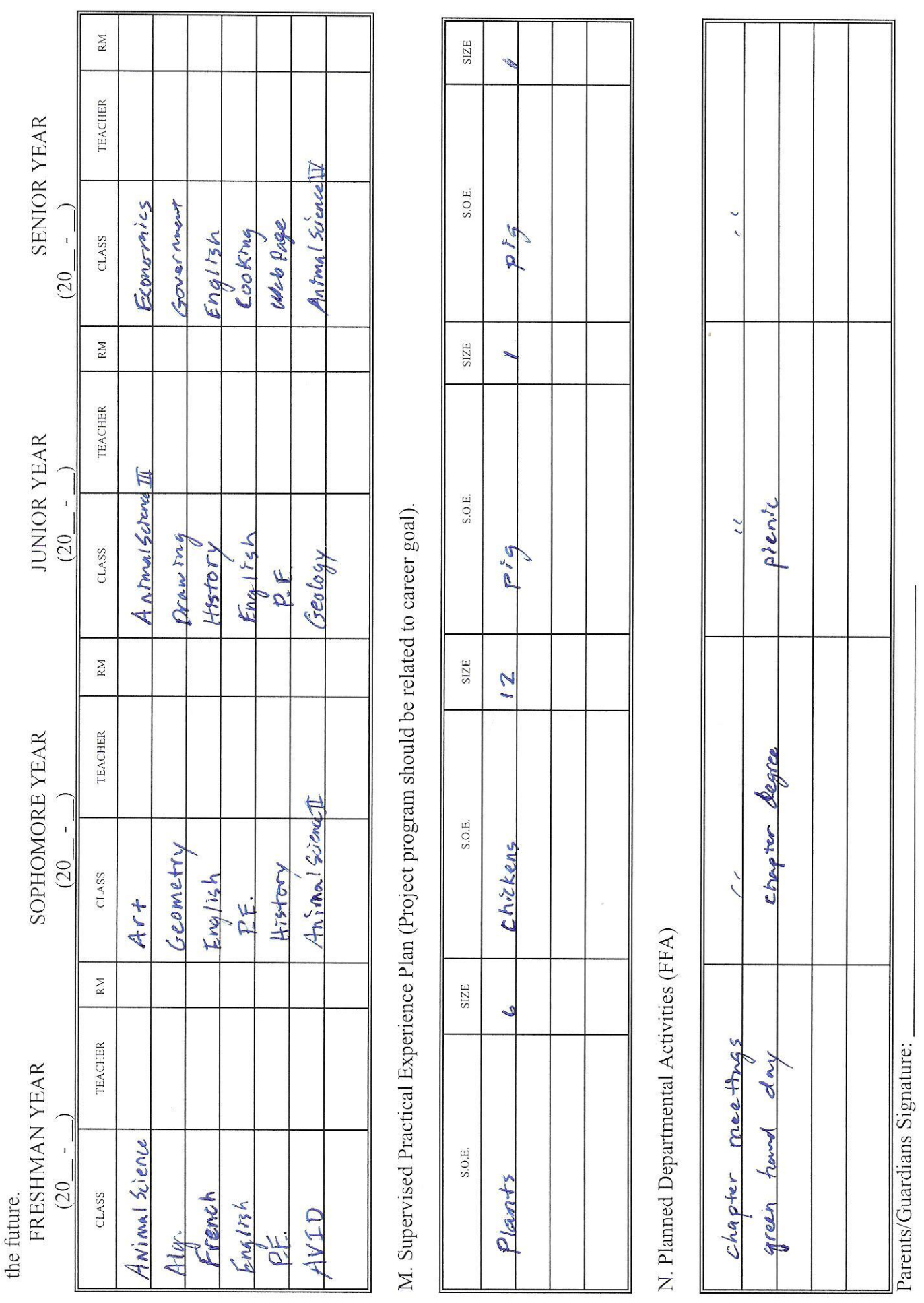


\section{b. Permanent Vo-Ag Student Records}

Currently the department does not have a permanent file for each student in one location. The information on each student such as record books, safety tests and other information are available but have not yet been organized into a filing system. The plan is to dedicate a filing cabinet to hold all of this information and organize it by grade level. 


\section{c. Course Outlines}




\section{Apple Valley Unified School District Course of Study Description}

Course Title: Introduction to Agricultural/Industrial Engineering

Grade Level: $9-12$

Check one: $\underline{X}$ Year Course/10 units credit

Course Prerequisites: None

Semester Course/5 units credit:

I. Course Description:

Introduction to the theory and practical applications of basic metalworking and design will be presented. This course will emphasize agricultural/industrial: shop safety, material selection, job planning, bench-work, quality control and inspection. Hand tools, drill presses, pedestal grinders, band saws, basic welding processes and precision-measuring equipment will be used to complete required projects. Also included are techniques in preventative and general maintenance of metalworking machinery. The student will study, interpret, and draw basic industrial blueprints through the use of mechanical and computer drawing equipment.

II. Goals:

The student will:

19. Practice the rules for personal and group safety while working in a fabrication shop environment.

20. Demonstrate safe work habits on the job.

21. Demonstrate the ability to work well with others.

22. Learn and follow an orderly process to create a project from idea to finished product.

23. Learn and demonstrate mechanical skills.

24. Follow directions

25. Critically evaluate good workmanship

26. Apply problem-solving skills in the production of projects.

27. Understand how to design project plans by using mechanical drawing techniques

28. Employ math skills in working with measurements.

29. Know how to identify common metals, sizes, and shapes.

30. Know basic tool-fitting skills.

31. Know layout skills.

32. Know basic cold metal processes (e.g., shearing, cutting, drilling, threading, bending.).

33. Complete a metal project, including interpreting a plan, developing a bill of materials, selecting materials, shaping, fastening, and finishing.

34. Know how to properly set up, adjust, shut down, and maintain an oxy-fuel system.

35. Operate and maintain various arc welding and cutting systems safely and appropriately.

36. Operate and maintain fabrication tools and equipment safely and appropriately.

III. Standards Taught in the Course:

Geometry standards 8.0, 9.0, 10.0, 11.0, 14.0, 15.0, 16.0, 20.0

Algebra standards 10.0, 15.0

Agriculture Mechanics Pathway standards B1.1, 1.2, 5.1, 5.2, 5.3, 5.4, 5.5, 7.2, 8.1, 9.2, 9.3, 9.4

\section{Course Outline}

A. Basic Shop Safety

1. Housekeeping safety

2. Hand tool safety

3. Power tool safety 
4. Personal protection gear

5. Arc and gas welding safety

6. Shop cleaning procedures

B. Measurement and Layout

1. Common measuring tools

2. Units of measure

3. Layout tools and procedures

4. Area and volume calculations

C. Mechanical Drawings and Blue Prints

1. Mechanical sketching by hand

2. 3 Dimensional Computer Aided Drafting (Solids Modeling)

3. Reading and interpreting welding symbols and blue prints

D. Hand and Power Tools

1. Identification

2. Proper tool usage

E. Metal Materials

1. Identification of metal materials

2. Material properties and selection

F. Oxy-fuel Systems

1. Proper setup, usage, shutdown and maintenance

G. Arc Welding and Cutting Systems

1. Operate and maintain equipment safely and appropriately

H. Project Construction

1. Design, layout and construction of basic metal project

\section{Scope and Sequence of the Course:}

\section{Units in the Semester}

Basic Shop Safety

Measurement and Layout

Mechanical Drawing

Computer Solids Modeling

Hand and Power Tools

Metal Materials

Oxy-fuel Systems

Arc Welding and Cutting Systems

Project Construction

\section{Assessment and Standards for Student Performance}

A. Written tests and quizzes that are short answer in format.

B. Performance based assessments such as demonstrations of skills, and projects completed.

C. Written assignments to include worksheets, book assignments and drawings. 
D. Teacher observation of participation on a daily basis.

E. SAE project and FFA participation are required and account for at least $25 \%$ of student's grade.

VII. List Standards Based Textbooks

\section{Modern Metalworking}

John R. Walker, The Goodheart-Willcox Company, Inc, 1985. 


\section{Apple Valley Unified School District Course of Study Description}

Course Title: Intermediate Agricultural/Industrial Engineering

Grade Level: 10th-12th grades

Check one: $\underline{X}$ Year Course/10 units credit

_ Semester Course/5 units credit:

Course Prerequisites: 10th graders will need to have taken Introduction to Agricultural/Industrial Engineering

\section{Course Description:}

This course introduces students to various welding techniques. The course is designed for students who have an interest in basic welding or possibly a career in the welding field. The course will include classroom and practical instruction in the following area: shop safety, metallurgy (study of metals),tools \& equipment identification, blueprint reading, computer aided drafting, math \& measuring, effects of heat, welding positions, oxy-acetylene safety, oxy-acetylene cutting \& welding, shielded metal arc welding, shielded metal arc welding electrode identification, gas tungsten arc welding, gas metal arc welding, and plasma arc cutting II. Goals:

The student will:

37. Practice the rules for personal and group safety while working in a fabrication shop environment.

38. Demonstrate safe work habits on the job.

39. Demonstrate the ability to work well with others.

40. Learn and follow an orderly process to create a project from idea to finished product.

41. Learn and demonstrate mechanical skills.

42. Follow directions

43. Critically evaluate good workmanship

44. Apply problem-solving skills in the production of projects.

45. Understand how to design project plans by using mechanical drawing techniques

46. Employ math skills in working with measurements.

47. Know how to identify common metals, sizes, and shapes.

48. Know basic tool-fitting skills.

49. Know layout skills.

50. Know basic cold metal processes (e.g., shearing, cutting, drilling, threading, bending.).

51. Complete a metal project, including interpreting a plan, developing a bill of materials, selecting materials, shaping, fastening, and finishing.

52. Know how to properly set up, adjust, shut down, and maintain an oxy-fuel system.

53. Use welding tools and equipment, such as MIG, TIG, SMAW, to combine or join manufactured parts and products, resulting in a finished product that meets the standards of the American Welding Society or a similar industry. Operate and maintain fabrication tools and equipment safely and appropriately.

54. Use computers to design and produce welded products, write numerical control programs, and control robots.

III. Standards Taught in the Course:

Geometry standards 8.0, 9.0, 10.0, 11.0, 14.0, 15.0, 16.0, 20.0

Algebra standards 10.0, 15.0

Agriculture Mechanics Pathway standards B1.1, 1.2, 5.1, 5.2, 5.3, 5.4,7.1, 7.2,7.3,7.4, 7.5, 8.1, 8.2, 8.3, 8.4, 9.1, 9.2, 9.3, 9.4, 9.5, 9.6. 9.7

\section{Course Outline}


A. Basic Shop Safety

1. Housekeeping safety

2. Hand tool safety

3. Power tool safety

4. Personal protection gear

5. Arc and gas welding safety

6. Shop cleaning procedures

B. Measurement and Layout

1. Common measuring tools

2. Units of measure

3. Layout tools and procedures

4. Area and volume calculations

C. Mechanical Drawings and Blue Prints

1. Mechanical sketching by hand

2. 3 Dimensional Computer Aided Drafting (Solids Modeling)

3 . Reading and interpreting welding symbols and blue prints

D. Hand and Power Tools

1. Identification

2. Proper tool usage

E. Metal Materials

1. Identification of metal materials

2. Material properties and selection

F. Oxy-fuel Systems

1. Proper setup, usage, shutdown and maintenance

G Arc Welding and Cutting Systems

1. Operate and maintain SMAW, GMAW, and GTAW equipment safely and appropriately

H. Project Construction

1. Design, layout and construction of basic metal project

V. Scope and Sequence of the Course:

$\begin{array}{cl}\times & \text { Shop Safety } \\ \times & \text { Metallurgy (Study of Metals) } \\ \times & \text { Tools \& Equipment Identification } \\ \times & \text { Mechanical and CAD Drawing } \\ \times & \text { Weld Symbols and Blueprint Reading } \\ \times & \text { Math \& Measuring } \\ \times & \text { Effects of Heat } \\ \times & \text { Welding Positions } \\ \times & \text { Oxyacetylene Safety } \\ \times & \text { Oxyacetylene Cutting \& Welding } \\ \times & \text { Shielded Metal Arc Welding } \\ \times & \text { SMAW Electrode Identification } \\ \times & \text { Gas Tungsten Arc Welding } \\ \times & \text { Gas Metal Arc Welding } \\ \times & \text { Plasma Arc Cutting }\end{array}$

VI. Assessment and Standards for Student Performance 
A. Written tests and quizzes that are short answer in format.

B. Performance based assessments such as demonstrations of skills, and projects completed.

C. Written assignments to include worksheets, book assignments and drawings.

D. Teacher observation of participation on a daily basis.

E. SAE project and FFA participation are required and account for at least $25 \%$ of student's grade.

\section{List Standards Based Textbooks}

Primary: Modern Welding. Althouse, Andrew D., Carl H. Turnquist, William A. Bowditch, and Kevin E. Bowditch.

\section{Supplemental: Modern Metalworking}

John R. Walker, The Goodheart-Willcox Company, Inc, 1985. 


\section{Apple Valley Unified School District Course of Study Description}

Course Title: Advanced Agricultural/Industrial Engineering

Grade Level: 11 th-12th grades

Check one: $\underline{X}$ Year Course/10 units credit

Semester Course/5 units credit:

Course Prerequisites: Students will need to have taken Intermediate Agricultural/Industrial Engineering.

\section{Course Description:}

This course expands student's knowledge of various welding techniques to a higher level and introduces them to the construction and fabrication of metal products. The course is designed for students who have basic welding skills. The course will include classroom and practical instruction in the following area: shop safety, metallurgy (study of metals),tools \& equipment identification, blueprint reading, computer aided drafting(CAD), computer aided machining(CAM), math \& measuring, effects of heat, welding positions, oxyacetylene safety, oxy-acetylene cutting \& welding, shielded metal arc welding, shielded metal arc welding electrode identification, gas tungsten arc welding, gas metal arc welding, and plasma arc cutting.

II. Goals:

The student will:

55. Practice the rules for personal and group safety while working in a fabrication shop environment.

56. Demonstrate safe work habits on the job.

57. Demonstrate the ability to work well with others.

58. Learn and follow an orderly process to create a project from idea to finished product.

59. Learn and demonstrate mechanical skills.

60. Follow directions

61. Critically evaluate good workmanship

62. Apply problem-solving skills in the production of projects.

63. Understand how to design project plans by using mechanical and computer drawing techniques.

64. Employ math skills in working with measurements.

65. Know how to identify common metals, sizes, and shapes.

66. Know basic tool-fitting skills.

67. Know layout skills.

68. Know basic cold metal processes (e.g., shearing, cutting, drilling, threading, bending.).

69. Interpret scaled welding prints; gather design and materials information; perform calculations; and use the detail to plan, lay out, and produce parts or finished products.

70. Select and use appropriate welding tools, equipment, and inspection devices to manufacture parts or products.

71. Complete a fabrication, an assembly, or a repair by using appropriate techniques and processes.

72. Know how to properly set up, adjust, shut down, and maintain an oxy-fuel system.

73. Use welding tools and equipment, such as MIG, TIG, SMAW, to combine or join manufactured parts and products, resulting in a finished product that meets the standards of the American Welding Society or a similar industry. Operate and maintain fabrication tools and equipment safely and appropriately.

74. Use computers to design and produce welded products, write numerical control programs, and control robots.

III. Standards Taught in the Course:

Geometry standards 8.0, 9.0, 10.0, 11.0, 14.0, 15.0, 16.0, 20.0

Algebra standards 10.0, 15.0

Agriculture Mechanics Pathway standards B1.1, 1.2, 5.1, 5.2, 5.3, 5.4, 5.5, 7.1, 7.2,7.3,7.4, 7.5, 8.1, 8.2, 8.3, 8.4, 9.1, 9.2, 9.3, 9.4, 9.5, 9.6. 9.7

\section{Course Outline}


A. Basic Shop Safety

1. Housekeeping safety

2. Hand tool safety

3. Power tool safety

4. Personal protection gear

5. Arc and gas welding safety

6. Shop cleaning procedures

B. Measurement and Layout

1. Common measuring tools

2. Units of measure

3. Layout tools and procedures

4. Area and volume calculations

C. Mechanical Drawings and Blue Prints

1. Mechanical sketching by hand

2. 3 Dimensional Computer Aided Drafting (Solids Modeling)

3 . Reading and interpreting welding symbols and blue prints

D. Computer Aided Machining

1.Plasma CAM

2.Tube bending

E. Metal Materials

1. Identification of metal materials

2. Material properties and selection

F. Oxy-fuel Systems

1. Proper setup, usage, shutdown and maintenance

G Arc Welding and Cutting Systems

1. Operate and maintain SMAW, GMAW, and GTAW equipment safely and appropriately

H. Project Construction

1. Design, layout and construction of advanced metal projects

V. Scope and Sequence of the Course:

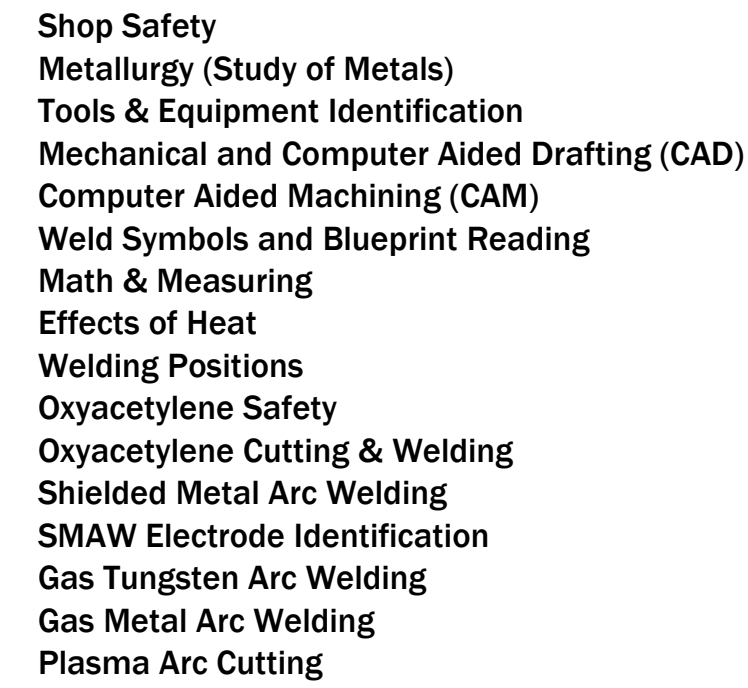




\section{Assessment and Standards for Student Performance}

A. Written tests and quizzes that are short answer in format.

B. Performance based assessments such as demonstrations of skills, and projects completed.

C. Written assignments to include worksheets, book assignments and drawings.

D. Teacher observation of participation on a daily basis.

E. SAE project and FFA participation are required and account for at least $25 \%$ of student's grade.

VII. List Standards Based Textbooks

Primary: Modern Welding. Althouse, Andrew D., Carl H. Turnquist, William A.

Bowditch, and Kevin E. Bowditch.

Supplemental: Modern Metalworking

John R. Walker, The Goodheart-Willcox Company, Inc, 1985. 
d. Daily Grade Sheets 


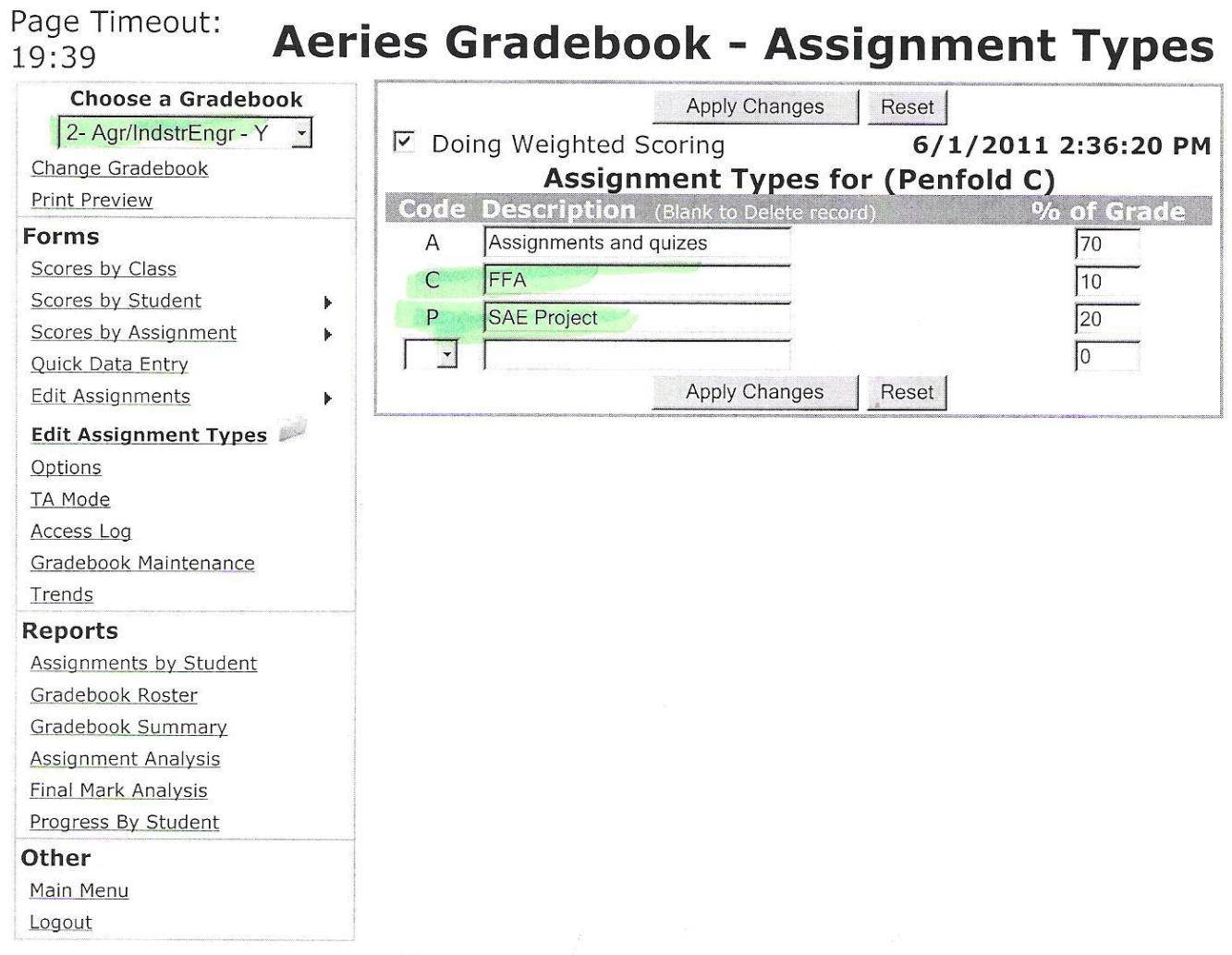

ABI Version 4.11.5.20 Copyright (c) 2011 Eagle Software. All rights reserved. 
Page Timeout: 19:37

Aeries Gradebook - Assignment Types

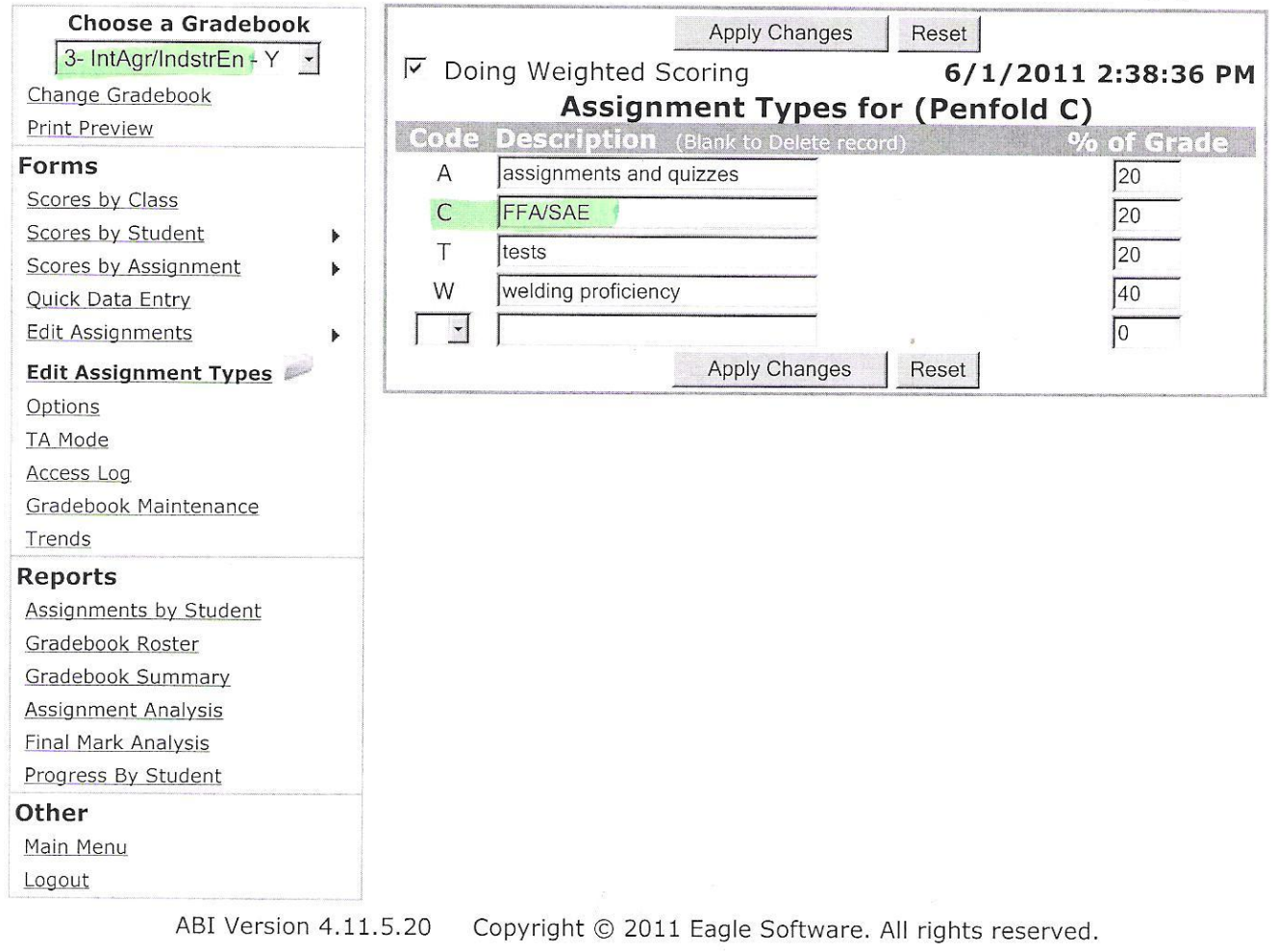

http://abi.avusd.org/GradebookTypes.asp?cache=6\%2F1\%2F2011+2\%3A38\%3A26+PM\&_.. 6/1/2011 


\section{Page Timeout: Aeries Gradebook - Assignment Types
19:49}

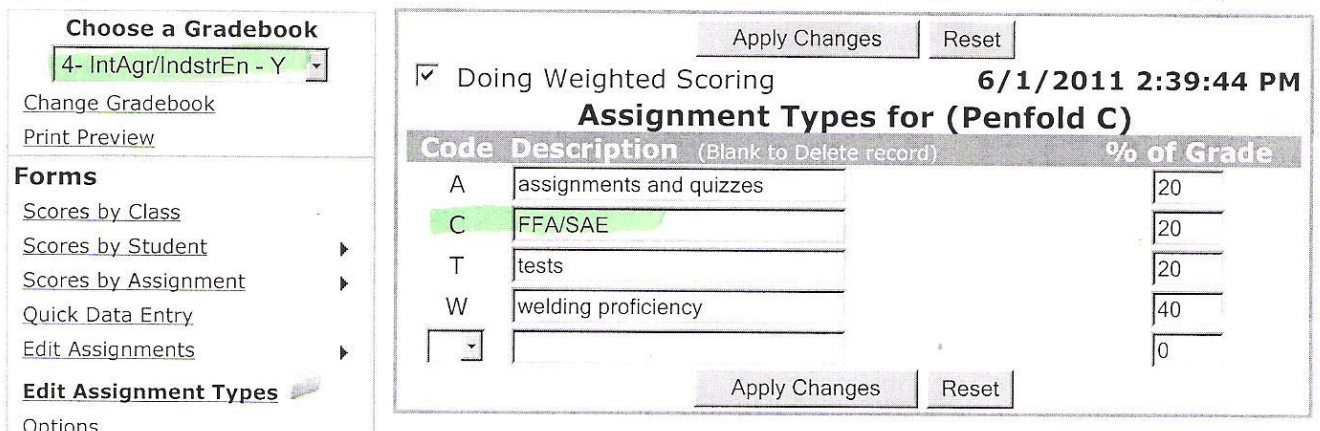

Options

TA Mode

Access Log

Gradebook Maintenance

Trends

Reports

Assignments by Student

Gradebook Roster

Gradebook Summary

Assignment Analysis

Final Mark Analysis

Progress By Student

Other

Main Menu

Logout

ABI Version 4.11.5.20 Copyright (c) 2011 Eagle Software. All rights reserved. 


\section{Page Timeout: $19: 46$ \\ Aeries Gradebook - Assignment Types}

Choose a Gradebook
5-Animal Sci II-Y
Change Gradebook
Print Preview

『 Doing Weighted Scoring $\frac{\text { Apply Changes }}{\text { Reset }}$ 6/1/2011 2:40:21 PM

Forms

Scores by Class

Scores by Student

Scores by Assignment

Quick Data Entry

Edit Assignments

Assignmen

(Penfold C)

Edit Assignment Types

Options

Corle Degardivion (Blank to Delete recora)

F $\longdiv { \text { FFA involvement } }$

$\begin{array}{lll}\mathrm{F} & \text { FFA involvement } & \\ \mathrm{N} & \text { Notebook } & 25 \\ \mathrm{~S} & \text { SAE } & \end{array}$

TA Mode

Access Log

Gradebook Maintenance

Trends

Reports

Assignments by Student

Gradebook Roster

Gradebook Summary

Assignment Analysis

Final Mark Analysis

Progress By Student

Other

Main Menu

Logout

ABI Version 4.11.5.20 Copyright (c) 2011 Eagle Software. All rights reserved. 
Page Timeout: 19:47

\section{Aeries Gradebook - Assignment Types}

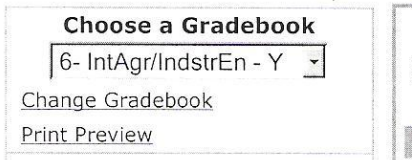

\section{Forms}

Scores by Class

Scores by Student

Scores by Assignment

Quick Data Entry

Edit Assignments

Edit Assignment Types

Options

TA Mode

Access Log

Gradebook Maintenance

Trends

\section{Reports}

Assignments by Student

Gradebook Roster

Gradebook Summary

Assignment Analysis

Final Mark Analysis

Progress By Student

\section{Other}

Main Menu

Logout

\begin{tabular}{|c|c|c|c|c|}
\hline & & Apply Changes & Reset & \\
\hline$\sqrt{\nabla}$ Do & ng Weighted & oring & & 11 2:40:50 PM \\
\hline & Assign & ent Types & (Pe & C) \\
\hline conde & Degendyition & Blank to Delete re & & \%o ai etade \\
\hline A & assignments and & izzes & & 20 \\
\hline C & FFA/SAE & & & 20 \\
\hline $\mathrm{T}$ & tests & & & 20 \\
\hline W & welding proficienc & & & 40 \\
\hline$\exists$ & & & & 0 \\
\hline & & Apply Changes & Reset & \\
\hline
\end{tabular}

ABI Version 4.11.5.20 Copyright (C) 2011 Eagle Software. All rights reserved. 
e. Project Visit Forms 


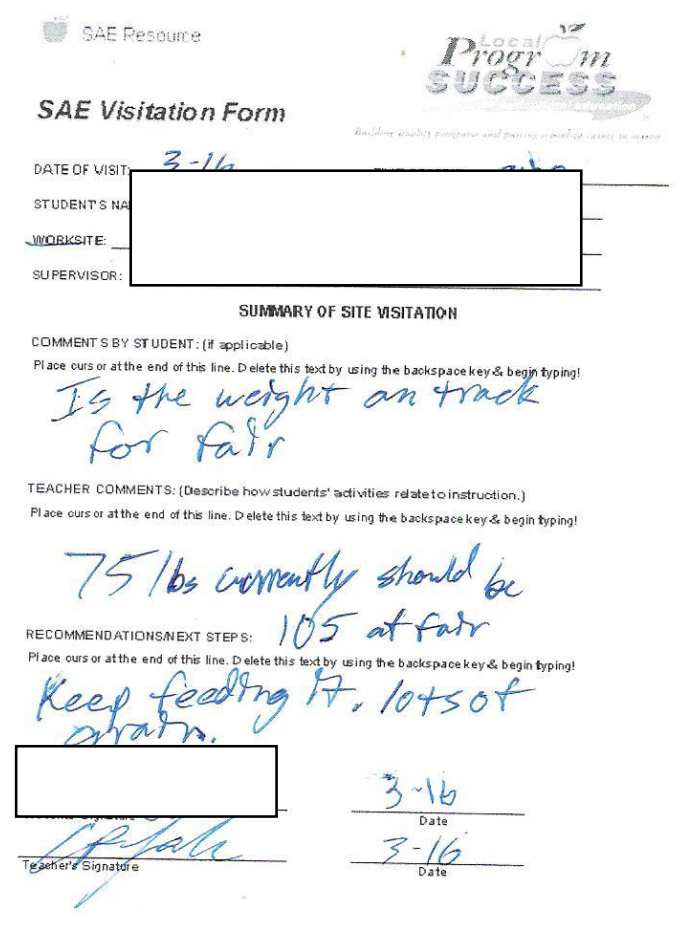




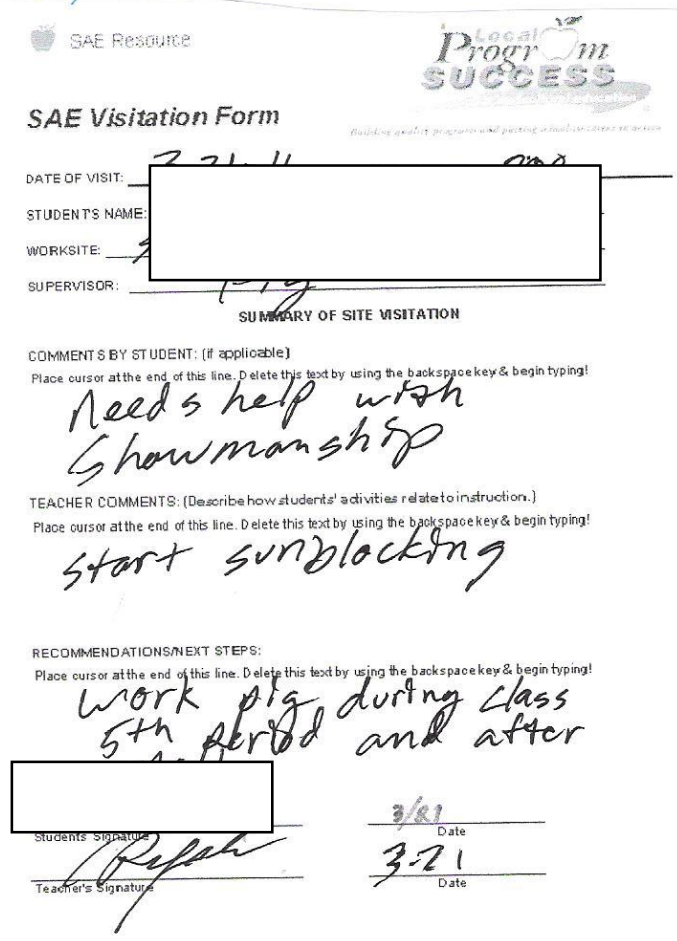




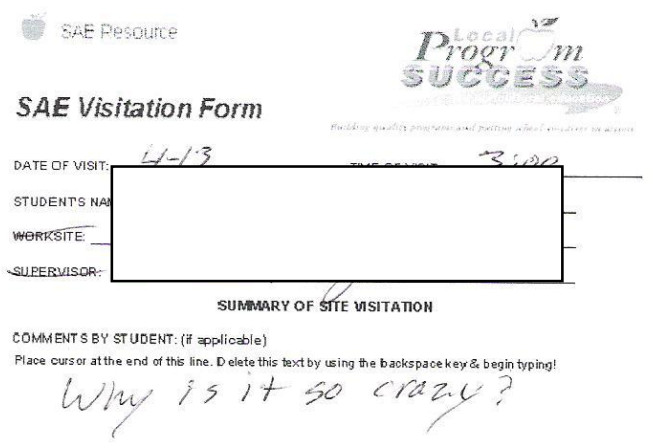

TEACHER COMMENT S: (Dessribe howstudents' adivities reste to instruction.]

Place oursor at the end of this line. Delete this text by using the gacks pace key a begin typing! more.

RECOMMENDATIONSNEXT STEPS:

Place cursor at the end of this line. Delete this text by using the backspace keyk begin typing!

get a bhow stick instead

of a whop.

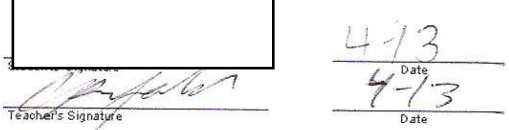

V. 


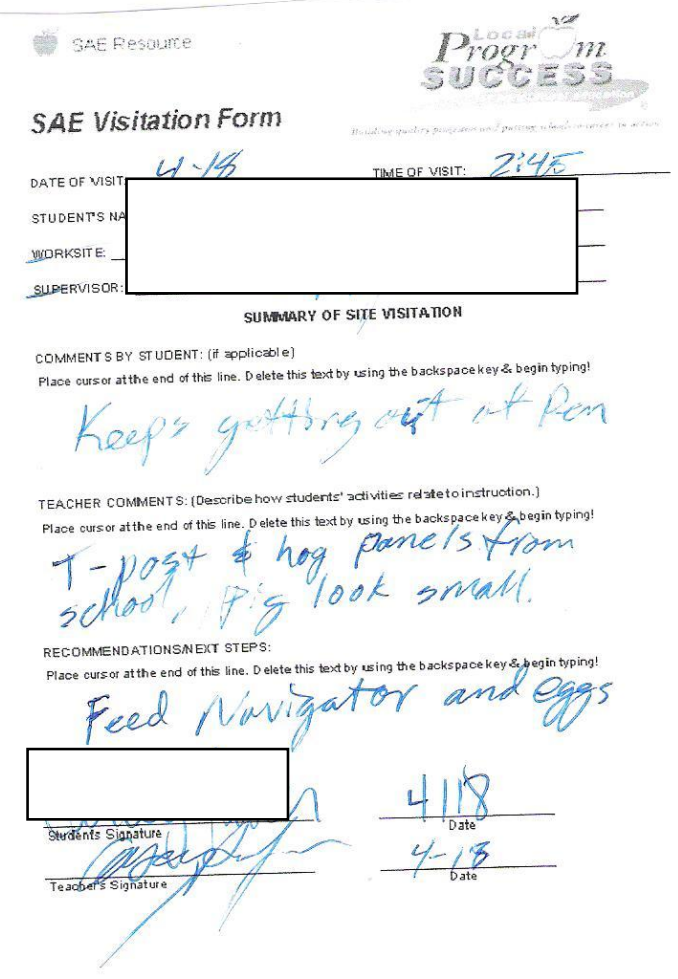




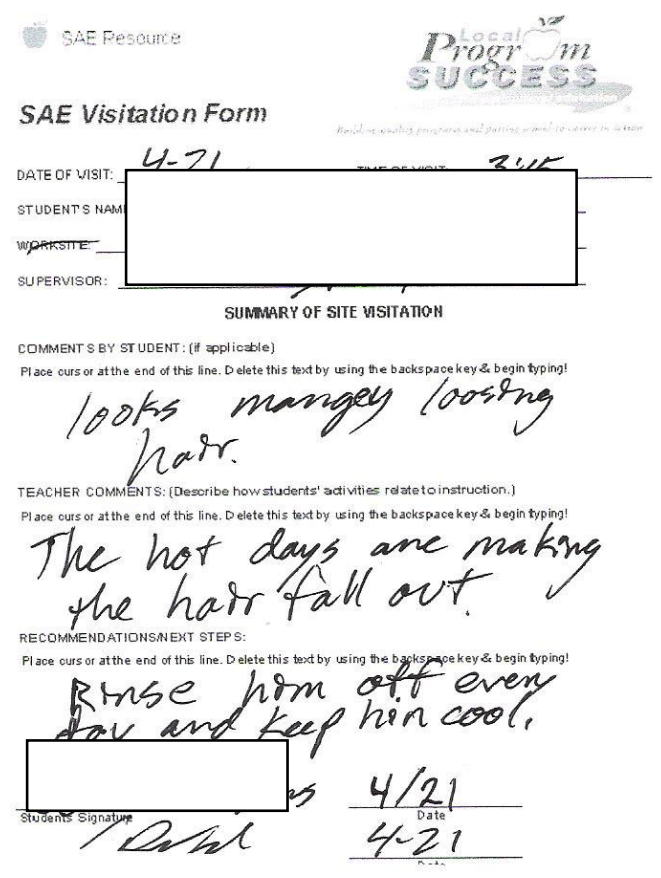




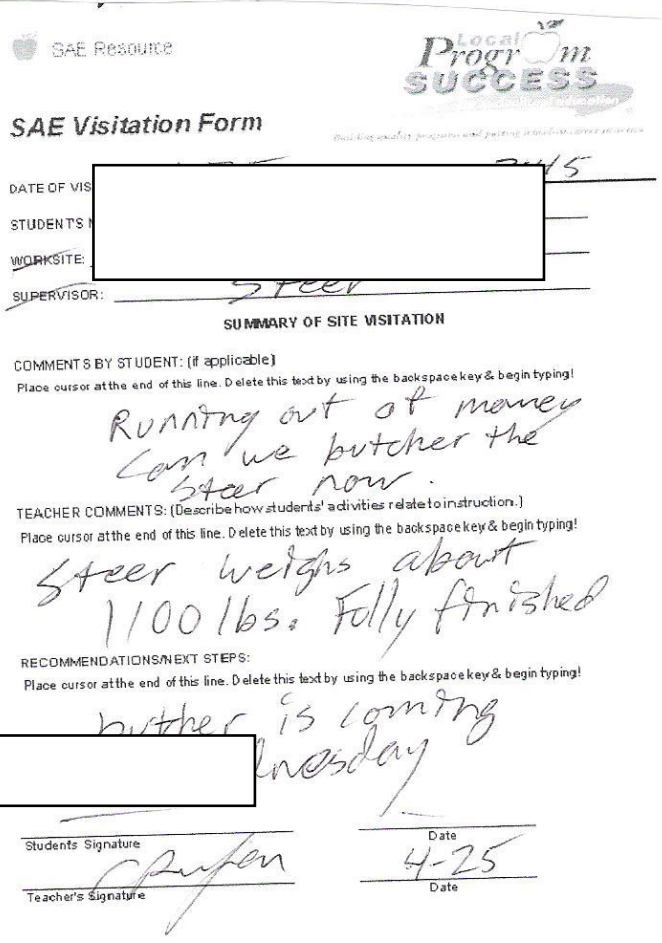




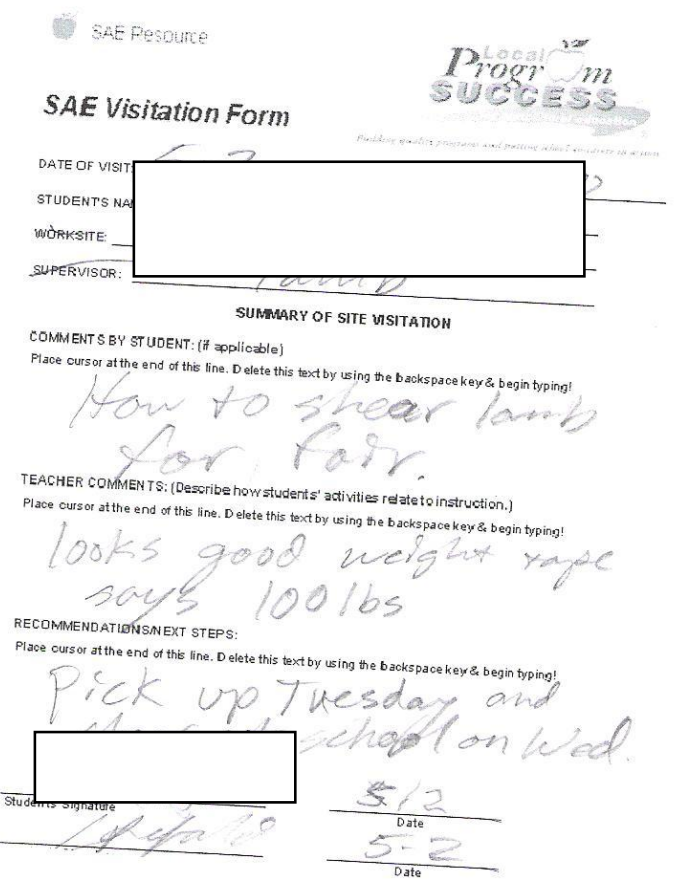




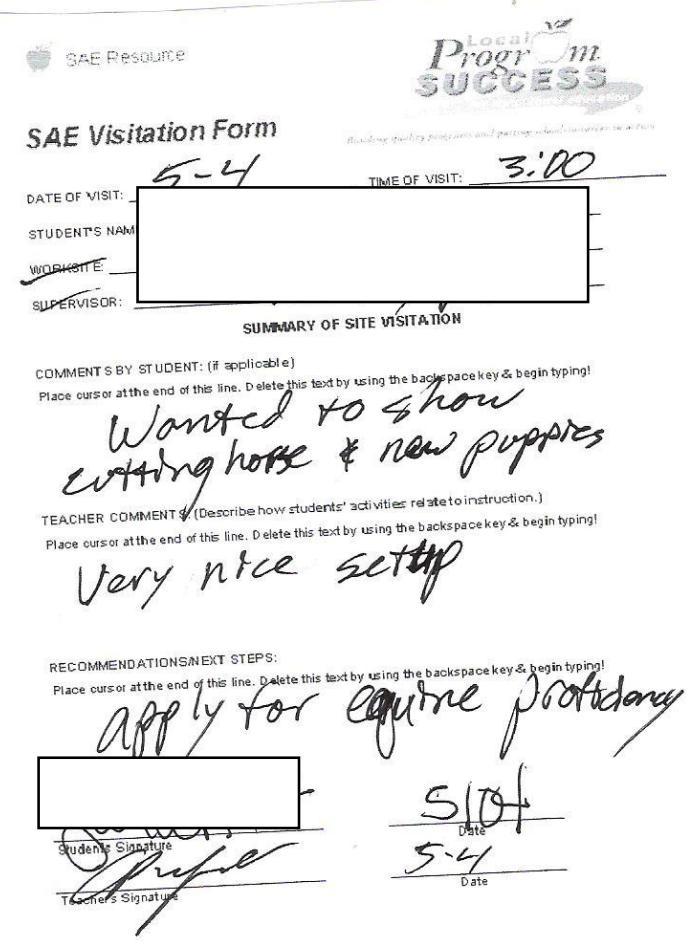




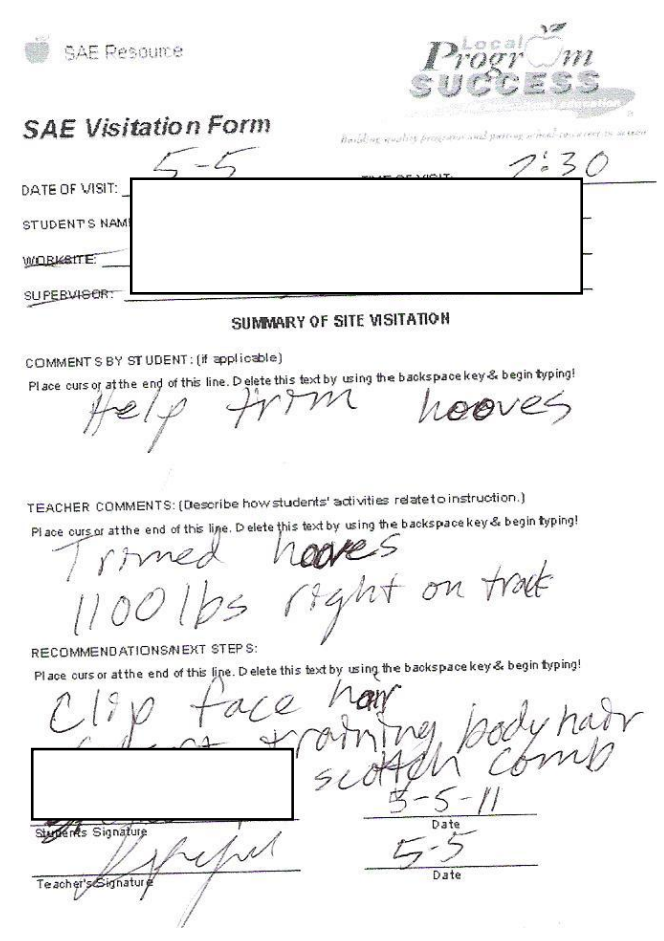




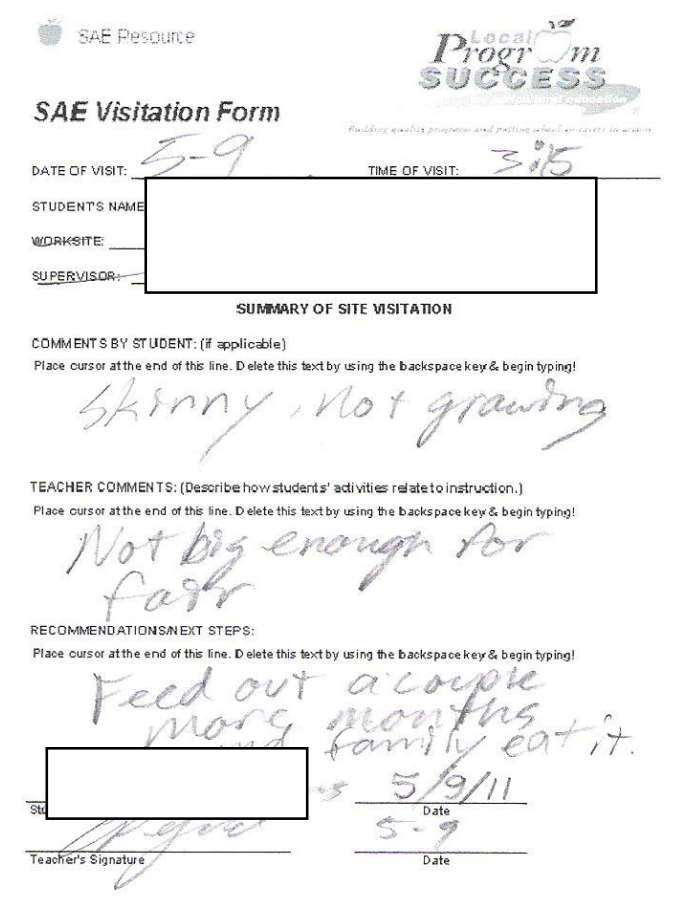




\section{f. Wall Chart of Project Visits}

Currently our department does not utilize a wall chart to record project visits that are made. We would like to implement a chart to keep as a visual reminder for us on which projects need to be visited. 
g. SOE Summary by Individual Student 


\section{OWNERSHIP ENTERPRISE AGREEMENT}

(Each enterprise requires a separate agreement)

\begin{tabular}{ll|l} 
This agreement is entered into this 1 day of January until \\
December 312010 & (Other Party) & (O) \\
and & the student's enterprise in:
\end{tabular}

Market Swine

(Name of Enterprise)

This agreement must contain statements concerning what each party is responsible to provide and/or benefits he/she will receive. Items that must be addressed are: equipment, land, buildings, capital (money), management, and profit or loss.

Please use complete sentences and be specific with details.

I will do all management including feeding and cleaning. My parents will be responsible for building and land. Capital will be provided from my parents and will be paid back upon sale o the animal.

Signatures

of Parties

Involved 


\section{PLACEMENT ENTERPRISE AGREEMENT}

(Paid and Unpaid Work Experience)

1 To provide a basis of understanding and to promote sound business relationships, this written agreement is established on January 1,2010 This work/training will start on January 1, 2010 and will end on or about January 1,2011 unless the arrangement becomes unstisfactory to either party.

2 Business name and type Unpaid Work Experience- Horse

3 Person (employer/trainer) responsible for training:

4 Wages: N/A Frequency of Payment N/A

5 Agricultural Job Skills to be Performed: Horse training Horse care

6 IT IS UNDERSTOOD THAT THE EMPLOYER WILL:

a. Instruct the student in ways of doing his/her work and acquaint him/her with management problems.

b. Help the teacher/coordinator make an honest appraisal of the student's performance.

c. Avoid subjecting the student to unnecessary hazards.

d. Notify the parent immediately in case of accident or sickness or if any other serious problem occurs.

e. Assign the student new experiences in keeping with his/her progress.

f. Cooperate with the teacher in arranging a conference with the student on supervisory visits.

7 THE STUDENT AGREES TO:

a. Do an honest day's work recognizing that the employer/trainer expects profit from wages or time spent to justify hiring/training him or her.

b. Be considerate of the employer/trainer by being punctual, dependable in attendance, and by telephoning if he or she will be absent.

c. Follow instructions, avoid unsafe acts, and be alert to unsafe conditions.

d. Be courteous and polite to the employer, his or her family, other employees, and all customers or patrons.

e. Keep records of occupational experience and make such reports as the school may require.

f. Develop plans for management decisions with the employer/trainer and teacher.

8 STUDENT'S SIGNATURE:
EMPLOYER/TRAINER'S SIGNATURE:

Business Telephone

760-954-5312 


\section{PLACEMENT ENTERPRISE AGREEMENT}

(Paid and Unpaid Work Experience)

1 To provide a basis of understanding and to promote sound business relationships, this written agreement is established on November 1, 2010 This work/training will start on November 4, 2010 and will end on or about November 1, 2011 unless the arrangement becomes unstisfactory to either party.

2 Business name and type Horse Training and Care

3 Person (employer/trainer) responsible for training:

4 Wages: 10.00 per hour Frequency of Payment Weekly

5 Agricultural Job Skills to be Performed: Horse Training

Horse Care Property Maintenance

6 IT IS UNDERSTOOD THAT THE EMPLOYER WILL:

a. Instruct the student in ways of doing his/her work and acquaint him/her with management problems.

b. Help the teacher/coordinator make an honest appraisal of the student's performance.

c. Avoid subjecting the student to unnecessary hazards.

d. Notify the parent immediately in case of accident or sickness or if any other serious problem occurs.

e. Assign the student new experiences in keeping with his/her progress.

f. Cooperate with the teacher in arranging a conference with the student on supervisory visits.

7 THE STUDENT AGREES TO:

a. Do an honest day's work recognizing that the employer/trainer expects profit from wages or time spent to justify hiring/training him or her.

b. Be considerate of the employer/trainer by being punctual, dependable in attendance, and by telephoning if he or she will be absent.

c. Follow instructions, avoid unsafe acts, and be alert to unsafe conditions.

d. Be courteous and polite to the employer, his or her family, other employees, and all customers or patrons.

e. Keep records of occupational experience and make such reports as the school may require.

f. Develop plans for management decisions with the employer/trainer and teacher.

8 STUDENT'S SIGNATURE:
EMPLOYER/TRAINER'S SIGNATURE: 


\section{h. Board Approved Department SOEP Policy, Procedures and Operations}


$\times \quad$ Shop Safety

$\times \quad$ Metallurgy (Study of Metals)

$\times \quad$ Tools \& Equipment Identification

Mechanical and CAD Drawing

$\times \quad$ Weld Symbols and Blueprint Reading

Math \& Measuring

$\times \quad$ Effects of Heat

Welding Positions

$\times \quad$ Oxyacetylene Safety

$\times \quad$ Oxyacetylene Cutting \& Welding

$\times \quad$ Shielded Metal Arc Welding

$\times \quad$ SMAW Electrode Identification

$\times \quad$ Gas Tungsten Arc Welding

$\times \quad$ Gas Metal Arc Welding

$\times \quad$ Plasma Arc Cutting

VI. Assessment and Standards for Student Performance

A. Written tests and quizzes that are short answer in format.

B. Performance based assessments such as demonstrations of skills, and projects completed.

C. Written assignments to include worksheets, book assignments and drawings.

D. Teacher observation of participation on a daily basis.

E. SAE project and FFA participation are required and account for at least $25 \%$ of student's grade.

VII. List Standards Based Textbooks

Primary: Modern Welding. Althouse, Andrew D., Carl H. Turnquist, William A. Bowditch, and Kevin E. Bowditch.

Supplemental: Modern Metalworking

John R. Walker, The Goodheart-Willcox Company, Inc, 1985. 


\title{
Vocational Education/Technology Department
}

\author{
PHILOSOPHY
}

The Technology Department believes in providing students an opportunity to explore, evaluate, and prepare for careers. We believe that all students have the right to select a career and receive education and training to make their goals
possible.

\section{GOALS}

5. Students acquire employability and entry level occupational skills, reinforce core academic competencies, and develop critical thinking and decision-making skills by participating in career-vocational education programs/courses.

6. Students are provided with competencies that reflect current technology and practices in business and industry. enabling them to make meaningful choices related to individual career goals. The Technology Department is divided into four instructional programs-Agriculture, Computers, Restaurant
Management, and Industrial Technologies.

\section{AGRICULTURE PROGRAM PHILOSOPHY}

Agriculture is a vital industry to society. It offers many career opportunities that combine skills of leadership, salesmanship, cooperation, and public relations with basic and advanced knowledge of agriculture production practices.

We will assist our students to develop:

GOALS

8. an involvement and interest in agriculture

9. an understanding of the importance of a strong agricultural industry

10. an interest in an agricultural career

11. skills acquired from raising or building an agricultural product, keeping accurate records, and olvement in Future Farmers of America (FFA) to further develop leadership public speaking, responsibility and community participation, summed up in the motto:

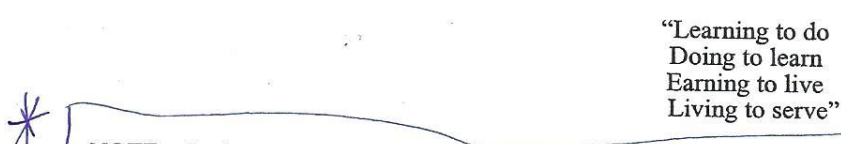

NOTE: Students are required to conduct a supervised occupational experience program (project) during the course of the E various activities of the Future Farmers of America. All agriculture classes require stude involvement in the student organization of FFA. Note: Refer to pages 9 and 10 for the University of California a-g requirements list of approved courses. Only
underlined courses on this list are weighted. 


$$
\text { i. Program of Work }
$$




\section{Apple Valley FFA Program of Work}

I. Supervised Agriculture Occupational Experience

A. All members are required to maintain a project or SOEP.

B. Chapter will encourage participation in local and sectional project competition.

C. Have a video for new members and promotional use.

D. Have a parent/member meeting to explain projects.

E. Recognize proficiency winners at annual banquet.

F. Expand and improve lab to facilitate more student projects.

G. Have five applications for sectional proficiency.

H. Submit five applications for State Farmer.

1. Officers and older students mentor first year members with their projects.

J. First year members with small animals, garden, home improvement, and landscape maintance submit pictures of project with record book.

$\mathrm{K}$. Develop a small animal unit to encourage member involvement.

L. All members own a project in our lab must attend mandatory workdays once a month.

II. Cooperation
A. Hold workdays for lab improvement.
B. Hold workdays for greenhouse improvement.

III. Community Service
A. Improve and beautify school agricultural area.
B. Hold farm awareness days for preschool and early elementary age school children.
C. Community improvement projects.
C. Hold a trash-a-thon.
D. Participate in fair workday.
E. Adopt a highway.
F. Garden program with Marianna's Elementary school

IV. Leadership
A. Encourage more members to participate in public speaking.
B. Conduct officer retreat.
C. Participate in Sectional, Regional, State, and National Leadership Conferences.

D. Encourage members to run for office at the section and region levels. 
V. Earnings, Savings, and Investments
A. Each fundraiser's profits will be designated to specific projects.
B. Beef jerky sale.
C. Raffle-meat.
D. Pancake breakfast.
E. Auctions at meetings.
F. Catering.
E. Trash- a-thon
F. Kiss-a-pig
G. Sponsor Drive for a scholarship fund.

VI. Conduct of Meetings
A. Minimum of eleven (11) monthly meetings.
B. Officer meeting to be held after school within one week prior to monthly group meeting to plan the agenda.
C. A special activity to be held at each meeting such as contests, guest speakers, potlucks, door prizes, and auctions.
D. Member recognition.
E. Members must attend a minimum of six (6) activities to be permitted to show at the San Bernardino County Fair.

VII. Scholarships

A. Recognize top GPA Freshman, sophomore, Junior, and Senior at the annual awards banquet.

B. FFA officers will follow school board policy on GPA requirements.

B. Have a scholarship for seniors continuing in the agricultural field.

C. Recognize most improved member in all grades.

VIII. Recreation
A. Barbeques.
B. Competitive sports against other student organizations.
C. Sweetheart/Hunk contest.
D. Beginning of the year picnic. 
IX. Public Relations

A. Articles in every newsletter and school newspaper.

B. Articles in Community paper.

C. School bulletin announcements for each activity.

D. Conduct a number of activities during FFA week.

E. Participate in a community involvement activity.

F. Put up FFA, Welding, Softball field, Tennis courts, Auto Shop, Baseball field sign on the Apple Valley High School entrance sign.

X. Participation in State and National Activities

A. Attend sectional, regional, state, and national conferences.

B. Have two (2) delegates at state convention.

C. Participate in at least two (2) judging contests.

D. Participate in public speaking contests.

E. Compete in parliamentary procedure contest.

XI. Alumni Relations

A. Invite alumni to annual banquet.

B. Send out letter to solicit support throughout the year.

C. Provide groundwork for Alumni Association.

XII. Membership Development

A. Officer introduction video in first year classes.

B. Develop and conduct recruitment program at middle schools.

C. Develop activities for welding and floral. 
j. Board Approved Policy Statement Pertaining to FFA as an Integral Part of the Ag Program 
$\times \quad$ Shop Safety

$\times \quad$ Metallurgy (Study of Metals)

$\times \quad$ Tools \& Equipment Identification

Mechanical and CAD Drawing

$\times \quad$ Weld Symbols and Blueprint Reading

Math \& Measuring

$\times \quad$ Effects of Heat

Welding Positions

$\times \quad$ Oxyacetylene Safety

$\times \quad$ Oxyacetylene Cutting \& Welding

$\times \quad$ Shielded Metal Arc Welding

$\times \quad$ SMAW Electrode Identification

$\times \quad$ Gas Tungsten Arc Welding

$\times \quad$ Gas Metal Arc Welding

$\times \quad$ Plasma Arc Cutting

VI. Assessment and Standards for Student Performance

A. Written tests and quizzes that are short answer in format.

B. Performance based assessments such as demonstrations of skills, and projects completed.

C. Written assignments to include worksheets, book assignments and drawings.

D. Teacher observation of participation on a daily basis.

E. SAE project and FFA participation are required and account for at least $25 \%$ of student's grade.

VII. List Standards Based Textbooks

Primary: Modern Welding. Althouse, Andrew D., Carl H. Turnquist, William A.

Bowditch, and Kevin E. Bowditch.

Supplemental: Modern Metalworking

John R. Walker, The Goodheart-Willcox Company, Inc, 1985. 


\title{
Vocational Education/Technology Department
}

\author{
PHILOSOPHY
}

The Technology Department believes in providing students an opportunity to explore, evaluate, and prepare for careers. We believe that all students have the right to select a career and receive education and training to make their goals
possible.

\section{GOALS}

5. Students acquire employability and entry level occupational skills, reinforce core academic competencies, and develop critical thinking and decision-making skills by participating in career-vocational education programs/courses.

6. Students are provided with competencies that reflect current technology and practices in business and industry. enabling them to make meaningful choices related to individual career goals. The Technology Department is divided into four instructional programs-Agriculture, Computers, Restaurant
Management, and Industrial Technologies.

\section{AGRICULTURE PROGRAM PHILOSOPHY}

Agriculture is a vital industry to society. It offers many career opportunities that combine skills of leadership, salesmanship, cooperation, and public relations with basic and advanced knowledge of agriculture production practices.

We will assist our students to develop:

GOALS

8. an involvement and interest in agriculture

9. an understanding of the importance of a strong agricultural industry

10. an interest in an agricultural career

11. skills acquired from raising or building an agricultural product, keeping accurate records, and olvement in Future Farmers of America (FFA) to further develop leadership public speaking, responsibility and community participation, summed up in the motto:

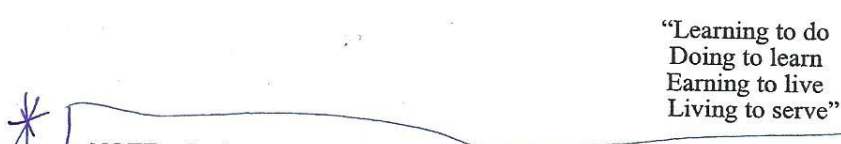

NOTE: Students are required to conduct a supervised occupational experience program (project) during the course of the E various activities of the Future Farmers of America. All agriculture classes require stude involvement in the student organization of FFA. Note: Refer to pages 9 and 10 for the University of California a-g requirements list of approved courses. Only
underlined courses on this list are weighted. 


\section{k. Recruitment Program}

The recruitment plan for Apple Valley's Agriculture Program starts with making as much contact into the community as possible. From the large involvement in the San Bernardino County Fair to the Dodge Ram Drive and Ride Fundraiser which includes radio advertisements, the Apple Valley FFA is in the public's eye and is well known in the community. Most middle and elementary students know of the agriculture program long before they are enrolled in high school because of school farm field trips and petting zoos put on by FFA students. When it comes time for the eighth grade students to start choosing classes for high school a few of our officers go down to the middle schools and put on a presentation of the pathways and activities done in the agriculture program. At the high school one evening, in the spring, eighth grade students and their parents come to the high school and tour clubs sports and academic programs. Our displays are always the most popular and get the most attention by students and parents. 


\section{Apple Valley High School Animal Sciences}

Animal Science class provide you the opportunity to learn animal nutrition, reproduction, health care and animal training along with many science concepts in a
hands-on way.

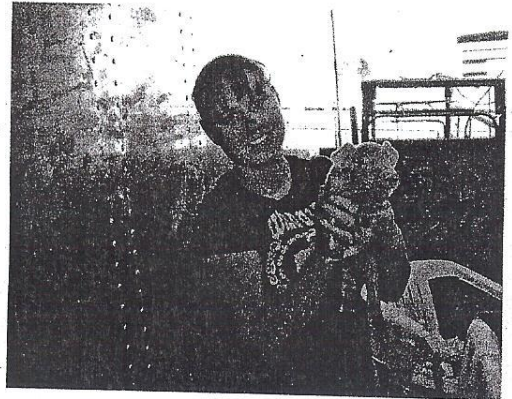

You will also learn to identify symptoms of illness and administer medications for the animals. Many students will work with local veterinarians while in high school.

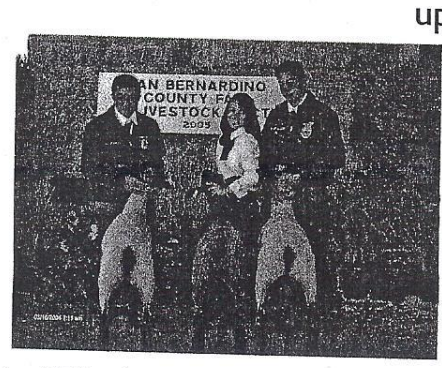

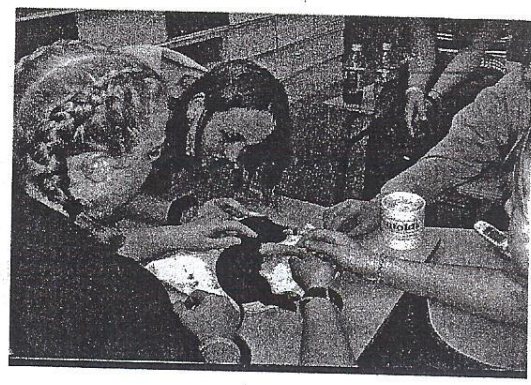

In the classroom, students earn science credit in $\mathrm{Ag}$ Biology while learning in a fun and challenging way. If you like animals and would like to learn more, sign up for an Animal Science class now!

Students in FFA show a variety of livestock at fairs and jackpots throughout California while developing leadership and personal growth.

For more information about our Animal Science Program, call Mir. Duane Penfold at 247-7206 ext. 308, or call the Counseling office at 247-7206 ext. 134 
Introduction Ag./Industrial Engineering-

Pre Requisite-None $9^{\text {th }}-12^{\text {th }}$ grades

-Mechanical Drawing

-CAD Drawing- SolidWorks

30 new laptop computers

-Small metal project-

Intermediate Ag./Industrial Engineering -

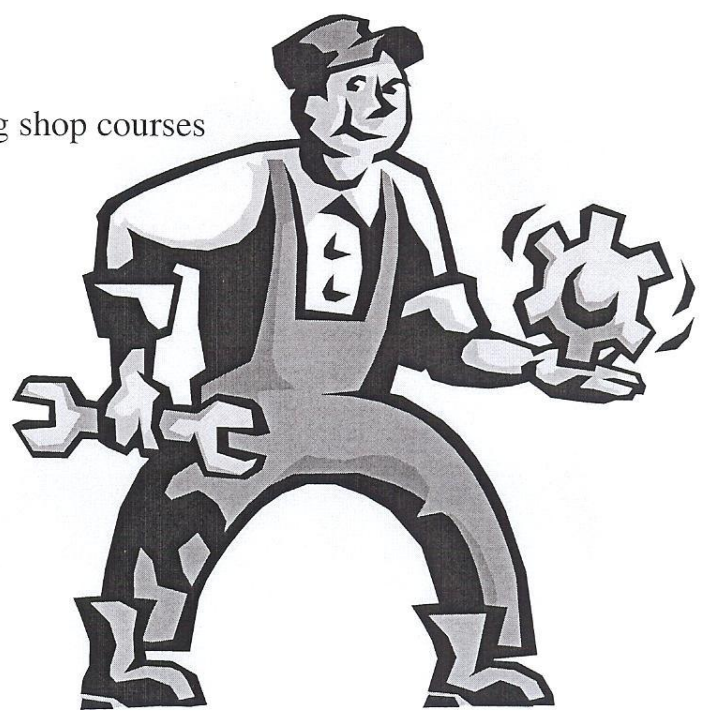

Pre Requisite- $11^{\text {th }}-12^{\text {th }}$ grades and $10^{\text {th }}$ graders that have taken Intro Ag Eng.

-Beginning welding skills and Solidworks review.

Advanced Ag./Industrial Engineering -

Pre Requisite-students that have taken Intermediate Ag. Engineering

-Advanced welding and fabrication skills.

-SolidWorks, Plasma CAM, Tube Bending Software.

Welding III- After School Tuesday and Thursday from 2:00-4:30

Pre Requisite- for students that have taken or are in an intermediate or advanced Ag.

Eng. class.

-Additional shop time for practice welding and project building. 


\section{l. Chapter Scrapbook}



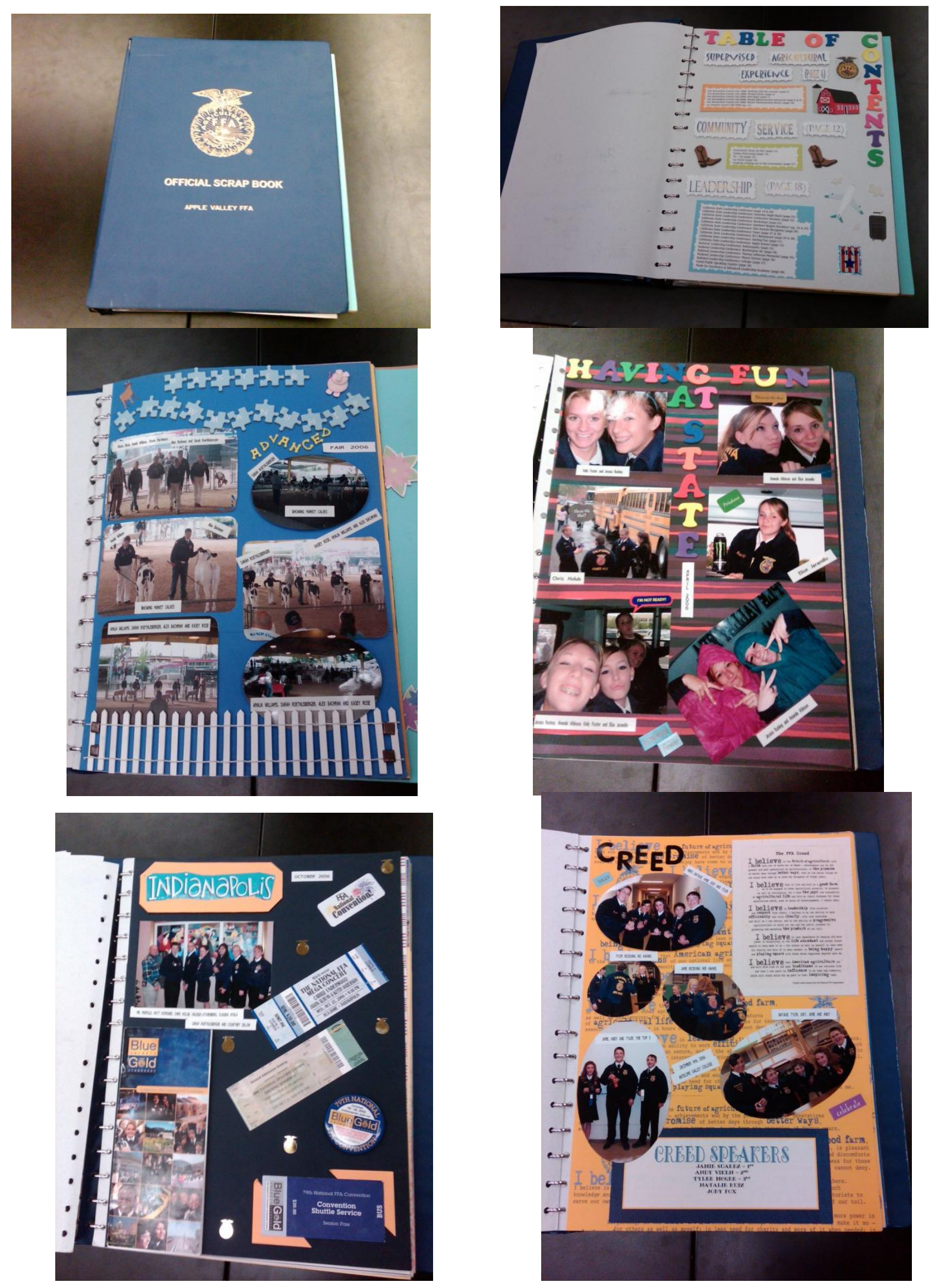


\section{m. Summer Activities Schedule}

At Apple Valley High School's Agriculture Department there are no summer activities for normal members. The only activities that go on in the summer are the officer retreat for the Chapter FFA Officers. Our fair is in May before school gets out so there are no students with animals except for the occasional dairy replacement heifer projects, breeding swine projects and the equine projects over summer. 


\section{n. Vo-Ag Follow-up Survey Form}

The department has a survey form that is given out before students graduate to see where they are going after high school. There is a plan to create a form that is mailed home about 6 months after graduation to verify that the students have actually followed through with the plan they have set up before graduation. 


\title{
Senior Survey
}

\author{
class: \\ Per. \\ /Teacher \\ SENIOR CLASS OF:
}

NAME:

1. Are you planning on attending college next fall? Yes. No

A. 4 year college/university:

UC:

CSU:

Private College/University Or Out Of State College/University:

B. 2 Year Community College

VVC other:

C. Vocational/Technical School:

Intended major(s):

Career interest(s):

2. If you answered NO to question 1 , please list your post-graduate plans:

Military: Air Force Army Navy Marines Coast Guard National Guard

Work: Is your job related to your ROP Class/Classes: Yes___No

A. Employer's Name:

B. Full Time Part Time

Other: 


\section{o. Up-to-Date File on Status of Graduates}

Along with the creation of a follow up survey there will be the results file to show the up-to-date information showing where students have gone after completing the program. This will be supplemental to the R-2 follow-up report. 


\section{Graduate Follow-up Report \\ Year $=2010$}

\# CA0295 Apple Valley

Apple Valley Sr. HS

11837 Navajo Rd.

Apple Valley, CA 92308

Printed: 3/29/2011 5:21:32 PM

\begin{tabular}{|l|l|}
\hline Total Seniors (Year=2009): & 86 \\
\hline $\begin{array}{l}\text { Total Seniors having completed } \\
\text { 3 or more years of Ag Instruction: }\end{array}$ & 13 \\
\hline \multicolumn{2}{|l|}{ Program Completer Status } \\
\hline Two Year College Ag Major & 2 \\
\hline Two Year College Non-Ag Major & 7 \\
\hline Four Year College Ag Major & 2 \\
\hline Employed - Fulltime Ag Job & 1 \\
\hline Military & 1 \\
\hline
\end{tabular}

CalAgEd Home | R-2 Home | R-2 Online Home | Roster | Teacher | FAQ | Help | Log Out Site developed and maintained by ATI Net, California State University, Fresno with funds from the California Department of Education, Agricultural Education Unit. 


\section{Graduate Follow-up}

\# CA0295 Apple Valley

Apple Valley Sr. HS

11837 Navajo Rd.

Apple Valley, CA 92308

Year: 2010 Go

Last Name First Name Graduate Status

\begin{tabular}{|l|l}
\hline Two Year College-Ag Major \\
Two Year College-Non-Ag Major \\
Military- \\
Two Year College-Non-Ag Major \\
Two Year College-Non-Ag Major \\
Employed - Fulltime-Ag Job \\
Four Year College-Ag Major \\
Two Year College-Non-Ag Major \\
Two Year College-Non-Ag Major \\
Four Year College-Ag Major \\
Two Year College-Non-Ag Major \\
Two Year College-Non-Ag Major
\end{tabular}

Printed: 3/29/2011 5:20:23 PM

Count: 13 


\section{p. Vo-Ag Comprehensive Plan}

The agriculture department does not currently have the program plan organized into a binder. The plan is to create the binder utilizing most of the information compiled for this project as well as all the other additional information needed to create the plan. 


\section{q. Advisory Committee Minutes}




\section{Apple Valley High School Agriculture Advisory Committee Minutes \\ September 14, 2010}

The meeting was called to order by chairman Matt Rueckheim at $6 \mathrm{pm}$ In attendance were:

Lee Graham, Neville Slade, Carrie Foster, Gary Foster, John Ostlie, Casey Penfold, Mary Lieby, Patrick Schlosser, Josh McClane, Ken Alstott, Duane Penfold, and the FFA officer team.

A chili and corn bread meal was served, and the FFA officers presented a powerpoint presentation of their goals for the year.

Matt discussed the program curriculum and invited Neville Slade from VVC to describe the partnership between Apple Valley High School agriculture and VVC. Neville mentioned that even with confusing leadership at the college, the animal science courses are expanding and he hopes to tie some of the courses into the high school program plan.

Matt asked Mr. Schlosser about the possibility of adding a horticulture teacher next fall. Mr. Schlosser commented that he wishes he could, but with budgets getting tighter, he doubted that would happen next year. However, he began a lively discussion of ways to convert ROP welding courses to regular day classes for freshmen, and brought up that he needed classes to put students into at the semester. He and Casey Penfold brainstormed ideas and a class discussed that would involve engineering and computer aided drafting, helping students with math skills. They are going to continue working on a plan for this course.

Matt brought out the old five year plan for the agriculture program, went through each of the past years, and showed how the majority of the plan had been actually implemented, and that we needed to create our next five-year plan. Because it was getting late, Matt instructed all to be thinking of plans and goals for the next five years, and we would put it together at the next meeting.

The meeting was adjourned at 8:45pm. 
San Bernardino County Superintendent of Schools

REGIONAL OCCUPATIONAL PROGRAM

\section{ROP ADVISORY COMMITTEE MINUTES}

School Year: 2010-201

District: Apple Valley Unified

Course Title(s): Welding Technology III

\section{INDUSTRY REPRESENTATIVES}

Name

Mark Haynes

Adam Bechtold

Gary Menser

Terry Jacobs
Representing

Airgas West

Flory Industries

Victor Valley College

Txi Riverside Cement
Meeting Date/Time: Jan. 11, 2011 7:00pm

Meeting Location: Welding Shop

Chair: Duane Penfold

Mailing Address $\quad$ Email Address

17052 Sequoia Rd, Hesperi www.airgas.com

4737 Toomes Rd. Salida, 9! abechtold @ floryindustries.

18422 Bear Valley, Victorvil menserg@ vvc.edu

19409 National Trails Highu tjacobs@txi.com

Note: According to Ed Code, Industry Representatives must be greater than 50\%.

EDUCATIONAL REPRESENTATIVES

Name

Casey Penfold

Representing
Apple Valley H.S.

Duane Penfold Apple Valley H.S.

John Ostlie

SBCSS

Mailing Address

Email Address

11837 Navajo Rd, Apple Vacasey_penfold@avsd.k12

11837 Navajo Rd, Apple Va duane_penfold@avsd.k12

144 North Mt. View Ave, Sa john_ostlie@sbcss.k12.ca

Note: The number of educators and staff cannot exceed the number of industry representatives (i.e., listing two education representatives requires four industry representatives).

\section{STAFF OR OTHER REPRESENTATIVES}

Name $\quad$ Representing Mailing Address $\quad$ Email Address

CURRICULUM VALIDATION_Validate that curriculum content and equipment meets industry standards and id any industry certification offered. If validating more than one course, the curriculum for each course must be reviewed and approved and recommendations noted.

The committee felt the curriculum being taught is up to date with the current demands of the industry . Our program provides a large scope across many different areas in the industry so that students can experience several levels and choose the path they are the most interested in. The students are learning how to operate state of the art equipment that exceeds industry standards. They have the opportunity to experience the latest in computer aided designing and manufacturing techniques. Several members appreciate the infusion of

\section{RESULTS OF VOTE TO APPROVE CURRICULUM}

COURSE 1

Number Approve: $\quad 5$

Vumber Disapprove:

Number Abstain
COURSE 2

Number Approve:

Number Disapprove:

Number Abstain: 


\section{ROP ADVISORY COMMITTEE MINUTES-Page 2}

SKILLS ASSESSMENT VALIDATION - Share the method and criteria used to evaluate whether your students a acquired the identified skills and knowledge (i.e., competencies). Share copies of tests, project scoring guide, grade policy, etc

The committee supported the assesment techniques used in the program to identify the students welding skills and knowledge. Examples included witten test materials and practical welding samples along with welding projects.

LABOR MARKET CONDITIONS—Verify local labor market conditions.

Once again the committee expressed their concern for the hard economic times in the industry and said that that it has really slowed down just like every other industry. Gary mentioned that many companies have been down sizing their operations and laying off workers just to maintain their buisiness. Some areas are doing ok such as the latest technology areas. The students that are learning the computer aided machines are going to have a better chance to fine a job in this part of the industry.

WASC ACTION PLAN—Review action plan and progress.

OTHER BUSINESS-(i.e., donations, fieldtrips, community classroom opportunities, marketing ideas, additional advis committee members, employment opportunities for students).

Adam is very glad that we have been able to add the 3 -dimensional solids modeling program SolidWorks to the program to keep up with the engineering and design standards. Mark let us know that Anderson Trailers in Adelanto would be a great field trip opportunity.

Minutes reviewed by:

ROP District Coordinator Signature

Date

County ROP Administration Onlv

Distribution of Advisory Minutes:

$\square$ File original in course folder.

$\square$ One copy to OSI for email distribution list. 
r. Completed Student Program Plan 


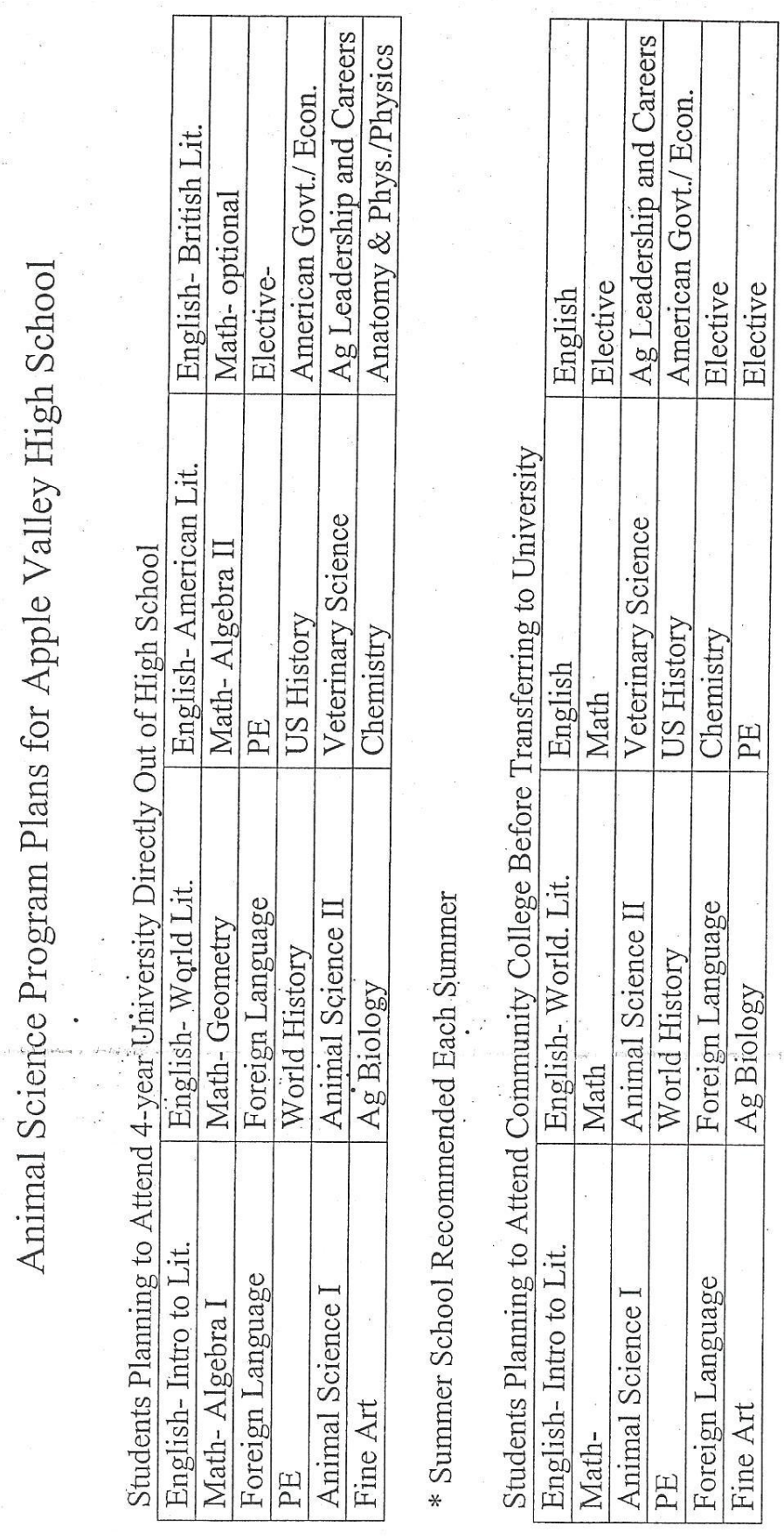


s. Proficiency Standards 


\section{Agricultural/Industrial Engineering Proficiency Standards}

The students will:

1. Practice the rules for personal and group safety while working in a fabrication shop environment.

2. Demonstrate safe work habits on the job.

3. Demonstrate the ability to work well with others.

4. Learn and follow an orderly process to create a project from idea to finished product.

5. Learn and demonstrate mechanical skills.

6. Be able to follow directions

7. Practice good record keeping skills.

8. Critically evaluate good workmanship

9. Apply problem-solving skills in the production of projects.

10. Understand how to design project plans by using mechanical drawing techniques

11. Employ math skills in working with measurements.

12. Know how to identify common metals, sizes, and shapes.

13. Know basic tool-fitting skills.

14. Know layout skills.

15. Know basic cold metal processes (e.g., shearing, cutting, drilling, threading, and bending.).

16. Complete a metal project, including interpreting a plan, developing a bill of materials, selecting materials, shaping, fastening, and finishing.

17. Know how to properly set up, adjust, shut down, and maintain an oxy-fuel system.

18. Use welding tools and equipment, such as MIG, TIG, SMAW, to combine or join manufactured parts and products, resulting in a finished product that meets the standards of the American Welding Society or a similar industry.

19. Operate and maintain fabrication tools and equipment safely and appropriately.

20. Use computers to design and produce welded products, write numerical control programs, and control computer operated equipment. 
t. Copy of Teaching Credentials 
Summary of Application Status and Credentials Held | California Commission on Teacher... Page 1 of 1

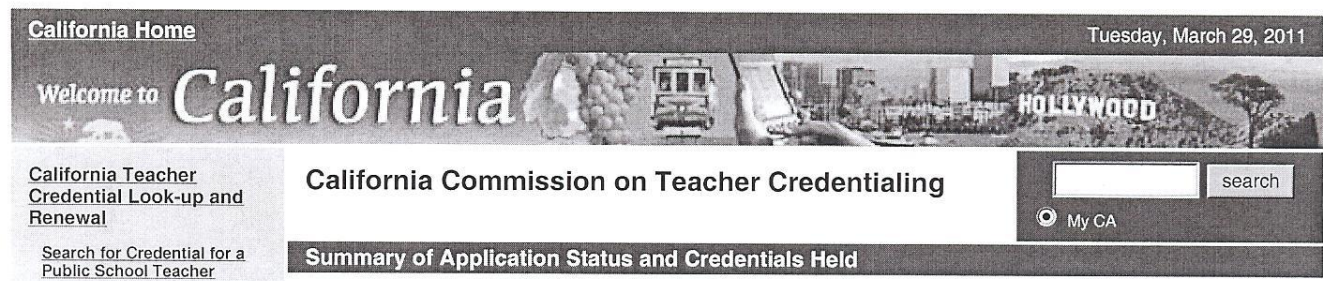

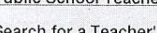

Search for a Teacher's Credentials Held

Renew Credentials

Direct Application

(Non-Recommendation Only)

Track Payment

(Renewal Only)

Track Payment

(Recommendation Only)

Start the IHE Login Page

Start the Student Applicant

Login

Frequently Asked Questions

Glossary of Credential

Terms

California Commission

on Teacher Credentialing

Web Site

Governor's Home Page

Contact the Commission

on Teacher Credentialing

Following are the results of your search. To view detailed information about an existing

credential, click on the document title in the Credentials Held section below. To determine the

processing time of your pending application, please click on the California Commission on

Teacher Credentialing Web Site in the left hand column

\begin{tabular}{|c|l|}
\hline \multicolumn{2}{|c|}{ Status of Application(s) } \\
\hline \multicolumn{2}{|c|}{ Name: PENFOLD, CASEY DUANE } \\
\hline Date Received & Status \\
\hline $06 / 07 / 2010$ & Online Recommended Application Granted 06/09/2010 \\
\hline
\end{tabular}

\begin{tabular}{|l|l|}
\hline \multicolumn{1}{|c|}{ Credentials Held } \\
\hline Document Title & Expiration Date / Status \\
\hline $\begin{array}{l}\text { Certificate of Clearance (valid five years if issued on or after } \\
7 / 1 / 2007)\end{array}$ & \\
\hline Emergency 30-Day Substitute Teaching Permit & $09 / 01 / 2008$ \\
\hline Clear Specialist Instruction Credential (Agriculture) & $02 / 01 / 2013$ \\
\hline Preliminary Single Subject Teaching Credential & $02 / 01 / 2013$ \\
\hline Preliminary Full Time Designated Subjects Career Technical & $02 / 01 / 2013$ \\
\hline Education Teaching Credential & $06 / 01 / 2015$ \\
\hline Clear Single Subject Teaching Credential & \\
\hline
\end{tabular}

New Search

Select to Renew Credentials eligible for online renewal.

Back to Top of Page

Conditions of Use | Privacy Policy | E-mail Webmaster (c) 2002 State of California. Arnold Schwarzenegger, Governor. 


\section{u. Calendar of Department/Chapter Activities}

The most complete calendar of activities is posted in the front of the agriculture class room for students, officers, and instructors to use. 


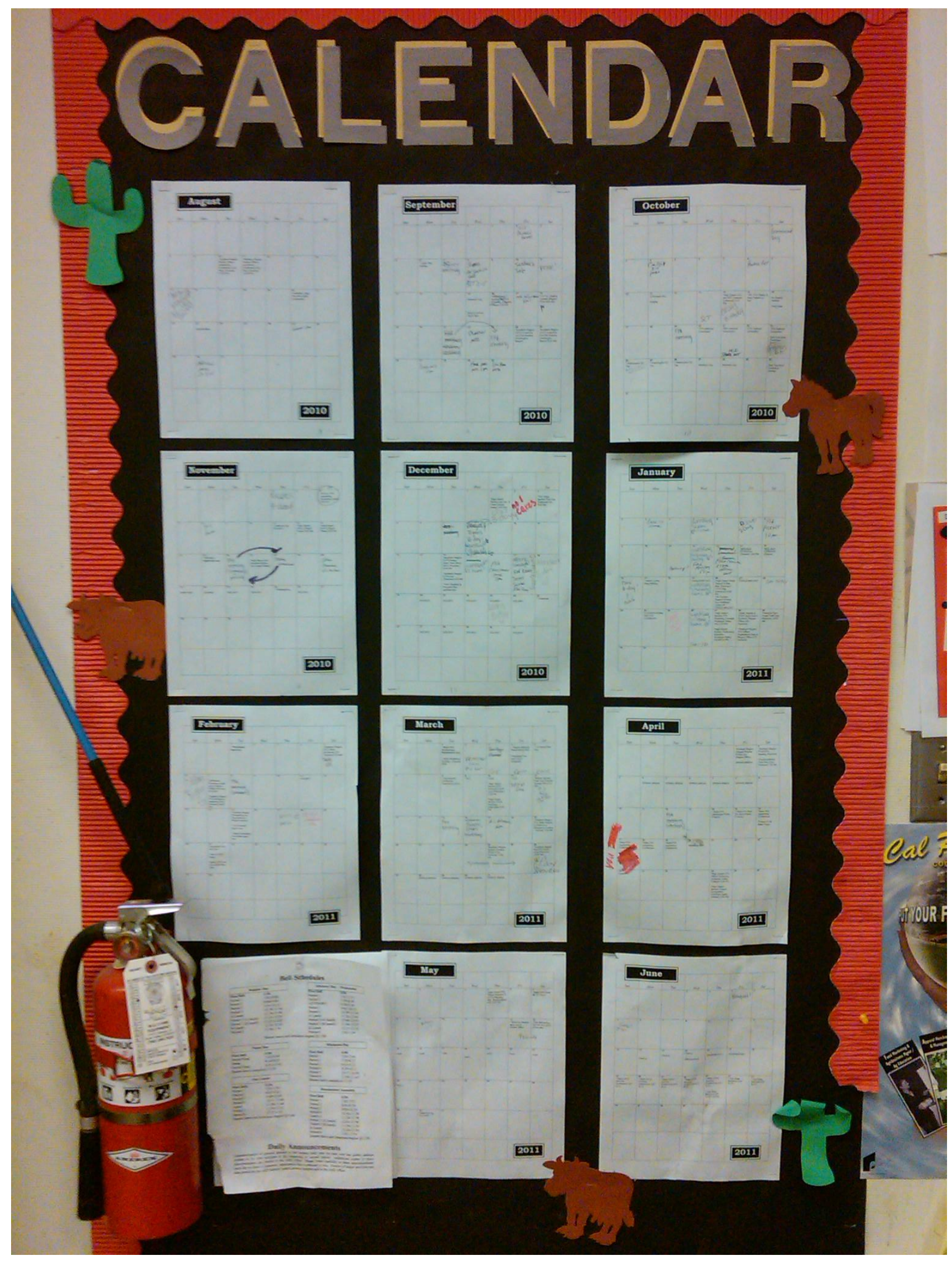




\section{v. Daily Log}

I keep a daily log in a daily planner that the students get at the beginning of the year. I keep lessons that I give each class and assignments that I assign. I also keep track of the hours in and out of school that pertains to my ROP class so that I can fill out a time sheet at the end of every month. 

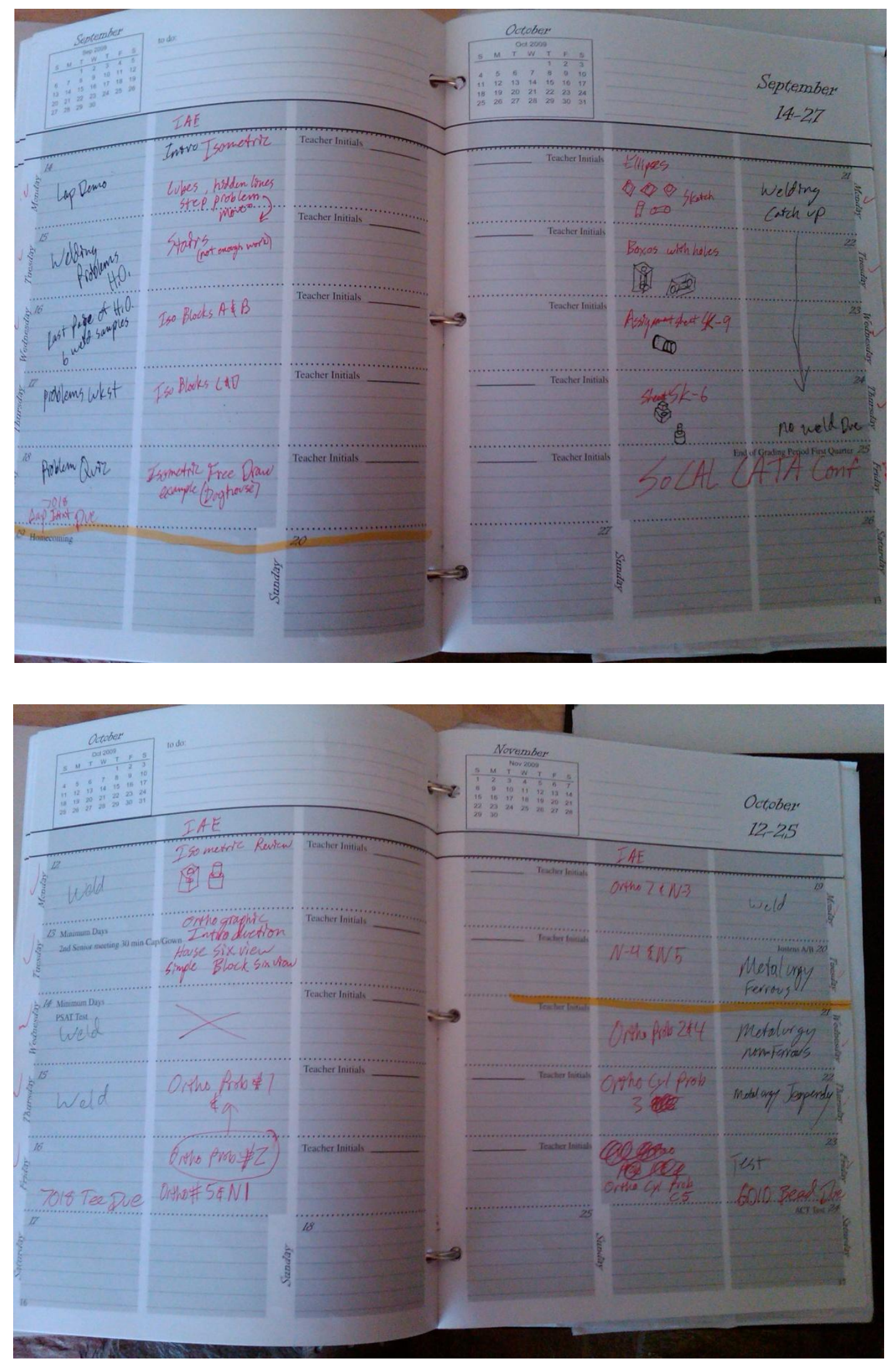


\section{w. Expected Professional Growth Activities}




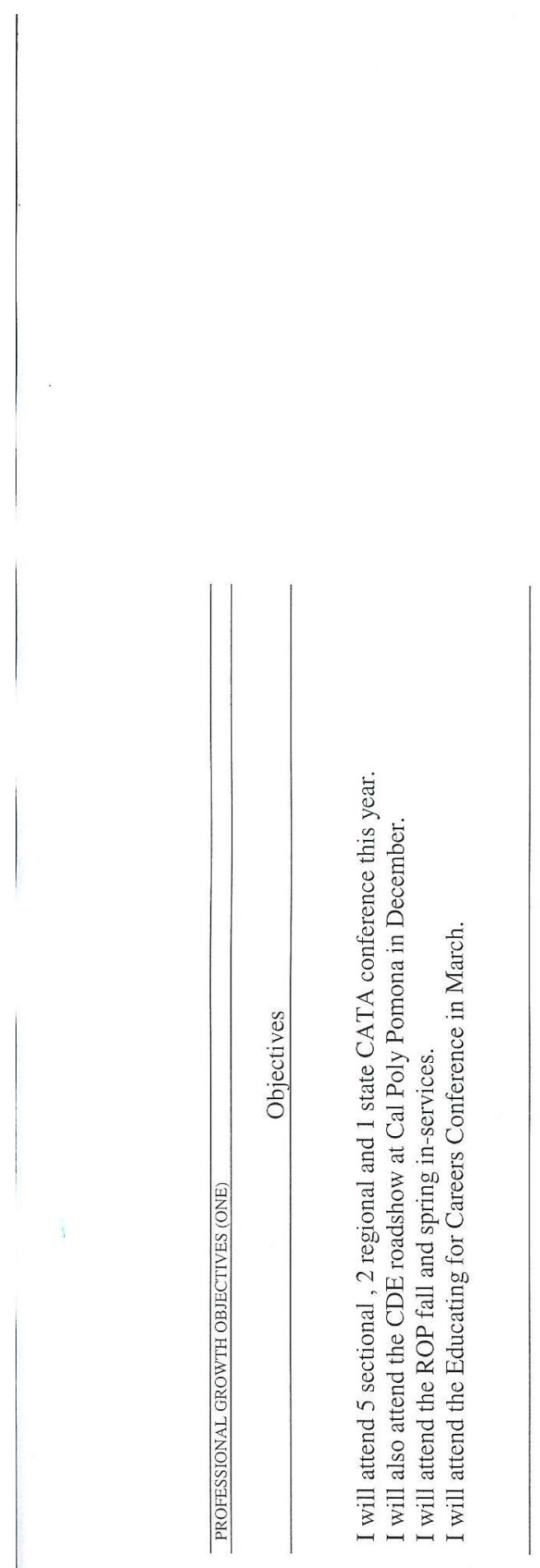




\section{x. Current Year's R-2 Report}




\section{California Ag Education www.calaged.org \\ School at a Glance}

Select a school: $<<$ Select a School $>>\quad$ GO $>$

Data for Year: 2010-2011

School:

\# CA0295 Apple Valley

Apple Valley Sr. HS

11837 Navajo Rd.

Apple Valley, CA 92308

Get Map

Web Site

Teachers: 3

\section{Courses Offered:}

\begin{tabular}{llrr} 
Type & Course & Enrollment H.S. Grad Credit UC Credit \\
Ag Biology & Ag Biology & 28 & Not Entered \\
Ag Biology & Ag Biology & 28 & Not Entered \\
Ag Bus Mgt & Ag Business & 27 & Not Entered \\
Ag Bus Mgt & Ag Business & 27 & Not Entered \\
Ag Mechanics & Ag Welding 1 & 17 & Does Not Meet \\
Ag Mechanics & Ag Welding 1 & 12 & Does Not Meet \\
Ag Mechanics & Ag Welding 1 & 22 & Does Not Meet \\
Ag Mechanics & Ag Welding 1 & 18 & Does Not Meet \\
Ag Mechanics & Ag Welding 1 & 12 & Does Not Meet \\
Ag Mechanics & Ag Welding 1 & 22 & Does Not Meet \\
Animal Science Animal Science 1 & 27 & Not Entered \\
Animal Science Animal Science 1 & 26 & Not Entered \\
Animal Science & Animal Science 1 & 26 & Not Entered \\
Animal Science Animal Science 1 & 27 & Not Entered \\
Animal Science & Animal Science 2 & 34 & Not Entered \\
Animal Science & Animal Science 2 & 34 & Not Entered \\
O.H./Floral & Advanced Floral Design & 16 & Not Entered \\
O.H./Floral & Advanced Floral Design & 16 & Not Entered \\
O.H./Floral & Floral Design & 22 & Not Entered \\
O.H./Floral & Floral Design & 25 & Not Entered \\
O.H./Floral & Floral Design & 24 & Not Entered \\
O.H./Floral & Floral Design & 13 & Not Entered \\
O.H./Floral & Floral Design & 22 & Not Entered \\
O.H./Floral & Floral Design & 24 & Not Entered \\
O.H./Floral & Floral Design & 25 & Not Entered \\
O.H./Floral & Floral Design & 13 & Not Entered \\
& TOTAL & 587 & \\
& Average Class Size & 22.6 & \\
\hline
\end{tabular}


FFA Students by Pathway:

$\begin{array}{lr}\text { Pathway } & \text { Count } \\ \text { Ag Bus Mgt } & 1 \\ \text { Ag Mech. } & 92 \\ \text { Agriscience } & 39 \\ \text { An. Science } & 105 \\ \text { Forestry/NR } & 2 \\ \text { O.H. } & 79 \\ \text { Plant/Soil Sci. } & 19 \\ & 337\end{array}$

FFA Students by Grade Level:

Grade Level Count

981

$10 \quad 57$

$11 \quad 113$

$12 \quad 74$

$13 \quad 12$

Total 337

FFA Students by Years in Ag:

Years in $\mathrm{Ag} \quad$ Count

1207

272

$3 \quad 36$

$4 \quad 15$

$5 \quad 7$

Total 337

Average Years 1.6

Ed Data provides basic demographic data for schools in California. To view this data click on the button.

View Ed Data 


\section{y. Extended Contract}

No agriculture teachers at Apple Valley High School receive and extended contract. However, my father Duane Penfold receives a summer stipend for working with students with animal projects during the summer months and the FFA officer for planning the upcoming year's activities. 


\section{Apple Valley Unified School District}

- Certificated Contract Supplemental Time Report

Duarie PENFod

Employee's Name

Work month is from the 1st of one month through the last day of the same month.

Please submit your time card to the PAYROLL OFFICE by the 5 th of the month.

Time Cards not received by the 5 th are not guaranteed to make the payroll deadline.

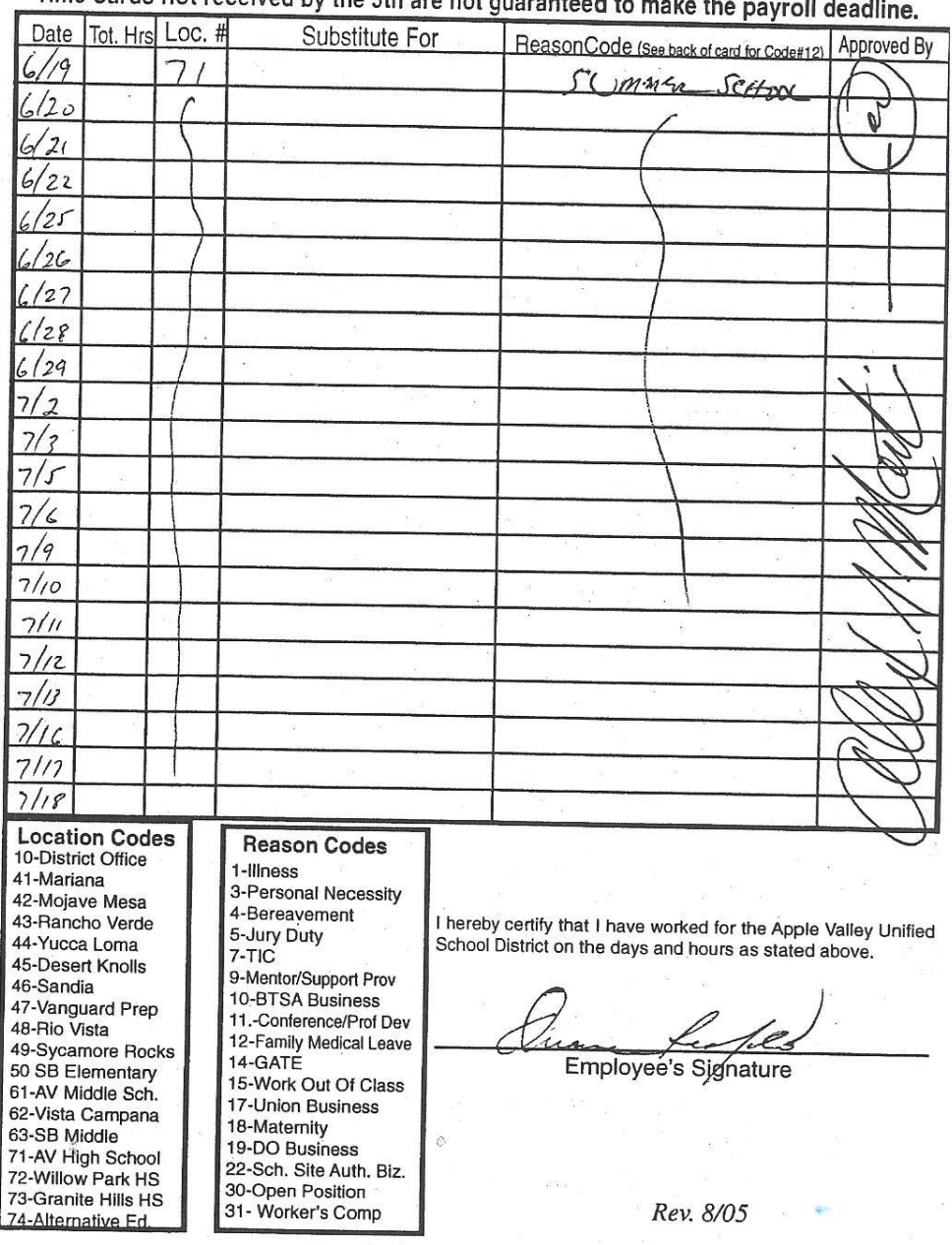




\section{z. Completed Travel Plan Submitted to the Administration}




\section{Apple Valley Unified School District \\ Request for Approval of Field Trip/Off Campus Activity}

(This form must be typed)

Check One:

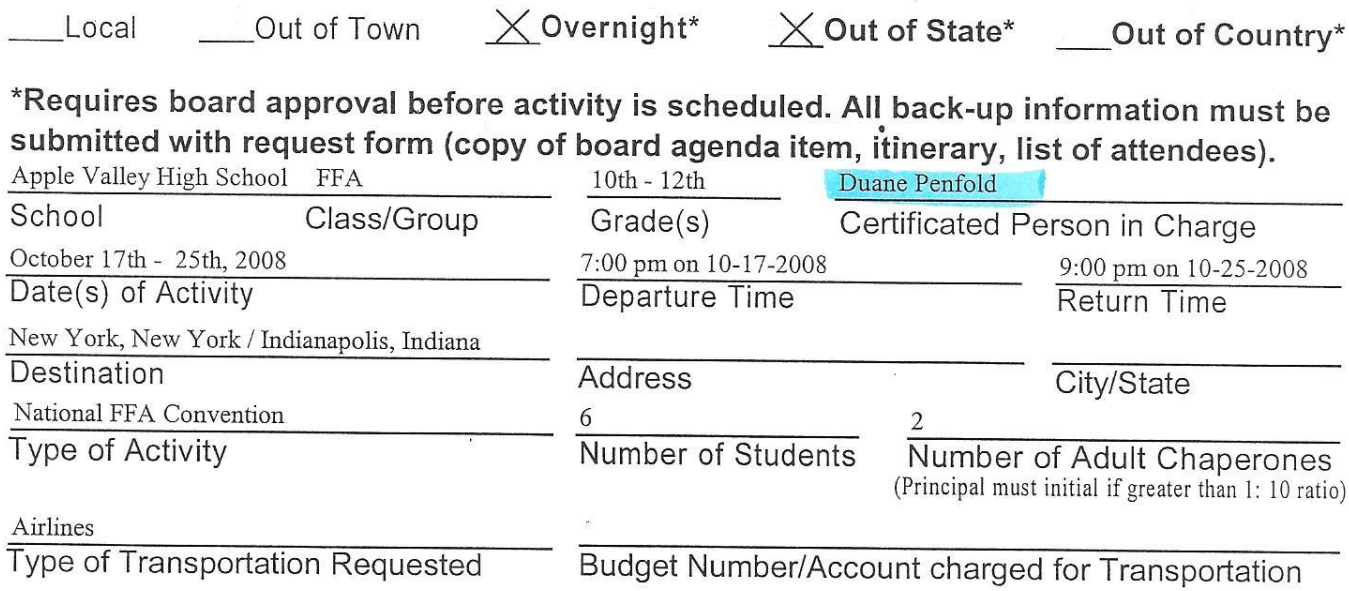

Describe the activity, its purpose and its relation to the course of study.

The National FFA convention is an activity where FFA students from across the country gather to do workshops and group sessions.

Signature of Person in Charge

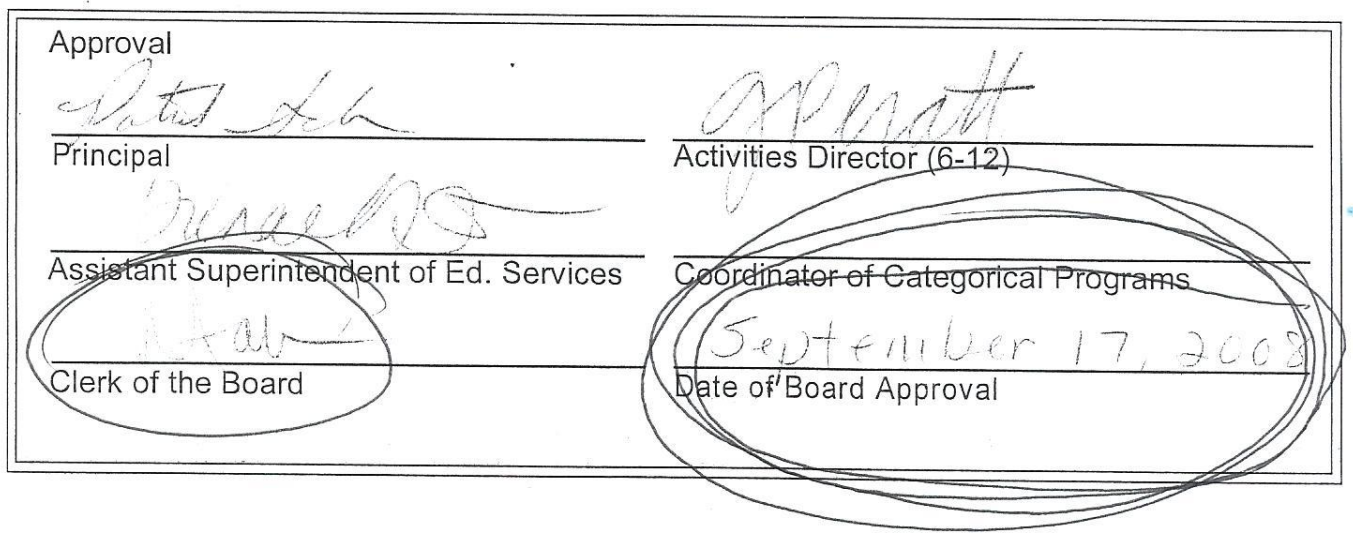

White - Educational Services Yellow-Requestor Pink - To purchasing with requisition and quote 
aa. CATA Membership Card 


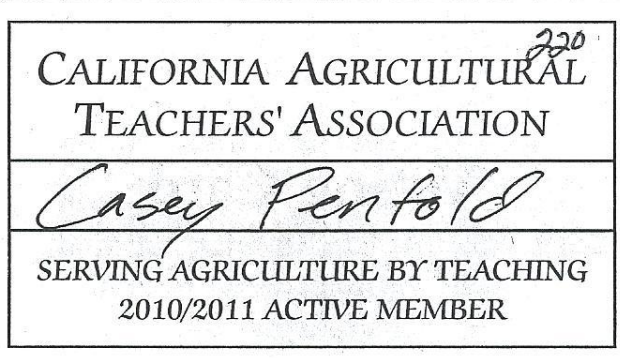




\section{bb. Meeting Reports Submitted to Administration}

Meeting reports are not required by district administration. We do not have formal department meetings because we do not have department heads. However, it is nice to send the administration a report updating them on the activities and items taking place in the agriculture department and will be submitted in the future. 
cc. Wish List 
Wish List

1. 48" Box and Pan Sheet Metal Break 12ga $\$ 5400$

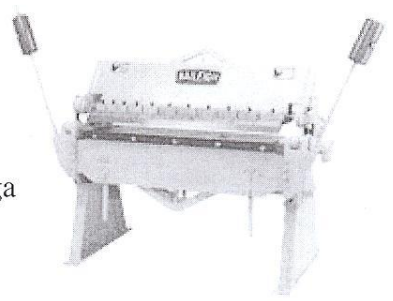

2. Bend Tech Pro tube and sheet bending software. Works with our bender.

$\$ 450$
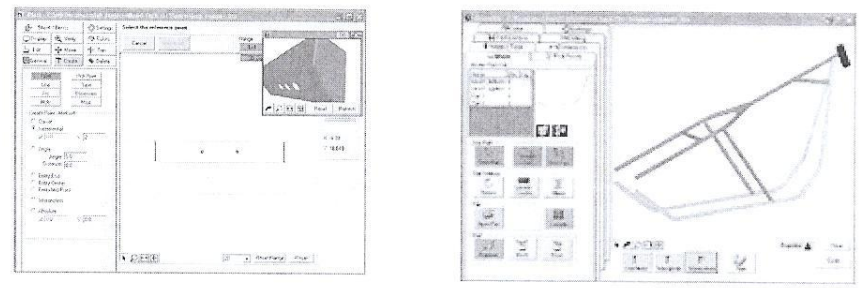

3. Replacement Plasma Cutter for Plasma Cam-lower amperage, smaller kerf

Ex: Hypertherm Powermax 600-40amp 1/2" max

$\$ 2000$

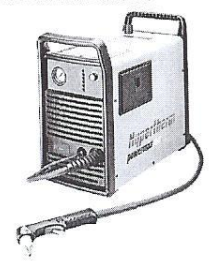

4. Jancy Radius Master Belt Sander

$\$ 2200$

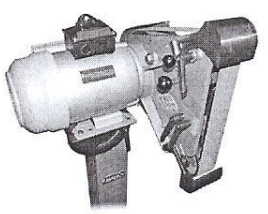

5. New ventilation system

$\$ 50,000-150,000 ? ? ?$ 
5. 3D Printer- from SolidWorks drawing to plastic model $\$ 15,000-20,000$
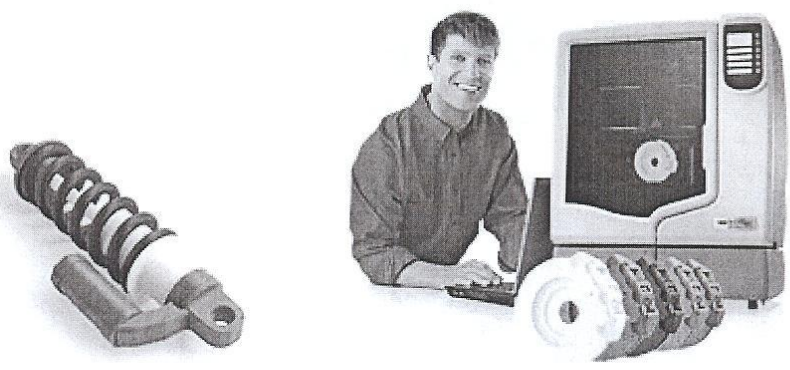

6. Powder Coating Oven $\$ 15,000$

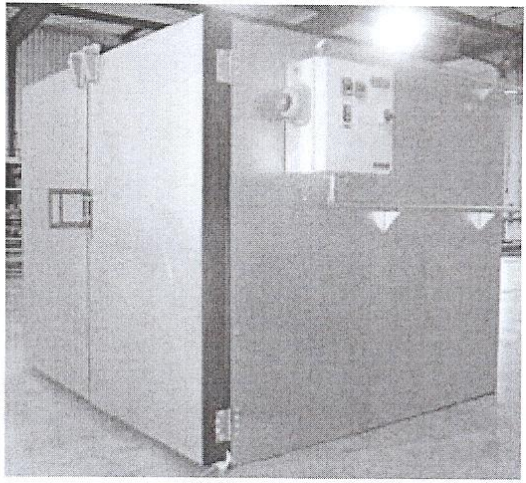

dd. 


\section{ee. Advisory Committee Agendas for Current Year}




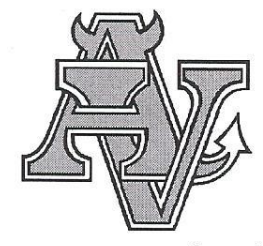

Agriculture Advisory Committee Meeting

\section{Agenda}

$1-11-11$

1. Introduction of members, dinner

2. FFA Report- officers

3. Program Review- D. Penfold

4. Ag Engineering Courses- C. Penfold

5. Discussion Items

- Five-Year Plan Review

- Curriculum- Horticulture, Animal Science, Ag Engineering

- Facilities

6. Other 


\section{Apple Valley High School- ROP Welding \\ Advisory Meeting Agenda}

1) Introductions-

Gary Menser- Victor Valley College

Mark Haynes- Airgas West

Duane Penfold- Apple Valley High School

John Ostlie- San Bernardino County Schools/ROP

Terry Jacobs- TXI Riverside Cement

Adam Bechtold- Flory Industries

2) Job Market Conditions-

What do you think the current welding and fabrication job market looks like?

3) Review Curriculum-

-New Pathway

Introduction/Intermediate/Advanced Agriculture and Industrial Engineering

(Mechanical Drawing, Computer Modeling, Welding and Fabricating)

- ROP Welding Technology III

Any changes or recommendations?

4) Facilities, Equipment and Supplies

-Look at wish list ... approve / disapprove

What else is needed? 


\section{ff. Advisory Committee Charter and Bylaws}

We do not currently posses a charter and bylaws for our advisory committee but it is being developed in the near future. 


\section{gg. Operating Budget for Vo-Ag}




\title{
Agriculture Department Funding 2009-10
}

\author{
Ag Incentive Grant \\ Student Affiliation FFA \\ $\$ 11,784$ \\ Substitutes for Activities \\ Laptops for classroom/shop \\ Perkins Funds \\ Ultrasound \\ $\$ 35,000$ \\ Books for Vet Science \\ Ag Teacher Stipend \\ ROP \\ Welding Supplies \\ Welding Equipment \\ Floral Supplies \\ Floral Equipment \\ $\$ 10,000$ \\ $\$ 4000$
}

Total Agriculture Funding

$\$ 60,784$ 
hh.VEA District Allocation 


\section{Requisitions for Agriculture Sciences \\ Perkins 2010-11}

$\begin{array}{ll}\begin{array}{l}\text { Plant } \& \text { Soil Science } \\ \text { FarmTek }\end{array} & \$ 5686.29 \\ \text { Vet Science } & \\ \quad \text { Insight Media } & \$ 6450.10 \\ \text { Nasco } & \$ 5460.12 \\ \text { Subtotal } & \$ 17596.51\end{array}$

$\begin{array}{cc}\text { Ag Engineering } & \\ \text { Brake } & \$ 4158.09 \\ \text { Vices } & \$ 1279.09 \\ \text { Software } & \$ 1392.00\end{array}$

Subtotal

$\$ 6829.51$

Total Expenditure $\quad \$ 24426.02$ 


\section{ii. Department Budget Process}

There are three major funding sources that support the Agriculture Department at Apple Valley High School: Agriculture Incentive Grant, Perkins Funds, and ROP Funds. The Agriculture Incentive Grant is put together by my father and I and allocated throughout the program. The Perkins funds are handled by our district administrator who is in charge of CTE programs throughout the district. The moneys from Perkins are lumped together in large amounts and rotated throughout the programs in CTE. A large sum goes to a different program every year. The ROP funds are handled by the same district administrator and the woodshop teacher who is very involved with ROP operations. ROP monies get split up among the ROP programs depending on the cost of operating those courses. 


\section{jj. Department Chairperson's Duties}

I am not the Department Chairperson for our agriculture department. Currently there are no department chairperson duties for any department at Apple Valley High School. 


\section{kk. Chart of Responsibilities}




\begin{tabular}{|c|c|c|}
\hline & \multicolumn{2}{|c|}{ Chat of Responsibility } \\
\hline & D. Penfols & c. Pentol \\
\hline \multicolumn{3}{|l|}{ Projet Superígin } \\
\hline \multicolumn{3}{|l|}{ 4s. ples tanics } \\
\hline Eesef & $x$ & $x$ \\
\hline Horticulturé & $x$ & \\
\hline Foultry & $x$ & \\
\hline sheep & $x$ & \\
\hline Swaine & $x$ & $x$ \\
\hline work Expenene & $x$ & $x$ \\
\hline \multicolumn{3}{|l|}{ JudgirRTeamL and Oontest } \\
\hline \multicolumn{3}{|l|}{ 4ag. Me: tanics } \\
\hline Eest Informed G rentand & $x$ & \\
\hline Creed & $x$ & \\
\hline Exte mp./Fre pai red Spakarg & $x$ & \\
\hline Ope nirg and closirg & $x$ & \\
\hline Officer Team & $x$ & \\
\hline \multicolumn{3}{|l|}{ Fundrásirg } \\
\hline TriTipsale & $x$ & $x$ \\
\hline R4 bult forkand & $x$ & $x$ \\
\hline \multicolumn{3}{|l|}{ MEtal.4t } \\
\hline Pantsak & $x$ & \\
\hline \multicolumn{3}{|l|}{ Feports } \\
\hline Frrgera of work & $x$ & \\
\hline $\mathrm{F} 2$ & $x$ & \\
\hline Inentike Grantand Eudget & $x$ & $x$ \\
\hline \multicolumn{3}{|l|}{ Other st int ies } \\
\hline Ag. Advisory minutes & $x$ & $\mathrm{x}$ \\
\hline FFA Meti & $x$ & \\
\hline FFA.Adrigors & $x$ & $x$ \\
\hline DE partme mt ctai re ron & $x$ & \\
\hline San Ee mandino County' Fair & $x$ & $x$ \\
\hline Eectional Lade rship oo rf. & $x$ & \\
\hline
\end{tabular}




\section{ll. Substitute Teacher Procedure and Plans}




\section{Lesson Plans for Friday, September 24, 2009}

The students are going to be watching videos in all classes. No students are allowed to work in the shop at all. When showing the videos on the projector cart, use the black DVD player that is also the sound receiver. The projector may need some time to warm up once you turn it on. When the day is over could you please turn off the projector by pushing down the power button twice and unplug the cart.

Period 1- Conference Period

Period 2- The Introduction Ag Engineering students will watch the History ChannelWelding video. No Worksheet.

Period 3- The Intermediate Ag Engineering students will watch the Arc Welding I video and do the worksheet while watching it. Please collect it at the end of class. There are also Advanced students and TA's in this class and they do not need to do the assignment.

Period 4- The Intermediate Ag Engineering students will watch the Arc Welding I video and do the worksheet while watching it. Please collect it at the end of class. There are also Advanced students and TA's in this class and they do not need to do the assignment.

Lunch-

Period 5- This class is Animal Science II. They will be meeting in room C-8 which is right through the hallway. This is my Dad's classroom but it is his conference period and he will also have a substitute today. The students will be watching a Dirty Jobs Video. The sub for his classes can help you set up the video if needed. If its not working in there you can move them into the shop to show it.

Period 6- The Intermediate Ag Engineering students will watch the Arc Welding I video and do the worksheet while watching it. Please collect it at the end of class. There are also Advanced students and TA's in this class and they do not need to do the assignment.

Please leave me a note about each class and a list of trouble students if there are any. I have included an alternative assignment if the students are misbehaving. It is an essay that the students can copy. Thank you.

Casey Penfold 


\section{How to behave for a substitute teacher}

Enter the classroom quietly and sit in your seat. Answer to your name when he or she takes attendance.

Show the substitute teacher the same respect that you show your regular teacher. Do not be rude, disruptive or disrespectful while they are teaching the class. If your peers goof off and treat the substitute disrespectfully, refuse to join in.

Understand that everything is new for the substitute. He or she probably doesn't know the class routine. They are not your regular teacher and might not do everything exactly the same as your regular teacher. Just because their style or methods are different does not mean they are wrong.

Help the substitute teacher run the class if they ask for your help. Do not make it more difficult for them to do their job.

Cooperate with the substitute teacher. Follow the instructions of the substitute teacher and do all the work that they ask you to do.

Behave the way your regular teacher would expect you to behave. The substitute teacher will report back to your regular teacher to let them know how the class behaved.

Understand that your poor behavior will have consequences. If I would have just followed these simple common sense rules I would be in a much more desirable place right now. I have now broken the trust of my teacher which is much harder to gain back then it was to lose it. Next time, I will be much more respectful and cooperative toward the substitute teacher. 


\section{mm. Proficiency for Vo-Ag Students}


Page: 1 $<$ Back $>$

3/29/2011 4:41:07 PM

\section{Gradebook Summary}

3 - IntAgr/IndstrEn - Y

\begin{tabular}{||rrrr|}
\hline$\#$ \# & Type $\quad$ Description & Assigned & Due Date \\
\hline 7 welding proficiency 7018 Bead & $9 / 17 / 2010$ & $9 / 20 / 2010$ \\
8 & welding proficiency 7018 butt joint & $9 / 17 / 2010$ & $9 / 20 / 2010$ \\
9 & welding proficiency 7018 lap joint & $9 / 17 / 2010$ & $9 / 20 / 2010$ \\
10 & welding proficiency 7018 tee joint & $9 / 17 / 2010$ & $9 / 20 / 2010$ \\
15 & welding proficiency 6010 Bead & $10 / 21 / 2010$ & $10 / 22 / 2010$ \\
16 & welding proficiency 6010 Tee & $10 / 21 / 2010$ & $10 / 22 / 2010$ \\
17 & welding proficiency 60103 Pass Tee & $10 / 21 / 2010$ & $10 / 22 / 2010$ \\
18 welding proficiency 7018 Vert tee & $10 / 21 / 2010$ & $10 / 22 / 2010$ \\
31 welding proficiency MIG bead & $1 / 24 / 2011$ & $1 / 25 / 2011$ \\
32 welding proficiency MIG butt joint & $1 / 24 / 2011$ & $1 / 25 / 2011$ \\
33 welding proficiency MIG lap & $1 / 24 / 2011$ & $1 / 25 / 2011$ \\
34 welding proficiency MIG tee & $1 / 24 / 2011$ & $1 / 25 / 2011$ \\
35 welding proficiency MIG vert lap & $1 / 24 / 2011$ & $1 / 25 / 2011$ \\
36 welding proficiency MIG vert tee & $1 / 24 / 2011$ & $1 / 25 / 2011$ \\
37 welding proficiency MIG sq. tube & $1 / 24 / 2011$ & $1 / 25 / 2011$ \\
\hline
\end{tabular}

\begin{tabular}{|l|l|l|l|l|l|l|l|l|l|l|l|l|l|l|l|l|}
\hline Student\# & Grd & 7 & 8 & 9 & 10 & 15 & 16 & 17 & 18 & 31 & 32 & 33 & 34 & 35 & 36 & 37 \\
\hline
\end{tabular}

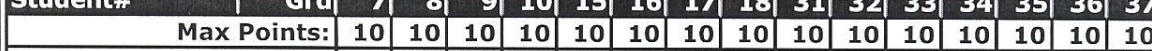

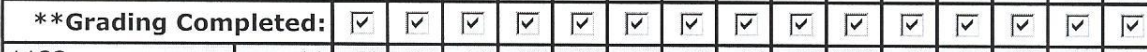

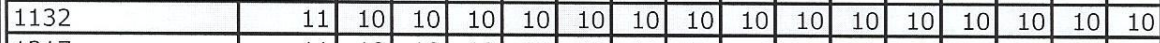

\begin{tabular}{|l|r|r|r|r|r|r|r|r|r|r|r|r|r|r|r|r|}
\hline 1317 & 11 & 10 & 10 & 10 & 10 & 10 & 10 & 10 & 10 & 10 & 10 & 10 & 10 & 10 & 10 & 10 \\
\hline
\end{tabular}

\begin{tabular}{|l|r|r|r|r|r|r|r|r|r|r|r|r|r|r|r|r|}
\hline 1324 & 11 & 10 & 10 & 10 & 10 & 10 & 10 & 10 & 10 & 10 & 10 & 10 & 10 & 10 & 10 & 10 \\
\hline 1396
\end{tabular}

1396

\begin{tabular}{|l|r|r|r|r|r|r|r|r|r|r|r|r|r|r|r|r|}
\hline 1606 & 11 & 10 & 10 & 10 & 10 & 10 & 10 & 10 & 10 & 10 & 10 & 10 & 10 & 10 & 10 & 10 \\
\hline
\end{tabular}

\begin{tabular}{|l|r|r|r|r|r|r|r|r|r|r|r|r|r|r|r|r|}
\hline 1806 & 12 & 10 & 10 & 10 & 10 & 10 & 10 & 10 & 10 & 10 & 10 & 10 & 10 & 10 & 10 & 10 \\
\hline
\end{tabular}

\begin{tabular}{|l|r|r|r|r|r|r|r|r|r|r|r|r|r|r|r|r|}
\hline 1809 & 11 & 10 & 10 & 10 & 10 & 10 & 10 & 10 & 10 & 10 & 10 & 10 & 10 & 10 & 10 & 10 \\
\hline
\end{tabular}

\begin{tabular}{|l|r|r|r|r|r|r|r|r|r|r|r|r|r|r|r|r|}
\hline 1843 & 10 & 10 & 10 & 10 & 10 & 10 & 10 & 10 & 10 & 10 & 10 & 10 & 10 & 10 & 10 & 10 \\
\hline
\end{tabular}

\begin{tabular}{|l|r|r|r|r|r|r|r|r|r|r|r|r|r|r|r|r|}
\hline 1856 & 12 & 10 & 10 & 10 & 10 & 10 & 10 & 10 & 10 & 10 & 10 & 10 & 10 & & & \\
\hline
\end{tabular}

\begin{tabular}{|l|r|r|r|r|r|r|r|r|r|r|r|r|r|r|r|r|}
\hline 1941 & 10 & 10 & 10 & 10 & 10 & 10 & 10 & 10 & 10 & 10 & 10 & 10 & 10 & 10 & 10 & 10 \\
\hline 2215 & 11 & 10 & 10 & 10 & 10 & 10 & 10 & 10 & 10 & 10 & 10 & 10 & 10 & 10 & 10 & 10 \\
\hline
\end{tabular}

\begin{tabular}{|l|r|r|r|r|r|r|r|r|r|r|r|r|r|r|r|r|}
\hline 2215 & 11 & 10 & 10 & 10 & 10 & 10 & 10 & 10 & 10 & 10 & 10 & 10 & 10 & 10 & 10 & 10 \\
\hline 2254
\end{tabular}

\begin{tabular}{|l|r|r|r|r|r|r|r|r|r|r|r|r|r|r|r|r|}
\hline 2254 & 11 & 10 & 10 & 10 & 10 & 10 & 10 & 10 & 10 & 10 & 10 & 10 & 10 & 10 & 10 & 10 \\
\hline 2268 & 10 & 10 & 10 & 10 & 10 & 10 & 10 & 10 & 10 & 10 & 10 & 10 & 10 & 10 & 10 & 10 \\
\hline
\end{tabular}

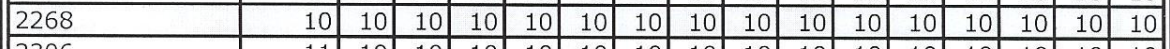

\begin{tabular}{|l|r|r|r|r|r|r|r|r|r|r|r|r|r|r|r|r|}
\hline 2306 & 11 & 10 & 10 & 10 & 10 & 10 & 10 & 10 & 10 & 10 & 10 & 10 & 10 & 10 & 10 & 10 \\
\hline 2341 & 11 & 10 & 10 & 10 & 10 & 10 & 10 & 10 & 10 & 10 & 10 & 10 & 10 & 10 & 10 & 10 \\
\hline
\end{tabular}

\begin{tabular}{|l|r|r|r|r|r|r|r|r|r|r|r|r|r|r|r|r|}
\hline 2341 & 11 & 10 & 10 & 10 & 10 & 10 & 10 & 10 & 10 & 10 & 10 & 10 & 10 & 10 & 10 & 10 \\
\hline 2637 & 12 & 10 & 10 & 10 & 10 & 10 & 10 & 10 & 0 & 10 & 10 & 10 & 10 & & & \\
\hline
\end{tabular}

2637

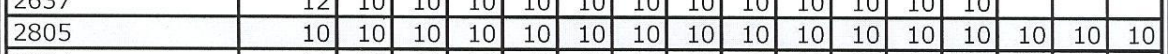

2854

Student\#

\begin{tabular}{r|rrrrrrrrrrrr|r|r|r|r|r|r|}
11 & 10 & 10 & 10 & 10 & 10 & 10 & 10 & 10 & 10 & 10 & 10 & 10 & 10 & 10 & 10 \\
\hline
\end{tabular}

* Indicates Max Values of 0 (zero). $* *$ Assignments are not counted until graded. 


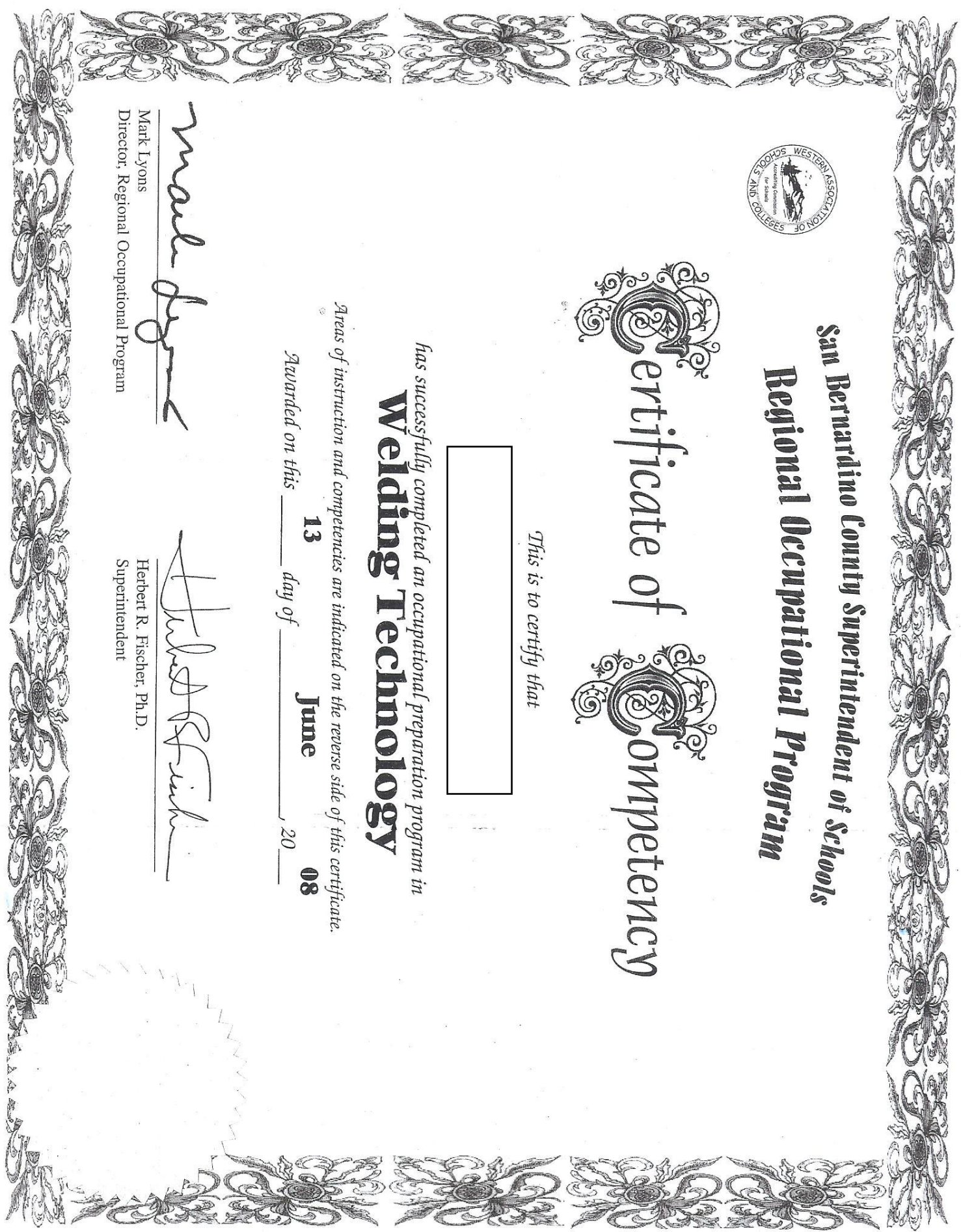




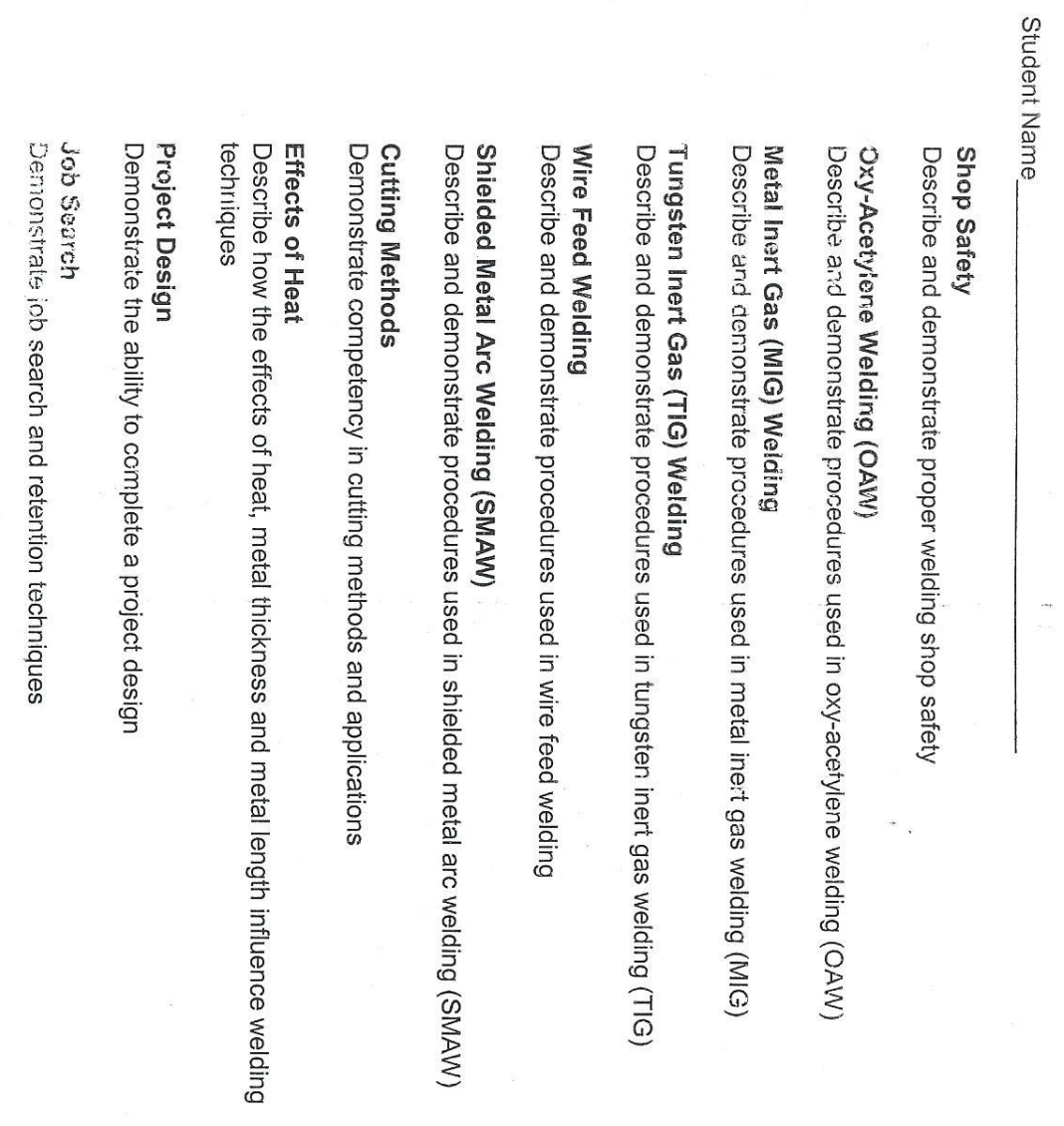

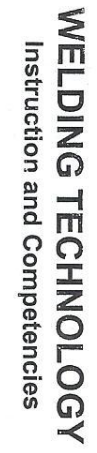
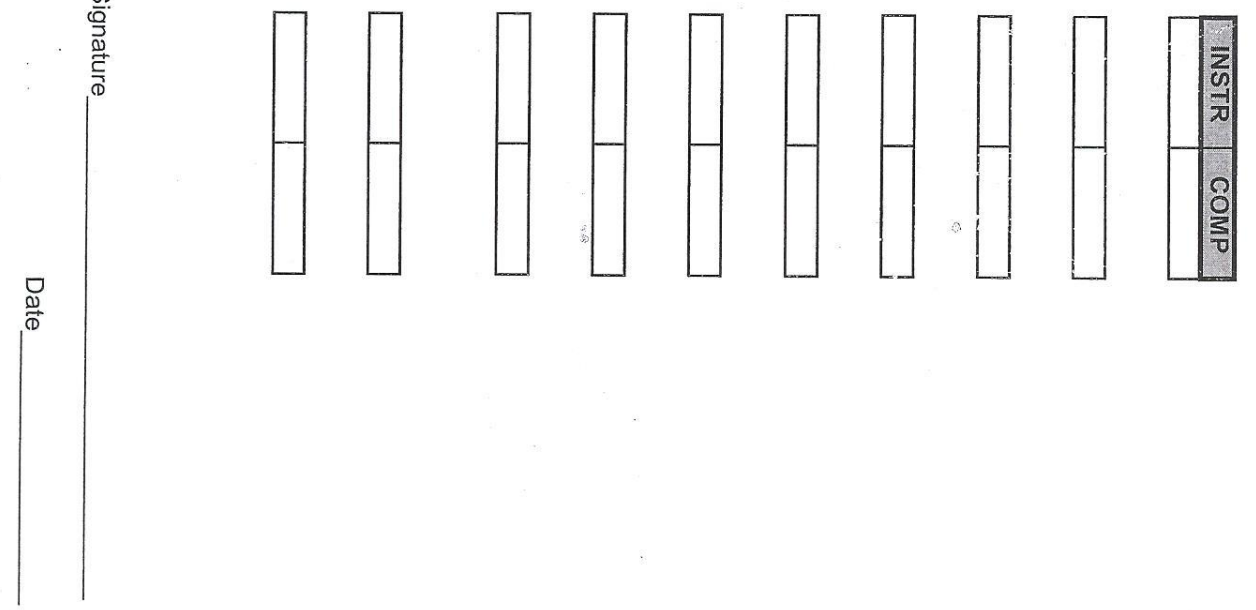


\section{nn.2+2 Articulation Agreement}




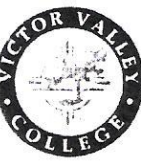

TECH PREP Request to Articulate

Articulation - Tech Prep

18422 Bear Valley Rd.

Victor Valley College, Ca. 92395

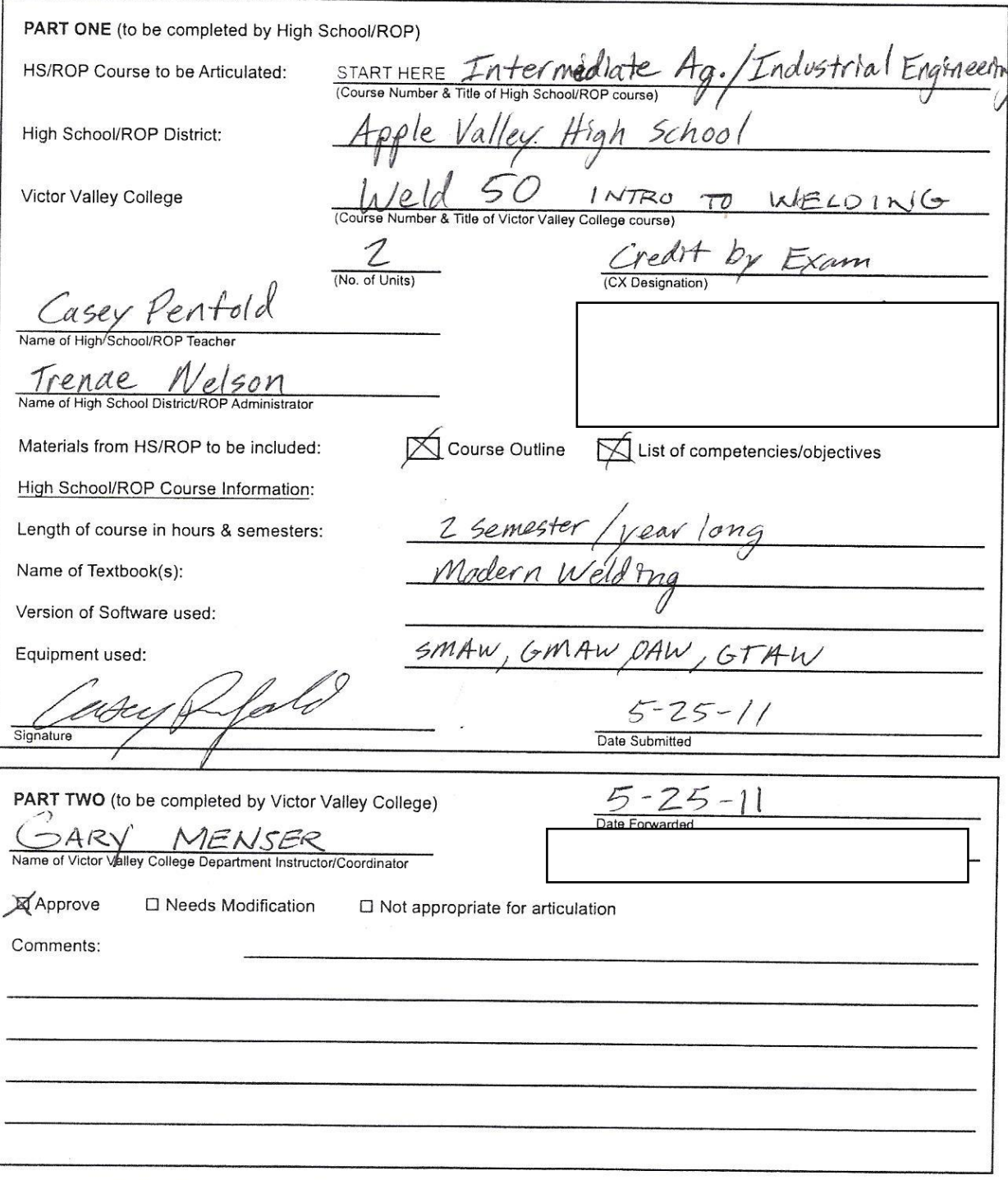

This form is to be used by High School and/or ROP teachers as a formal request to articulate a college credit

course between Victor Valley Community College and the identified High School District or ROP.

Part 1 is completed by the High School and/or ROP and submitted at Tech Prep workshops or by mail:

Victor Valley College, ATTN: Tech Prep 18422 Bear Valley Rd. Victorville, Ca. 92395 


\section{oo. Reimbursement for Personal Expenses}

Currently I have not incurred any personal expenses that have required reimbursement. The process is fairly simple though. I would fill out a form that lists all the types of expenses and what the trip or activity was for and attach all the receipts and submit it to the district accounting secretaries. 